\title{
Sistemas Hipertexto: Discussões, Um Projeto e Sua Implementação
}

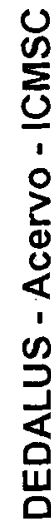

Maria da Graça Campos Pimentel

Orientação:

Profa. Dra. Maria Carolina Monard

岂

Profa. Dra. Maria Carolina Monard

Dissertação apresentada ao Instituto de Ciências Matemáticas de São Carlos USP, como parte dos requisitos para obtençâo do título de Mestre em Ciências de Computação e Matemática Computacional. 
Aos meus pais e ao Cesar. 


\section{Agradecimentos}

À Maria Carolina, pela orientação. Ao Cesarr è Renata pelas sugestões. À Luisa, pelo auxílio na produção do texto final e Lirio, pela produção das fotos. 


\begin{abstract}
Hypertext is a form of electronic document wich includes a number of new features and where the selection of documents is done by association. This technology opens some very exiting new possibilities, particularly for new uses of the computer as a communication and thinking tool.

In this work we survey most of the existing hypertext systems, their applications and their design. The advantages and disadvantages of hypertext are discussed and we show in some detail its fundamental features as well as design options for constructing Hypertext Systems, providing a background for several lines of research.

Using the ideas developed in this work, we designed and built an Hypertext System called Based Hypertext System for PC-based microcomputer.

The user interface employs a form of direct manipulation designed to exploit a two-bottom mouse. The database is a graph of textual nodes that can be distributed across an indefinite number of files and be as large as available disk space permits. The nodes in the database correspond to windows on the screen on a one to one basis.

Windows may contain any number of individual items linked to other nodes or used to invoke programs. A browser displays the current node and its neighbors showing how nodes are directly related with each other in the graph.
\end{abstract}




\section{Resumo}

Neste trabalho apresentamos as principais características dos Sistemas Hipertexto e discutimos os objetivos atuais e futuros desta tecnologia. Discutimos, também, as vantagens e desvantagens dos sistemas hipertextos e analisamos os aspectos mais relevantes ao projeto desses sistemas.

Um sistema hipertexto é uma ferramenta não convencional para a organização e recuperação de informações, que pode ser visto como uma nova, e muito interessante, técnica de representação de conhecimento.

Como resultado desses estudos, propomos o projeto de um Sistema Base para Hipertextos para ambiente de microcomputador PC-compativel e realizamos sua implementação.

A interface com o usuário utiliza um dipositivo de manipulação direta, mouse, e múltiplas janelas para a seleção e apresentação das informações.

A base de dados está representada por um grafo cujos nós e arestas correspondem, respectivamente, aos arquivos de texto e às ligações estabelecidas entre os conteúdos desses arquivos. Cada nó pode ter um número qualquer de ligações que são utilizadas, também, para ativar a execução de programas. Um browser apresenta ao usuário o nó corrente e os nós na vizinhança à qual ele está diretamente relacionado. 


\section{Conteúdo}

1 Introdução 1

2 Sistemas Hipertexto - Apresentação $\quad$ : 6

2.1 Abordagem Geral ................... 7

2.2 As Primeiras Propostas . . . . . . . . . . . . . 8

2.3 Aplicações ............................. 9

2.4 Navegação . . . . . . . . . . . . . . . . . 10

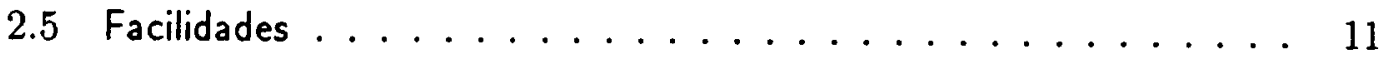

2.6 Questões Relevantes . . . . . . . . . . . . . . . 11

2.7 Linhas Atuais de Pesquisa . . . . . . . . . . . . . 12

3 Evolução Histórica 13

4 Aspectos Relevantes ao Projeto de Sistemas Hipertexto 21

4.1 Implementação de Nós . . . . . . . . . . . . . . . . . 22

4.1 .1 O Tamanho do Nó . . . . . . . . . . . . . 22

4.1 .2 O Tipo do Nó ..................... 24

4.2 Implementação de Ligações . . . . . . . . . . . . . . . 26

4.2 .1 Ligação e Âncora . . . . . . . . . . . . . . . 26 
4.2 .2 Objetos Ligados . . . . . . . . . . . . . 27

4.2 .3 Direção da Ligação . . . . . . . . . . . . . . . 28

4.2 .4 Visualização da Ligação . . . . . . . . . . . . . 28

4.2 .5 Operações sobre a Ligação . . . . . . . . . . . . . . . 29

4.2 .6 Ligações Tipadas e Não Tipadas . . . . . . . . . . . 30

4.3 Navegação em Hiperdocumentos . . . . . . . . . . . . . . 32

4.3 .1 Seleção de Ligação . . . . . . . . . . . . . . . 32

4.3 .2 Seleção Através de Índice . . . . . . . . . . . . . 32

4.3.3 Pesquisa de Padrão . . . . . . . . . . . . . . 34

4.3.4 Navega ção em Gráfico de Nós e Ligações . . . . . . . . . . 36

4.3 .5 Uso da Estrutura Existente ............... 37

4.3.6 Navega ção em Caminhos Pré-Definidos . . . . . . . . . . 37

4.4 Cria ção de Hiperdocumentos . . . . . . . . . . . . . 37

4.4 .1 Ferramentas ........................ 38

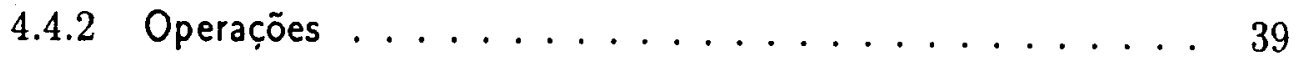

4.4 Proteção ..................... . . 40

4.4 .4 Estruturação ..................... 41

4.5 Adaptação de Documentos . . . . . . . . . . . . . 41

4.6 Controle de Versões . . . . . . . . . . . . . . . . . 41

4.7 Trabalho Cooperativo .................. 42

5 Soluções Adotadas nos Principais Sistemas 43

5.1 Hypertext Abstract Machine . . . . . . . . . . . . . . . . . 44

5.1 .1 Os Objetos do HAM ............... 45

5.1 .2 Navegação . . . . . . . . . . . . . . 46 
5.1 .3 Criaşão $\ldots \ldots \ldots \ldots \ldots \ldots \ldots \ldots \ldots$

5.1.4 Controle de Versões . . . . . . . . . . . . . . . 47

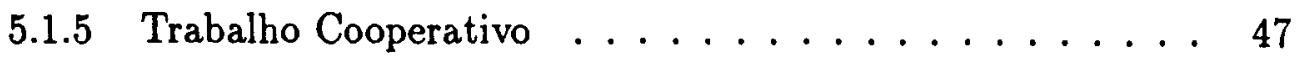

5.2 Intermedia $\ldots \ldots \ldots \ldots \ldots \ldots \ldots \ldots \ldots \ldots$

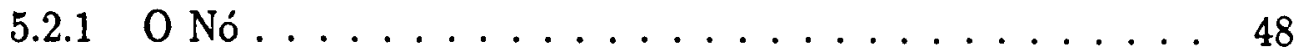

5.2 .2 Âncoras e Ligações . . . . . . . . . . . . . . . . . 48

5.2.3 Controle de Versões . . . . . . . . . . . . . . . 49

5.2 .4 Trabalho Cooperativo . . . . . . . . . . . 50

5.3 NoteCards . . . . . . . . . . . . . . . . 50

5.3 .1 O Nó $\ldots \ldots \ldots \ldots \ldots \ldots \ldots \ldots \ldots \ldots$

5.3 .2 A Ligação . . . . . . . . . . . . . . . . . . . 51

5.3 .3 Navegação . . . . . . . . . . . . . . . . . . . 51

5.3 .4 Controle de Versões . . . . . . . . . . . . . . . 52

5.3.5 Trabalho Cooperativo . . . . . . . . . . . 52

5.4 Knowledge Management System . . . . . . . . . . . . . . 53

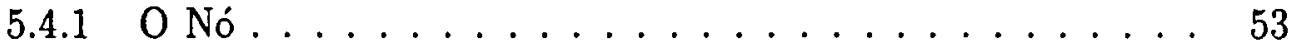

5.4 .2 Âncoras e Ligações . . . . . . . . . . . . . . . . . . . 54

5.4 .3 Navegação . . . . . . . . . . . . . . . 55

5.4 .4 Criação $\ldots \ldots \ldots \ldots \ldots \ldots \ldots \ldots \ldots$

5.4 .5 Controle de Versões . . . . . . . . . . . . . . 56

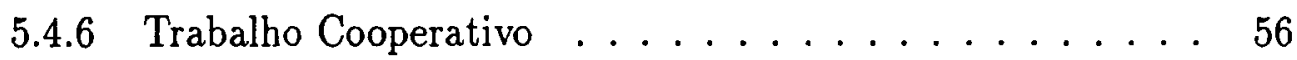

5.5 Conclusão $\ldots \ldots \ldots \ldots \ldots \ldots \ldots \ldots \ldots \ldots \ldots$

6 Proposta e Implementação do Sistema Base para Hipertextos 59

6.1 Considerações Iniciais . . . . . . . . . . . . . . . . 60 
6.2 Exemplo de Interação com o Sistema Implementado . . . . . . 63

7 Aspectos Relevantes ao Projeto do Sistema Base para Hipertextos 84

7.1 Diagrama Funcional do Projeto . . . . . . . . . . . . 84

7.2 O Nó ................................. 91

7.2 .1 O Tamanho do nó . . . . . . . . . . . . 91

7.2 .2 Tipos de Nó . . . . . . . . . . . . . . 91

7.3 A Ligação . . . . . . . . . . . . . . . . . . . . . . . . 92

7.4 Navegação . . . . . . . . . . . . . . . . . . . 94

7.4 .1 Seleção de Ligação . . . . . . . . . . . . . . . . . 94

7.4 .2 Pesquisa de Padrão . . . . . . . . . . . . . 95

7.4.3 Navegação em Gráfico de Nós e Ligações - Browser . . 96

7.4.4 Navegação em Caminhos Pré-Definidos . . . . . . . . . 96

7.5 Criação de Hiperdocumentos . . . . . . . . . . . . . . . . 97

7.5 .1 Visualização de todas as ligações . . . . . . . . . . 97

7.5 .2 Operações sobre as Ligações . . . . . . . . . . . . . 98

7.5.3 Operações de Edição . . . . . . . . . . . . . 98

7.6 Adaptação de Documentos . . . . . . . . . . . . . . . . 98

7.7 Controle de Versões . . . . . . . . . . . . . . . . . 999

7.8 Trabalho Cooperativo. . . . . . . . . . . . . 99

7.9 Expansões Sugeridas . . . . . . . . . . . . . 99

8 Conclusão 101

$\begin{array}{ll}\text { A Figuras } & 106\end{array}$ 


\section{Capítulo 1}

\section{Introdução}

Imagine-se lendo este trabalho na tela de um terminal de um computador onde o mesmo está armazenado de forma tradicional. Ao observar a lista de capítulos da figura 1.1, sente-se interessado em consultar a seção Soluções Adotadas nos Principais Sistemas. Para alcançar o conteúdo desejado percorre todo o documento existente entre a figura e aquele capítulo. Depara, então, com uma referência bibliográfica que lhe interessa e resolve consultar a bibliografia. Novamente tornase necessário deslocar-se através de todo o documento existente entre sua posição atual e o destino desejado. Essa é a essência do acesso seqüencial.

Imagine agora que, ao decidir alcançar o conteúdo de Soluçōes Adotadas nos Principais Sistemas, fosse possível posicionar o cursor sobre o nome do capítulo e ativar a execução de um comando que trouxesse o conteúdo desejado automaticamente à tela. Imagine que o mesmo pudesse acontecer no caso da referência bibliográfica. Poderia ser possivel, também, selecionar por exemplo o nome de uma figura durante sua referência no texto, obtendo como resultado a apresentação da figura na tela. Outro exemplo seria selecionar em algum momento a referência à Quinta Sinfonia de Beethoven, tendo como resultado a execução da peça no aparelho de som acoplado ao computador. Resultado análogo poderia ser obtido com a seleção do nome de um filme: ele seria exibido no equipamento de vídeo conectado à sua máquina. $\mathrm{O}$ sistema que armazena, recupera e apresenta as informações desta maneira é um sistema hipertexto e o documento gerenciado é chamado hiperdocumento.

O documento é armazenado na forma de nós, que contêm as informações de texto, som, imagem, etc. Esses nós são consultados interativamente na tela de um terminal de computador. Embutidas no conteúdo dos nós existem ligações que os relacionam. Por exemplo, em um nó existe a frase "o homem é um mamífero" 


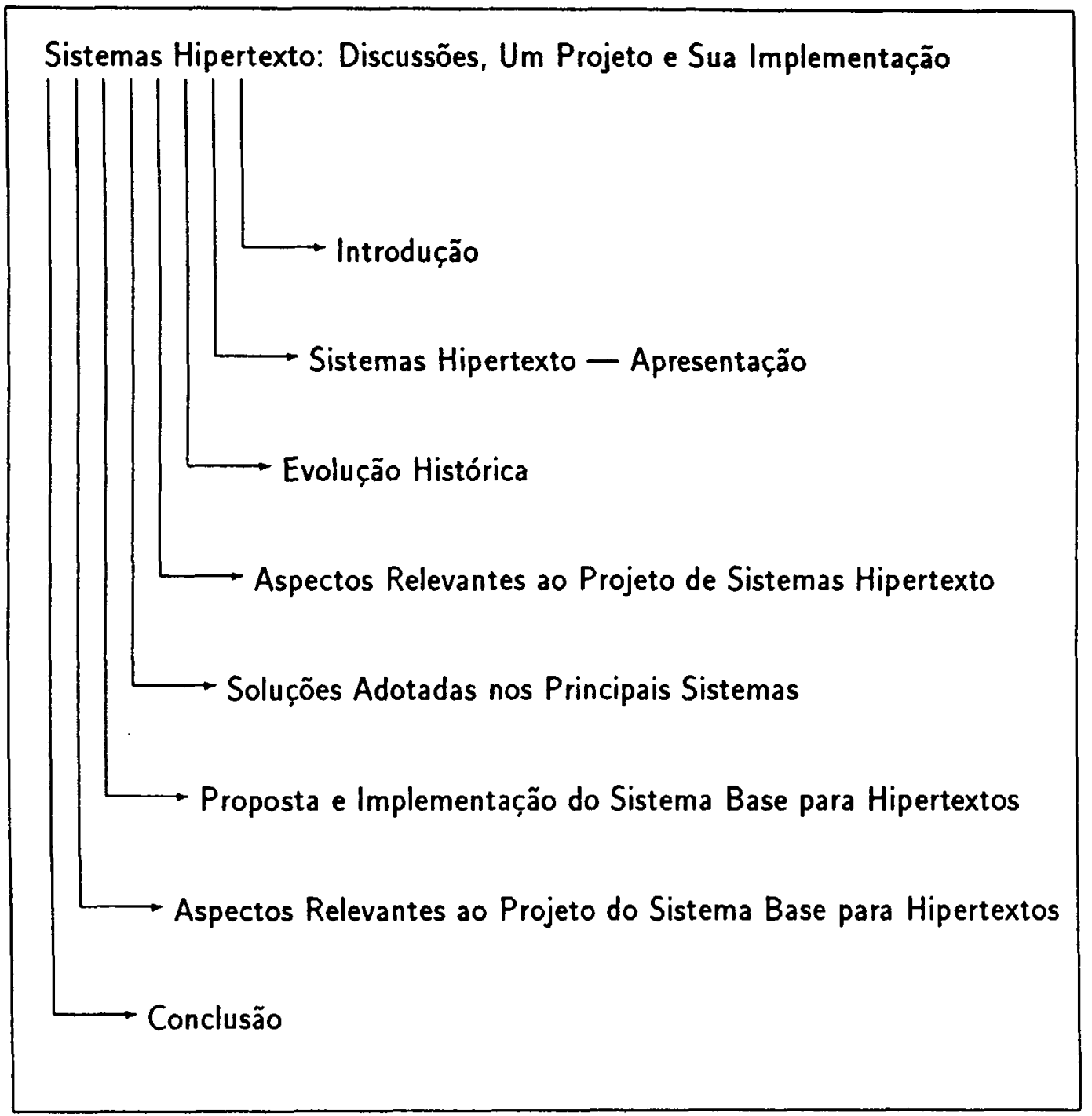

Figura 1.1: Estrutura do Trabalho 
e em outro nó existe um texto que explica o significado da palavra mamífero. Uma ligação poderia ser embutida na frase de modo que, quando selecionada pelo usuário, o texto relacionado fosse apresentado, Consideramos essa a forma natural de consultar um hiperdocumento: realizar acesso não seqüencial e navegar interativamente pelas informações armazenadas.

Os sistemas hipertexto podem ser vistos como uma nova técnica de representação de conhecimento. Depois de armazenada no sistema, a forma pela qual a informação é relacionada com outras informacões representa uma estruturação específica desse conhecimento, o qual é utilizado para informar ao usuário sobre os pontos relevantes do problema. Estabelecendo-se uma comparação entre sistemas hipertexto e sistemas especialistas, podemos dizer que o primeiro informa ao usuário o conhecimento armazenado sobre um problema, enquanto que o segundo é utilizado para resolver um problema específico.

Utiliza-se o termo hypermedia para designar os sistemas que permitem acesso não seqüencial sobre quaisquer tipos de informação possíveis de serem processadas num sistema computacional, como por exemplo informações gráficas, sons e imagens animadas, etc. No decorrer deste trabalho, utilizaremos o termo hipertexto para designar tanto os sistemas que manipulam apenas informações textuais como aqueles que são capazes de manipular quaisquer outros tipos de informação, utilizando-se de ligações embutidas e acesso não seqüencial.

A comunidade científica credita a Vanevar Bush a proposta dos princípios dos sistemas hipertexto. Em 1945 Bush propôs a construção de um sofisticado sistema de biblioteca utilizando a tecnologia disponível em sua época - microfilmagem e fotocélulas [Bush 45]. Em sua proposta, denominada sistema Memex, Bush permite o estabelecimento de ligações entre dois pontos quaisquer de documentos armazenados no sistema.

Os sistemas hipertexto atuais dispõem de muito mais recursos, oferecidos pelo desenvolvimento de todas as áreas da ciência da computação e demais tecnologias, o que lhes garante maior flexibilidade e os tornam efetivamente úteis a uma vasta gama de aplicações.

Jeff Conklin [Conklin 87] comenta o fato de vários autores sugerirem que os conceitos e vantagens dos sistemas hipertexto estiveram claros por várias décadas, mas não puderam ser aplicados devido ao pouco desenvolvimento tecnológico. Conklin considera que essa posição pode ser simplista, porque existe entre os pesquisadores mais antigos o sentimento de que algo mais mudou: há nos dias de hoje uma facilidade de aceitação do papel do computador como uma ferramenta para o processamento de idéias e conhecimento e como um veículo de comunicação 
entre os homens - e não apenas como um mero manipulador de dados. A aceitação desta tendência pela comunidade é recente e é também responsável pelo atual interesse nos sistemas hipertexto.

Com o objetivo de ilustrar as ligações embutidas no conteúdo dos hiperdocumentos, escrevemos os nomes de alguns tópicos deste trabalho em letras do tipo sans serif em algumas das seguintes situações: (a) no indice existente no início deste trabalho; (b) na apresentação de tópicos (os capitulos do trabalho ou as subseções de uma seção, por exemplo)e (c) na própria definição do tópico.

Entre as facilidades normalmente oferecidas pelos sistemas hipertexto, encontra-se uma ferramenta gráfica chamada browser gráfico. Essa ferramenta apresenta ao usuário uma visão gráfica das partes que formam o hiperdocumento da seguinte maneira: associa os itens que são fontes das ligações aos nós de um grafo e as ligações existentes entre os ítens às arestas do grafo. Como resultado, o usuário visualiza uma árvore como a da figura 1.1, no caso da porção do documento estar organizada hierarquicamente, ou visualiza um grafo com ciclos se existirem referências cruzadas no hiperdocumento.

Quando o browser gráfico estiver implementado num sistema, um grafo como o mostrado na figura 1.1, pode ser apresentado ao usuário, sempre que ele desejar ter uma visão geral da sua posição dentro do documento. As ligações do grafo podem ser selecionadas diretamente pelo usuário, o que o leva diretamente à porção do documento destino da ligação.

Os parágrafos seguintes indicam a estrutura de elaboração deste trabalho:

Apresentamos no capítulo 2 os (conceitos básicos relacionados aos sistemas hipertexto.

Mostramos no capítulo 3 a evolução dos sistemas hipertexto nas últimas décadas, através de referências a vários sistemas que possuem características de hipertexto.

No capítulo 4 discutimos detalhadamente questões relevantes ao projeto de sistemas hipertexto. Essas questões são estudadas, no capítulo seguinte, através da análise das opçóes de projeto dos principais sistemas hipertexto discưtịdos na literatura.

Apresentamos no capítulo 6 as principais características do sistema implementado e um exemplo de interação com o usuário. No capítulo 7 analisamos aspectos relevantes do projeto proposto e implementado.

Organizamos no apêndice A um conjunto de ilustrações de alguns sistemas 
estudados e que correspondem, normalmente, a fotografias de telas de terminais de computador. 


\section{Capítulo 2}

\section{Sistemas Hipertexto - Apresentação}

Com o objetivo de realizar uma apresentação de sistemas hipertexto, discutimos a seguir os seguintes tópicos: Abordagem Geral, As Primeiras Propostas, Aplicações, Navegação, Facilidades, Questões Relevantes e Linhas Atuais de Pesquisa. 
Sistemas Hipertexto - Apresentação

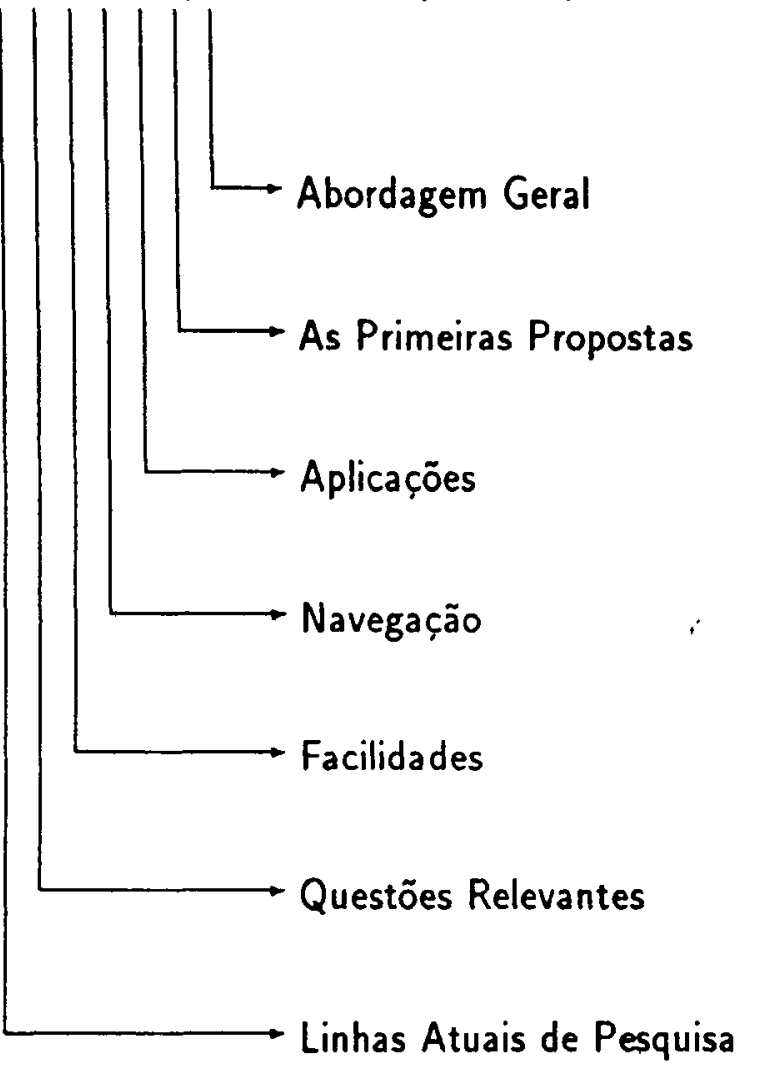

\subsection{Abordagem Geral}

O desenvolvimento tecnológico atual permite o armazenamento dos mais diversos tipos de informação em sistemas de computação. Os avanços constantes no projeto de dispositivos de armazenamento permitem manter cada vez mais informações em menor espaço físico e a custos decrescentes.

Entre as pesquisas importantes realizadas atualmente em ambientes ligados a sistemas de computação, encontramos aquelas que buscam ferramentas para a organização e a recuperação das informações armazenadas através de metodologias não convencionais. $\mathrm{O}$ sistema hipertexto é uma dessas ferramentas.

Um sistema hipertexto organiza o armazenamento das informações de um documento de modo a possibilitar a realização de pesquisas não seqüenciais. Para 
isso, o sistema suporta ligações embutidas no conteúdo do documento, ligações essas que permitem acessar diretamente uma outra porção de algum documento do sistema.

O termo hypertext é atribuído a Ted Nelson [Nelson 81] e diz respeito aos primeiros sistemas construídos com a filosofia de ligações embutidas. Atualmente utiliza-se o termo hypermedia para designar os sistemas que permitem o mesmo modo de acesso não seqūencial, porém, o acesso pode se dar sobre quaisquer tipos de informação possiveis de serem armazenadas (áudio, imagem estática ou animada, por exemplo) ou processadas (uso do sistema como interface com qualquer programa executável) em um sistema computacional.

\subsection{As Primeiras Propostas}

A comunidade científica credita a Vanevar Bush a criação da filosofia dos sistemas hipertexto. Em 1945 Bush propõe a utilização da tecnologia disponivel em sua época - microfilmagem e fotocélulas - para a construção de um sofisticado sistema de biblioteca, no qual poderia ser armazenada toda a literatura científica [Bush 45]. Em sua proposta, Bush permite o estabelecimento de ligações entre dois pontos quaisquer de documentos armazenados. Bush define seu sistema, batizado Memex, da seguinte forma:

Um dispositivo no qual um individuo guarda todos os seus livros, registros e comunicações e o qual é mecanizado de modo a poder ser consultado com extrema velocidade e flexibilidade. O dispositivo é um suplemento da própria memória do indivíduo.

Possivelmente, Bush não imaginava o que seria possivel armazenar num dispositivo físico quarenta anos depois. É provável que, se Bush pudesse imaginar onde a tecnologia chegaria em curto espaço de tempo, ele especificasse seu sistema de modo a acessar também gráficos, informações de áudio, imagens animadas, etc.

Podemos observar que Bush relaciona as ligações existentes entre os documentos com as ligações realizadas por nossa mente sobre as informações nela armazenadas. As palavras de Vanevar Bush continuam servindo à nossa realidade: 
A mente humana ... opera por associação. O homem não pode esperar que esse processo mental seja completamente duplicado, mas pode certamente aprender com ele. Ninguém pode esperar igualar a velocidade e flexibilidade com a qual a mente humana segue um caminho associativo, mas deveria ser possivel vencer decisivamente a mente no que diz respeito à permanência e a clareza dos ítens recuperados do armazenamento.

Jeff Conklin publicou em 1987 um artigo [Conklin 87] no qual apresenta um survey sobre os principais sistemas hipertexto. Nesse artigo, Conklin considera que a característica essencial descrita por Bush, na especificação do sistema Memex, é a facilidade para o interrelacionamento de itens. Essa característica influenciou o projeto de Douglas Engelbart ao propor o sistema H-LAM/T [Engelbart 63]. Engelbart é considerado o primeiṛo sucessor de Bush em relação às idéias sobre hipertexto. Esse e outros sistemas serão discutidos mais adiante.

Nos dias de hoje, um texto armazenado num sistema hipertexto pode ser visto como um texto convencional acrescido de ligações embutidas em seu conteúdo. Essas ligações permitem ao documento ser criado e consultado de maneira não seqüencial. $O$ texto é gerado em unidades normalmente pequenas chamadas nós e o documento final, chamado hiperd̈ocumento, compóe-se de uma rede de nós conectados pelas ligações embutidas no texto. As ligações permitem ao usuário, ao realizar uma consulta ao documento, optar por seguir ou não a estrutura seqüencial do documento. Ao usuário que gera o documento, as ligações permitem a criação dos ítens na ordem julgada mais conveniente.

\subsection{Aplicações}

Os sistemas hipertexto pretendem incorporar o processo de associação realizado pela mente humana, utilizando a tecnologia de redes de estações de trabalho que apresentam excelentes facilidades de interação homem-máquina - telas de vídeo de altíssima resolução e de dimensões adequadas, por exemplo - e dispositivos de transmissão e armazenamento com enorme velocidade e capacidade. Esses sistemas têm por objetivo servir como ferramenta para áreas como:

- engenharia de software;

- projeto auxiliado por computador;

- suporte ao ensino; 
- correio eletrônico;

- automação de escritórios;

- gerenciamento e manutenção de grande quantidade de informação;

- organização de assuntos pessoais;

- manutenção de manuais on-line;

- organização de idéias;

- gerenciamento de organizações; etc.

\subsection{Navegação}

Para seguir uma ligação em um sistema hipertexto, o usuário realiza os seguintes passos:

1. seleciona a ligação através do cursor - com auxilio de um mouse ou das teclas de direção;

2. executa um comando para seguir a ligação - geralmente acionando uma única tecla.

Nesse momento o sistema hipertexto se encarrega de buscar na base de dados - nó relacionado àquela ligação, exibindo-o na tela em uma janela que pode ou não sobrepor total ou parcialmente o nó origem da busca. Isso ocorre sempre que a ligação estiver associada a um nó que deve ter seu conteúdo exibido na tela. No caso da ligação estar relacionada à execução de um programa, por exemplo, o sistema toma as providências necessárias para essa execução.

Alguns sistemas oferecem esquemas adicionais de navegação, como por exemplo a pesquisa por padrão na base de dados e a visualização gráfica de um subconjunto de nós da rede, também chamada browser gráfico. 


\subsection{Facilidades}

Os sistemas hipertexto variam bastante no que diz respeito às facilidades oferecidas ao usuário para a utilização do sistema. Algumas facilidades que podem ser encontradas são:

- permissão ao usuário para, ao realizar uma consulta, gerar ligações para suas anotações particulares;

manutenção automática de diversas versōes do documento;

- suporte para que os nós não contenham apenas texto, mas também gráficos, sons, imagens animadas, etc. Tais sistemas são chamados hypermedia;

- suporte para que a base de dados esteja distribuída através de uma rede de computadores;

- suporte para que Nários usuários tenham acesso ao sistema de modo distribuido;

visualização gráfica dos nós da gede e suas ligações;

- visualização de vários nós simultaneamente na tela, utilizando um sistema de janelas; etc.

\subsection{Questões Relevantes}

Ao consultarmos a literatura, deparamos com questões apresentadas pelos autores como sendo relevantes ao projeto de sistemas hipertexto. Algumas questões comuns são:

- como deve ser a interface com o usuário? Qual a sua importância?

- como gerenciar a base de dados?

- como auxiliar o usuário a encontrar o que procura?

- como evitar que o usuário fique perdido na base de dados?

- é necessário fornecer uma visão gráfica da base de dados?

- que tipos de nós devem ser fornecidos?

- que tipos de ligações devem ser oferecidas? 


\subsection{Linhas Atuais de Pesquisa}

Várias instituições de pesquisa, entre universidades e empresas, desenvolvem atualmente pesquisas na área de hipertexto. Entre as linhas de pesquisa atuais encontram-se:

- definição da interface com o usuário;

- criação de ferramentas para pesquisa na base de dados;

- estudos sobre a utilização de sistemas hipertexto para a criação de documentos;

- estudos de como transformar documentos já existentes em hiperdocumentos;

- definição de quando fornecer visualizações gráficas da rede; etc.

A seguir apresentamos uma evolução histórica dos sistemas hipertexto. 


\section{Capítulo 3}

\section{Evolução Histórica}

Apresentamos a seguir uma lista cronológica e não exaustiva de sistemas que possuem características de hipertexto. Ela contém alguns dos projetos que têm influenciado significativamente o desenvolvimento desses sistemas.

$$
\begin{aligned}
& 1945 \text { - Memex, } 1960 \text { - Xanadu, } 1963 \text { - H-LAM/T , } \\
& 1968 \text { - NLS , } 1972 \text { - ZOG , } 1973 \text { - IBIS , } \\
& \text { 1980 - PIE , } 1981 \text { - KMS , } 1983 \text { - Textnet , } \\
& 1984 \text { - CREF, } 1985 \text { - Document Examiner, } \\
& 1985 \text { - Intermedia , } 1985 \text { - SYNVIEW , } 1986 \text {-WE, } \\
& 1986 \text { - Neptune, } 1986 \text { - Hyperties } 1986 \text { - PlanText, } \\
& 1987 \text { - NoteCards, } 1987 \text { - HyperCard, } \\
& 1987 \text { - Guide , } 1988 \text { - gIBIS. }
\end{aligned}
$$

\section{5 - Memex}

Como citamos, Vanevar Bush [Bush 45], com sua proposta do sistema Memex, introduziu os conceitos relacionados aos sistemas hipertexto.

\section{0 - Xanadu}

O projeto Xanadu, iniciado por Ted Nelson em 1960, além de permitir o armazenamento das informações e de ligações entre elas, possui ferramentas para a reconstrução automática de diferentes versões de um mesmo documento. Esta última característica é considerada, na atualidade, de bastante importância para 
sistemas hipertexto. Com sua proposta, Nelson torna-se pioneiro em outro ponto: ele propõe $o$ uso do termo hipertexto para identificar os sistemas com características comuns ao Xanadu. [Nelson 80, 81].

A primeira versão comercial do sistema Xanadu deve estar presente no mercado em 1989 [Byte 88]. Ted Nelson discute sobre as características e implementações das últimas versões do Xanadu em [Nelson 88].

\section{$1963-\mathrm{H}-\mathrm{LAM} / \mathrm{T}$}

Douglas Engelbart propõe o sistema H-LAM/T - Human using Language, Artifacts, and Methodology, in which he is Trained [Engelbart 63]. Nesse sistema o homem é apresentado como um elemento essencial que atua dinamicamente na base de informações armazenadas. Na mesma época Elgelbart apresenta outra de suas invenções, talvez a mais conhecida: o mouse.

1968 - NLS

Engelbart e English implementam o sistema NLS, oN Line System [Engelbart 68]. Os autores propõem que o sistema seja uma ferramenta de apoio ao desenvolvimento de projetos e permita a um grupo de pesquisadores armazenar, de maneira adequada e conveniente, as informações necessárias ao desenvolvimento de um projeto, em arquivos compartilháveis (especificações, planos, projetos, programas, documentação, artigos, memorandos, bibliografia, referências, etc.). $\mathrm{O}$ sistema proposto permite a criação de qualquer número de ligações de referência intra e entre os arquivos manipulados pelo sistema.

O NLS evoluiu para o sistema $N L S / A$ ugment e hoje é comercializado juntamente com um sistema para rede de computadores.

Uma equipe da Carnegie-Mellon University desenvolve o sistema batizado ZOG, proposto para ser um sistema hipertexto de propósito geral [Akscyn 84]. Entre os pontos defendidos pela equipe da CMU estão a implementação de um único tipo de nó (o qual possui tamanho fixo), a limitação do número de nós apresentados na tela e a grande importância dada à alta velocidade de acesso aos nós, que podem estar espalhados em uma rede de estações de trabalho. O sistema KMS (vide a seguir) é a versão comercial do ZOG. 
Rittel propõe o sistema IBIS, Issue Based Information Systems, que é uma ferramenta para trabalhar com análise de sistemas [Rittel 73]. 0 sistema IBIS fornece 3 tipos de nós (questões, posições e argumentos) e nove tipos de relações (resposta, defesa, contra-argumentação, etc.), sobre os quais os usuários trabalham. 0 sistema IBIS permite que o usuário mova-se rapidamente entre questões diferentes e entre argumentos distintos para a mesma questão. Existe atualmente uma versão do sistema IBIS executável em computadores pessoais da Apple.

\section{$1980-\mathrm{PIE}$}

Goldstein e Bobrow propõem o sistema PIE, Personal Information Enviroment [Goldstein 80,84 ] que tem como objetivo inicial ser uma ferramenta para auxiliar o desenvolvimento de projetos de software. Toda documentação, especificação e arquivos de programas fontes são representados como nós do sistema hipertexto. $\mathrm{O}$ sistema oferece facilidades diversas, de acordo com o interesse do usuário.

\section{$1981-\mathrm{KMS}$}

A equipe da Carnegie-Mellon University que desenvolveu o sistema ZOG cria a empresa Knowledge Systems com o objetivo de implementar uma versão comercial para o sistema ZOG. O sistema comercial é chamado KMS, Knowledge Management System [Akscyn 88] e uma primeira versão torna-se disponivel em 1983. Atualmente o KMS é um sistema comercial com características que o diferenciam dos demais sistemas hipertexto, tais como: a limitação do tamanho do nó, o número de nós apresentados simultaneamente na tela e a distribuição desses nós na tela. Este sistema é comentado com maiores detalhes na seção 5.4. Veja figuras A.1 e A.2.

1983 - Textnet

Em sua tese de $\mathrm{PhD}$, Randall Trigg [Trigg 83] propõe um sistema de hipertexto, Textnet, o qual possui algumas características definidas: as peças de texto são armazenadas em dois tipos distintos de nós; tipos variados de ligações são suportados para oferecer conteúdo semântico a cada ligação; listas compostas por nós e ligaçōes formam caminhos que podem ser visitados de forma programada pelo usuário para, por exemplo, obter determinadas visões de um conjunto de nós ou para imprimir um documento. 
Pitman propõe o sistema CREF [Pitman 85]. Em sua proposta original Pitman desejava que seu sistema fosse um protótipo de editor especializado em textos e gráficos. Porém, o CREF acabou sendo usado por Pitman para a realização de estudos referentes aos aspectos de implementação de sistemas hipertexto. $O$ sistema é constituído de peças de texto chamadas segmentos, que são organizadas em coleções. São fornecidos quatro tipos de ligações, que permitem estabelecer conexões hierárquicas ou não entre os segmentos. Outra ferramenta fornecida pelo CREF é um mecanismo que permite ao usuário relacionar um conjunto de segmentos em teorias. Essas teorias funcionam como filtros que selecionam contextos distintos referentes ao mesmo dado.

\section{5 - Document Examiner}

Walker propõe o Document Examiner [Walker 85], como um sistema exclusivamente de consulta. O sistema constitui um manual on-line, correspondente aos doze volumes referentes ao gerenciamento de telas da Simbolic Lisp Machine. Além de apresentar o texto página a página (comó pequenos nós), certos campos de texto são sensiveis ao cursor, como ligações. Essas ligações, quando selecionadas, fazem com que a seção relevante do manual seja adicionada ao conjunto de páginas correntemente visualizadas na tela.

\section{5 - Intermedia}

Uma equipe da Brown University propõe o Sistema Intermedia. Esse sistema é desenvolvido com o objetivo de ser uma ferramenta para o ensino universitário [Beeman 87], [Garrett 86], [Smith 88], [Yankelovich 85, 87, 88]. O sistema Intermedia é desenvolvido no Institute for Research in Information and Scholarship, IRIS, que é vinculado à Brown University. O sistema é composto por um conjunto de ferramentas que permitem construir e alterar diversos tipos de nós, os quais podem conter texto ou informação gráfica. O Intermedia permite que ligações embutidas sejam selecionadas, criadas e consultadas pelos alunos de uma aula de biologia ou literatura inglesa, por exemplo. Veja figuras A.3, A.4 e A.5. Discutimos mais detalhadamente este sistema na seção 5.2 . 


\section{5 - SYNVIEW}

David Lowe propõe o sistema SYNVIEW [Lowe 85], uma ferramenta para a análise de sistemas, que é similar ao sistema IBIS de Rittel, comentado anteriormente. O SYNVIEW possui uma característica adicional em relação ao IBIS: ele permite que os usuários tenham acesso às informações que validam ou invalidam, por exemplo, os argumentos e questões da base de dados.

1986 - WE

É desenvolvido na Universidade da Carolina do Norte o sistema WE, Writing Enviroment [Smith 86]. O objetivo do sistema é auxiliar o processo de criação de documentos, o que faz da seguinte forma: exige que o usuário organize primeiramente as idéias em hierarquias, as quais são posteriormente detalhadas em uma seqüência linear de palavras, sentenças, etc. $\mathrm{O}$ sistema possui um conjunto de comandos especializados para auxiliar a estruturação do material que esteja sendo escrito e utiliza uma base de dados relacional para o armazenamento dos nós e das ligações da rede.

1986 - Neptune

O sistema Neptune foi desenvolvido pela equipe de Norman Delisle [Delisle 86a] para suportar CAD, Computer Aided Design. A grande evolução trazida pelo Neptune é a construção do sistema na forma de niveis de programas. Neste conjunto de niveis, o subsistema que fornece ao Neptune suas características de hipertexto é chamado Hypertext Abstract Machine, HAM. As funções implementadas pelo HAM podem ser utilizadas por programas específicos que servem a aplicações determinadas. Estes programas específicos, ao utilizar as funçôes do subsistema HAM, estabelecem mais um nível de camada de programas. Entre os serviços suportados pelo HAM está o controle automático de versões. O HAM é analisado mais detalhadamente na seção 5.1 .

1986 - Hyperties

O Hyperties está sendo desenvolvido pela equipe de Ben Shneiderman e Gary Marchionini [Marchionini 88] com dois objetivos. 0 primeiro é o de ser uma ferramenta de aprendizagem utilizada por sistemas de ensino: o Hyperties auxilia 
o leitor a pesquisar em uma base de conhecimento. $O$ segundo objetivo da equipe é construir um instrumento de estudo sobre interfaces de sistemas hipertexto com os usuários. O Hyperties tem como nós pequenos artigos, os quais são interconectados por qualquer número de ligações. Uma característica encontrada nesse sistema é a manutenção, ao lado de cada ligação, de um pequeno resumo sobre o artigo destino da ligação. Esse resumo é utilizado para ser mostrado quando o usuário seleciona a ligação que leva ao artigo. De posse desse resumo na tela, o usuário decide pelo aprofundamento ou não naquela direção da base de dados. Outra característica é que as ligaçóes são indicadas alterando-se o tipo de letra do texto que é fonte da ligação. Veja a figura A.6, onde as ligações são indicadas em negrito.

\section{6 - PlanText}

O sistema PlanText foi desenvolvido na Microeletronics and Computer Technology Corporation, $M C C$, por Eric Gullichsen e outros [Gullichsen 88]. Seu objetivo inicial era servir como protótipo de um sistema hipertexto, mas logo acabou tornando-se uma ferramenta utilizada por vários grupos de trabalho da MCC. 0 PlanText está baseado no sistema de arquivos do UNIX e no sistema de gerenciamento de janelas SUN Sunview. Veja as figuras A.7 e A.8.

1987 - NoteCards

Frank Halasz, Randall Trigg e Thomas Moran construíram no XEROX PARC o sistema NoteCards [Halasz 87], com o objetivo de auxiliar os usuários a trabalharem com idéias. $O$ sistema fornece uma rede de nós, que o usuário utiliza para representar e organizar suas idéias. Este sistema é comentado mais detalhadamente na seção 5.3. Veja figuras de A.9 a A.13.

\section{7 - HyperCard}

Bill Atkinson, criador de várias ferramentas para os computadores Macintosh, apresenta o sistema HyperCard [Williams 87]. O HyperCard apresenta algumas características que permitem classificá-lo com sistema hipertexto para monousuário. Apesar de não permitir ligações embutidas no exato sentido da palavra, o sistema admite relacionar ligaçóes com cada nó da base, o que facilita a construção, pelo usuário, de diversos níveis de hierarquia de nós. 0 sistema ainda mantém armazenado o caminho visitado pelo usuário numa determinada sessão, para permitir o retorno pelo mesmo caminho. Outra ferramenta muito útil é a linguagem HyperTalk que permite ao usuário programar um conjunto de eventos que podem ocorrer no sistema. Veja as figuras A.14 e A.15. 
É lançado pela OWL International's o sistema Guide [Fiderio 88], desenvolvido para ser executável em computadores Macintosh e IBM Pc AT. O sistema suporta uma base de nós de texto e permite que esses nós sejam conectados por três tipos diferentes de ligaçöes.

\section{7 - gIBIS}

Michael Begeman e Jeff Conklin apresentam o sistema gIBIS, que encontra-se em desenvolvimento na MCC [Conklin 87][Begeman 88]. O sistema é proposto para ser uma ferramenta gráfica capaz de suportar trabalho em grupo com o uso da metodologia IBIS. Veja a figura A.16.

A tabela 3.1 fornece um resumo do histórico apresentado neste capítulo. 


\begin{tabular}{|l|l|l|l|}
\hline \hline ano & autor & sistema & objetivo principal \\
\hline \hline 1945 & Bush & Memex & Biblioteca Científica \\
\hline 1960 & Nelson & Xanadu & Biblioteca Científica \\
\hline 1963 & Engelbart & H-LAM/T & Base de Dados Pessoal \\
\hline 1968 & Engelbart & NLS & Suporte a CAD $\star$ \\
\hline 1972 & MacCracken & ZOG & Propósito Geral $\star$ \\
\hline 1973 & Rittel & IBIS & Análise de Problemas $\star$ \\
\hline 1980 & Goldstein & PIE & Desenv. Software \\
\hline 1981 & MacCracken & KMS & Propósito Geral $\star$ \\
\hline 1983 & Trigg & Texnet & Propósito Geral \\
\hline 1984 & Pitman & CREF & Propósito Geral \\
\hline 1985 & Walker & Document Examiner & Manual On-line \\
\hline 1985 & IRIS & Intermedia & Ensino e Pesquisa $\star$ \\
\hline 1985 & Lowe & SYNVIEW & Análise de Problemas \\
\hline 1986 & Smith & WE & Auxílio a Autoria \\
\hline 1986 & Delisle & Neptune & CAD $\star$ \\
\hline 1986 & Shneiderman & Hyperties & Ensino/Interface Usuário \\
\hline 1986 & Gullichsen & PlanText & Propósito Geral $\star$ \\
\hline 1987 & Halasz & NoteCards & Organização de Idéias \\
\hline 1987 & Bill Atkinson & HyperCard & Propósito Geral \\
\hline 1987 & OWL Int. & Guide & Propósito Geral \\
\hline 1987 & Begeman & gIBIS & Análise de Problemas $\star$ \\
\hline \hline
\end{tabular}

Tabela 3.1: Evolução Histórica

$\star$ sistemas que permitem processamento multi-usuário. 


\section{Capítulo 4}

\section{Aspectos Relevantes ao Projeto de Sistemas Hipertexto}

Apresentamos algumas discussões relativas às características comuns aos principais sistemas hipertexto, assim como procuramos mostrar particularidades específicas desses sistemas. As especificidades dos sistemas decorrem das distinções existentes entre os objetivos para os quais são construídos e do hardware sobre o qual o sistema pode ser implantado.

Os tópicos escolhidos cobrem os principais aspectos de projeto dos sistemas hipertexto; que são:

Implementação de Nós, Implementação de Ligações, Navegação em Hiperdocumentos, Criação de Hiperdocumentos, Adaptação de Documentos, Controle de Versões e Trabalho Cooperativo.

Em [Pimentel 89a] apresentamos uma visão geral dos aspectos discutidos neste capítulo. 
Aspectos Relevantes ao Projeto de Sistemas Hipertexto

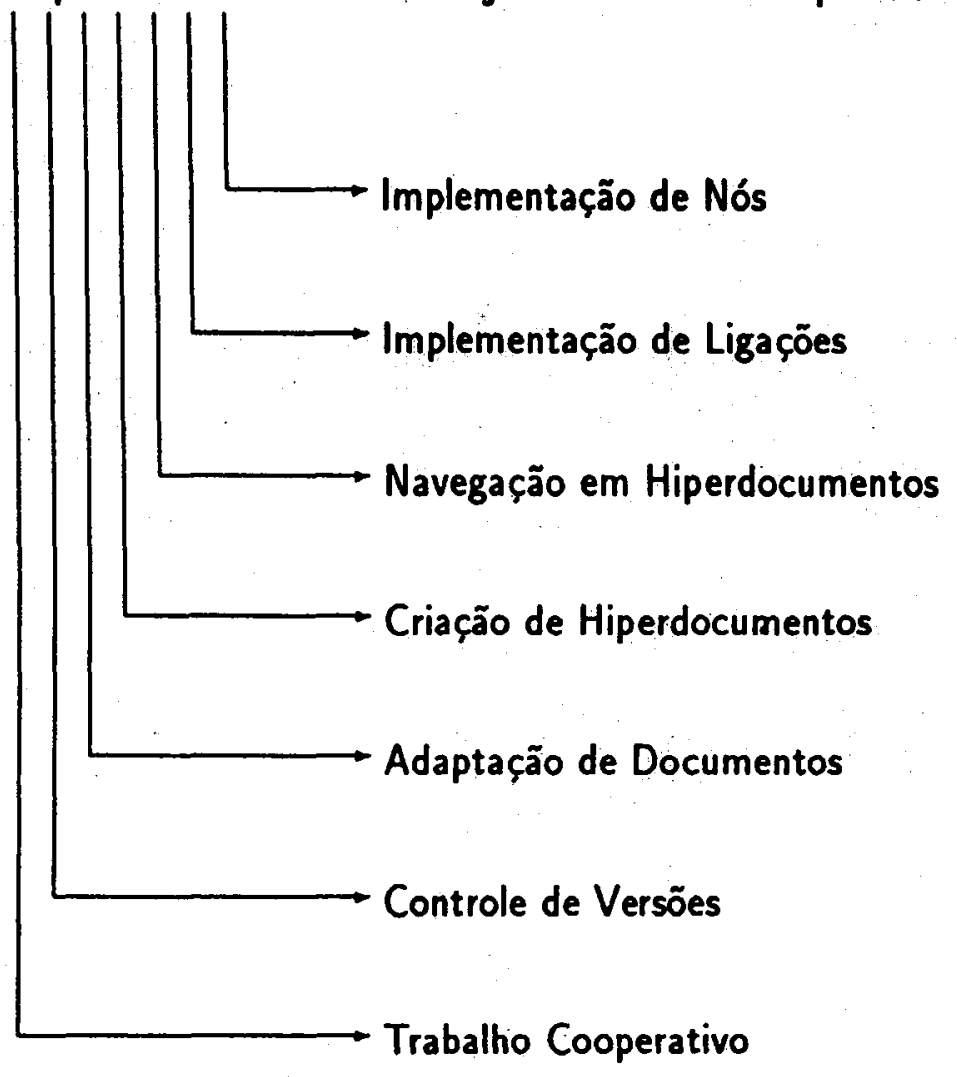

\subsection{Implementação de Nós}

A implementação de nós envolve decisões relacionadas com 0 Tamanho do Nó e O Tipo do Nó, as quais passamos a avaliar.

\subsubsection{O Tamanho do Nó}

Divisão de um documento: uma primeira distinção entre sistemas hipertexto pode ser observada em relação à forma de tratamento dos documentos. Existem sistemas que dividem os documentos em vários nós enquanto outros consideram todo o documento como um único nó. 
Implementação de Nós

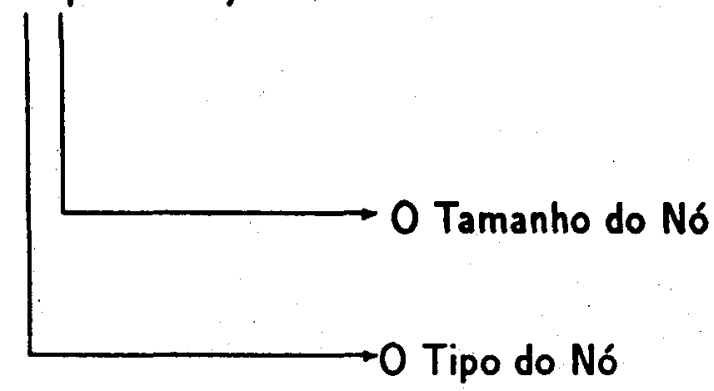

- no caso do documento não ser dividido em pequenas porções, o sistema suporta apenas ligaçốes entre documentos e deve ter mecanismos definidos para permitir ao usuário visualizar o documento como um nó da base de documentos. $\mathrm{O}$ sistema Hyperties, por exemplo, divide os documentos em páginas para apresentaçẫo ao usuário. Na figura A.6 temos a exibição de duas páginas de documentos distintos.

- no caso do documento estar dividido em pequenas porcóes, ou nós, Eada nó pode ter tamanho fixo ou variável. 0 sistema (KMS, por exemplo, implementa apenas um tamanho fixo de nó, correspondente a toda a tela. Porém, ele permite que os nós sejam visualizados de dois modos: apresentação apenas de sua metade esquerda (figura A.1), ou apresentação completa do nó (figura A.2). Os sistemas NoteCards figura A.9) Intermediz (figura A.5) admitem nós de tamanhos quaisquer.

Um sistema pode admitir nós de apenas um tamanho fixo ou várias opções de tamanhos fixos. Além disso, pode-se permitir ao usuário escolher ou mesmo definir que tamanhos de nós pretende utilizar.

Questões relevantes ao tamanho do nó: a definição do tamanho do nó requer a discussão de alguns aspectos de projeto:

- se alguns tamanhos fixos devem ser oferecidos, quais são eles ?

- se um único tamanho fixo deve ser oferecido, qual será ele? 
- se vários tamanhos forem fornecidos

- será permitido misturar nós de tamanhos diferentes no mesmo documento?

- como o usuário selecionará o tamanho desejado?

- será permitido ao usuário definir os tamanhos com os quajs deseja trabalhar?

maioria dos sistemas atuaís nãolimita o tamanho do nó. A flexibilidade obtida, entretanto, exige maior sofisticação no controle por parte do sistema.

\subsubsection{O Tipo do Nó}

Dizemos que os nós são de tipos distintos quando o sistema realiza sobre eles tratamento diferenciado.

Existem sistemas que oferecem apenas um tipo de nó, enquanto outros são tão flexíveis que deixam ao usuário a tarefa de especificar todos os tipos de nós com os quais deseja trabalhar. Tipos distintos de nós podem ser oferecidos com objetivos diversos, como:

conter tipos distintos de dados (yeja figuras A.3 e A.12, onde alguns nós contêm gráficos, outros textos, etc);

servir para fins distintos (código fonte, documentação, animação, etc.);

- estruturar os nós do hiperdocumento. Os fileboxes do sistema NoteCards, por exemplo, têm a função de estruturar hierarquicamente um conjunto de nós (os três nós existentes na parte inferior da figura A.10, são fileboxes);

- permitir a extensão do sistema implementando-se novos tipos de nós.

Entre as possibilidades de tipificação de nós que podem ser oferecidos por um sistema, destacamos as seguintes:

Um tipo distinto de nó para cada tipo de informação: neste caso o sistema oferece tratamento diferenciado para os diversos tipos de informação suportados (por exemplo, informaçōes de áudio e imagem animada). 
Um único tipo de nó constituído de diversos campos com conteúdo distinto: neste caso o nó é encarado pelo sistema como sendo de um único tipo. Porém, o sistema permite que o nó seja dividido internamente em campos, que são tratados diferentemente conforme o tipo de informação que contêm.

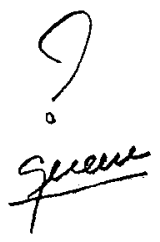

Um tipo de nó para apresentação de pontos de acesso: neste caso a base não é constituída dos nós armazenados como tal, mas sim por informacões a serem selecionadas de acordo com alguma condição. $O$ sistema monta o conteúdo em um nó, para apresentá-lo ao usuário, apenas quando ocorre a necessidade da seleção de um conjunto de informacões, no caso de uma consulta. Este caso pode ser aplicado, por exemplo, aos dicionarios eletrônicos. 0 sistema recebe uma consulta do usuário e monta o conteúdo do nó com a resposta encontrada. A figura A.17 apresenta vários nós, que correspondem a consultas realizadas a respeito da palavra abbreviate, no Oxford English Dictionary [Raymond 88]. Toda discussão a respeito do tipo do nó pode ser novamente aplicada.

Um tipo único de nó de tamanho fixo que pode conter qualquer tipo de informação: neste caso o sistema limita o tamanho do nó, por exemplo, ao tamanho da tela, e permite que qualquer tipo de informação seja colocada em seu interior (veja as figuras A.1 e A.2, onde são misturadas informaçōes gráficas e de texto).

Um tipo único de nó de tamanho variável que contém uma quantidade arbitrária de qualquer tipo de informação: neste caso o sistema permite a mistura de tipos de informação nos nós, não limitando seus tamanhos.

Um tipo especial de nó para estruturar nós comuns: existem neste caso, além de nós que contêm dados, outros nós cujo conteúdo serve para estruturar, hierarquicamente ou não, um conjunto de nós. Os nós organizados pelo nó de estruturação podem ser, por sua vez, nós de estruturação ou nós comuns. Este é o caso dos fileboxes da figura A.10.

Um tipo de nó com atributo relacionado: nós deste tipo servem a objetivos que variam da classificação dos nós, de acordo com algum objetivo do usuário, até o oferecimento, por parte do sistema, de ferramentas para o controle de versões dos documentos e dos nós individuais. 
Implementação de Ligaçōes

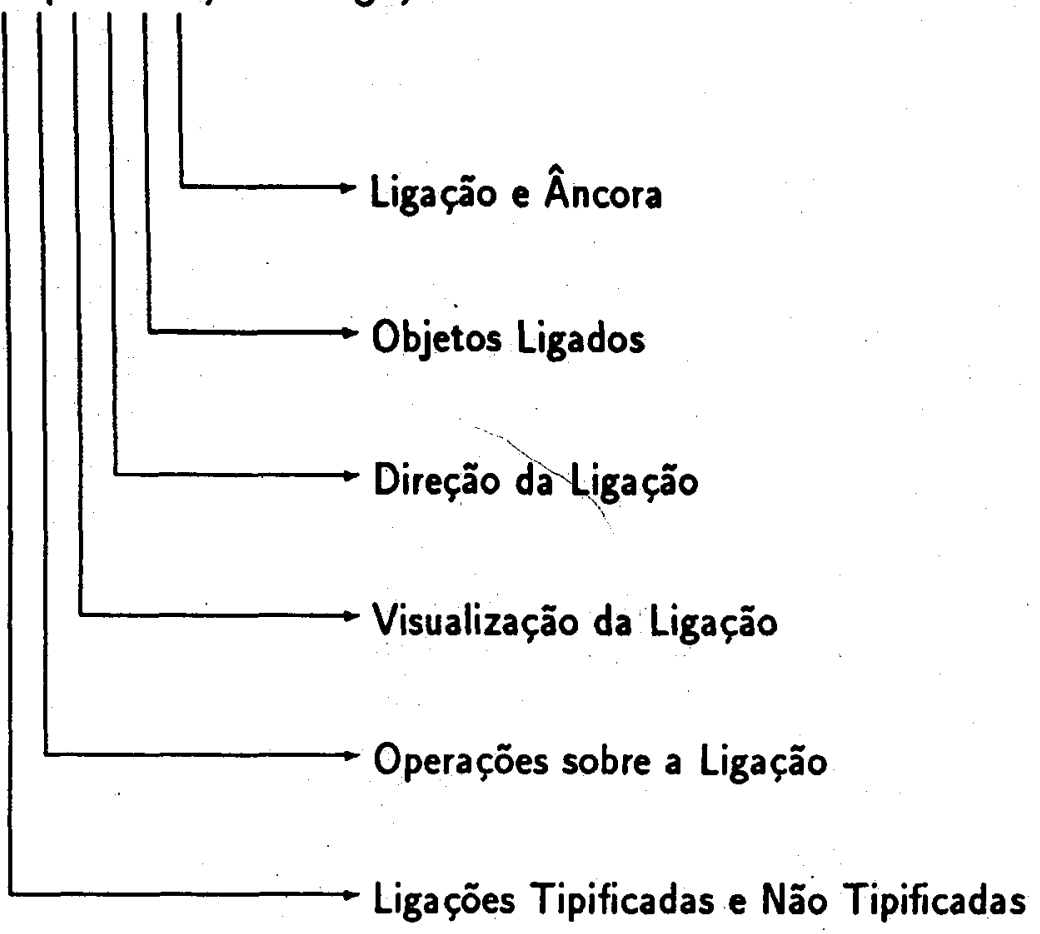

\subsection{Implementação de Ligações}

São vários os aspectos referentes à implementação de ligações embutidas nos sistemas hipertexto. As questões que discutimos a seguir são: Ligação e Âncora, Objetos Ligados, Direção da Ligação, Visualização da Ligação, Operações sobre a Ligação e Ligaçōes Tipificadas e Não Tipificadas.

\subsubsection{Ligação e Âncora}

Ligação: denomina-se ligação o ponteir que relaciona diretamente dois objetos da base de nós. Dizemos que os objetos são ligados. Por objetos da base de dados, referimo-nos a um ponto dentro de um nó, ao nó como um todo ou a qualquer porção do nó que possa ser especificada.

Âncora: denomina-se âncora objeto que possui uma ou mais ligações a ele relacionadas. Dizemos que uma ligação é ancorada ao objeto e que toda 
ligação relaciona diretamente duas âncoras (uma fonte e outra destino da ligação).

É necessário um estudo minucioso do projetista do sistema hipertexto, em relação às ligações e às âncoras. $O$ preço a ser pago por uma ferramenta mais flexível - permitir que mais de uma ligação esteja relacionada à mesma âncora, por exemplo - é provavelmente caro no que diz respeito ao custo do software e do tempo de gerenciamento do sistema. Além disso, ao abrir-se muitas opçōes ao usuário, aumenta-se a possibilidade de que ele fique perdido na rede de nós $\mathrm{e}$ ligações. Entretanto, é possível que, para algumas aplicaçōes, esse recurso seja obrigatório.

\subsubsection{Objetos Ligados}

Comentamos acima que uma âncora pode ser definida por diversos tipos de objetos. Isso significa que podemos ter uma enorme combinação de relacionamentos estabelecidos, pelas ligações, entre as âncoras. Como possibilidades de relacionamentos temos:

- um documento inteiro relacionado a outro documento inteiro;

- um documento inteiro relacionado a um nó de outro documento;

- um documento inteiro relacionado a um gráfico de outro documento;

- um documento inteiro relacionado a um ponto de outro documento;

- um nó de um documento relacionado a um nó de outro documento;

- um nó de um documento relacionado a um nó do mesmo documento;

- uma porção de um documento relacionada a outra porção do mesmo documento, por exemplo uma sentença, uma cadeia alfanumérica, uma palavra, um símbolo especial; etc.

Essas e outras combinações trazem, cada uma, vantangens em relação à flexibilidade de uso e, ao mesmo tempo, um nível diferente de complexidade para a implementação e gerenciamento do sistema. Tais pontos devem ser levados em consideração na proposta de um sistema hipertexto. $O$ projetista deve ter sempre em mente que as ferramentas por ele oferecidas aos usuários devem ser, antes de tudo, de fácil utilização, caso contrário, corre-se o risco do usuário optar por não utilizá-las e estas servirem apenas para onerar o sistema. 


\subsubsection{Direção da Ligação}

Ligação unidirecional: podemos navegar diretamente do nó fonte para o nó destino, mas não vice-versa. A maioria dos sistemas hipertexto atuais implementa um esquema para guardar o percurso que o usuário esteja seguindo. Isso lhe permite retornar por esse percurso; mesmo que não haja ligaçóes explícitas nessa direção.

Ligação bidirecional: neste caso sabemos da existência da ligação, e podemos selecioná-la, estando na âncora fonte ou destino da ligação.

Podemos verificar que existe um número muito grande de possibilidades de combinação dos ítens direção da ligação com os ítens objetos relacionados e, ainda, com o número de ligações ancoradas a uma mesmo objeto. Essas combinações oferecem uma grande quantidade de alternativas as quais o projetista do sistema pode manipular, usando toda sua capacidade criativa, tendo sempre em vista o que já comentamos anteriormente: que as ferramentas oferecidas devem ser amigáveis ao usuário.

\subsubsection{Visualização da Ligação}

Ligação transparente: Neste caso o usuário conhece a priori a existência da ligação em um determinado ponto do texto, o que torna desnecessária, redundante e indesejada a existência de marcas visuais para sua indicação.

Podemos colocar nesta classificação a forma de visualização que é uma variação da ligação transparente: a ligação normalmente não é visualizada pelo usuário mas, quando o usuário coloca o cursor sobre a âncora, o sistema apresenta um sinal visual dessa existência, por exemplo, mudando a forma de apresentação do cursor.

Marca textual: classificamos como visualização textual da ligação o seguinte: o conteúdo do nó é apresentado normalmente na tela do usuário e o sistema faz com que trechos do conteúdo - uma letra ou uma palavra, por exemplo - sejam apresentados de forma diferente (com a tela invertida, de cor diferente, etc.). 0 usuário reconhece o conteúdo como uma âncora. Esse tipo de visualização recebe várias críticas, entre elas, a privação do usuário em utilizar, como recursos de edição, as facilidades visuais alocadas para a identificação das âncoras. 
Marcá especial: esta é a forma de visualização na qual o sistema utiliza símbolos especiais para indicar a existência de ligações. Esses símbolos especiais - os quais não são permitidos ao usuário utilizar normalmente dentro de seu texto - são escolhidos, ou criados, de modo a não serem símbolos convencionais. Por exemplo, na figura A.2 as marcas especiais são pequenos círculos, na figura A.4 são retângulos pequenos que contêm setas e, na A.9, as marcas são indicadas por frases embutidas em retângulos. Um dos impasses, geralmente encontrado na definição desses símbolos, refere-se à escolha de seu tamanho. Se por um lado um símbolo de tamanho pequeno atrapalha pouco a visualização do conteúdo do nó, por outro lado ele pode ser um objeto difícil de ser visualizado e selecionado. Existem sistemas que permitem ao usuário inibir a apresentação do símbolo indicador de ligação, se julgar que o mesmo esteja atrapalhando momentaneamente a visualização do conteúdo do nó. Outra possibilidade é permitir ao usuário especificar, dentre um conjunto de símbolos possíveis, qual símbolo o sistema deve utilizar para representar as ligaçōes.

A criação de visualizações de ligação que forneçam informações sobre o destino da ligação ou o tipo da ligação pode ser uma alternativa. Um argumento a favor do uso desse tipo de marcas é que elas permitem ao usuário decidir por seguir ou não uma ligação possuindo mais informação do que apenas o contexto no qual a ligação esteja embutida. Um argumento contrário é o fato de que tais marcas podem congestionar o campo visual do usuário.

\subsubsection{Operações sobre a Ligação}

\section{Alteração do objeto ligado}

Algumas questões surgem quando o objeto onde encontra-se a âncora ou a ligação é modificado, entre elas:

Eliminação de objeto fonte ou destino: se um objeto fonte ou destino de uma ligação, ou de uma âncora, for eliminado, o que acontece com a ligação? Providências devem ser tomadas, como a eliminação da ligação inteira, ou a atracação do extremo afetado a um item especial para essa situação ou ainda, notificação ao usuário para medidas complementares.

Transferência de contexto: se um objeto, que era uma âncora, for transportado para outro lugar, pode ocorrer que o contexto no qual a ligação se apoiava seja perdido, pois no novo local a ligação pode não ter mais o mesmo 
(ou nenhum) significado. Estratégias semelhantes àquelas do parágrafo anterior devem ser adotadas.

Alteração do objeto: Suponhamos que uma âncora seja alterada, por exemplo, trocando-se a palavra pilha pela palavra fila. Se a palavra for originalmente a fonte de uma ligação para um conjunto de algoritmos para manipulação de pilhas, ocorre novamente perda de contexto, o que exige providências para contorno dessa situação.

\section{Herança de contextos}

Um problema que surge quando permitimos a realização de ligações entre nós é o que fazer quando uma ligação conecta dois nós que já possuem outras ligações? Duas alternativas possíveis são:

- a partir de cada um dos nós ligados, herda-se diretamente o direito de acessar as demais ligações existentes nos destinos;

- as ligações existentes anteriormente são invisíveis quando acessadas através da ligação efetuada a posteriori.

A primeira alternativa apresenta vantagens em relação à implementação, que é mais simples, porém não deixa opção ao sistema ou ao usuário para permitir acessos diferenciados ao mesmo documento, por exemplo.

Já a segunda alternativa implica perda de conhecimento (o usuário deixa de ter acesso às informações existentes no destino), o que pode muitas vezes ir contra o próprio objetivo do sistema hipertexto.

Essas opções produzem resultados distintos quando implementadas, por exemplo, com ligações unidirecionais ou documentos estritamente hierárquicos. Verificamos então que tais questões devem ser estudadas no conjunto do projeto do sistema hipertexto e não isoladamente.

\subsubsection{Ligações Tipadas e Não Tipadas}

Uma questão bastante debatida entre os projetistas de sistemas hipertexto diz respeito ao tipo das ligações. As alternativas básicas são implementar um único tipo de ligação ou implementar um número fixo de tipos de ligações. No primeiro 
caso a ligação não fornece nenhuma informação a respeito do tipo do relacionamento dos objetos; essa implementação, apesar de ser inflexível, é provavelmente a mais simples.

No caso do oferecimento de um número fixo de tipos de ligações, podemos pensar em utilizá-las, por exemplo, para permitir que o usuário diferencie as ligações que estruturam hierarquicamente um documento daquelas que realizam referências cruzadas ou ativam a execução de programas. Outra aplicação seria a atribuição de semântica às ligações.

Podemos perceber que quanto maior o número de tipos de ligação, mais informação o usuário pode ter a respeito de uma determinada ligação. Entretanto, o custo da implementação de diversos tipos de ligações deve tornar-se maior a cada novo tipo implementado. 


\subsection{Navegação em Hiperdocumentos}

Os mecanismos de navegação na base de nós constituem aspectos fundamentais dos sistemas hipertexto, uma vez que é através deles que o usuário pode ter acesso ao conjunto de informações armazenadas e, além disso, é através da utilização de tais mecanismos que um usuário cria a base de nós para posterior acesso pelos usuários que realizam consultas.

A forma natural pela qual os usuários pesquisam informações em hiperdocumentos é através da seleção de ligações que julgam relevantes. Os sistemas atuais normalmente oferecem outras ferramentas para a pesquisa de informação. A ferramenta mais comum é a que suporta a pesquisa em uma parte ou em toda a base de dados, por palavras, frases ou trechos fornecidos pelo usuário. Uma outra ferramenta oferecida por alguns sistemas, chamada browser gráfico, fornece uma visão gráfica de uma região especificada na base de dados. Nessa visão o usuário pode normalmente selecionar os nós que deseja visitar ou mesmo realizar a edição (inserção e remoção) de ligações e de nós da região relacionada.

Entre os métodos de pesquisa possíveis, discutimos: Seleção de Ligação, Seleção Através de Índice, Pesquisa de Padrão, Navegação em Gráfico de Nós e Ligaçōes, Uso da Estrutura Existente e Navegação em Caminhos Pré-Definidos.

\subsubsection{Seleção de Ligação}

Esta é a forma natural de navegação em hiperdocumentos: o usuário coloca o cursor sobre uma âncora e ativa o comando que faz com que a ligação seja atravessada, isto é, que o outro lado da ligação torne-se disponivel. Um sistema que não possua essa forma de navegação não satisfaz a única forma convencional de navegação em hiperdocumentos.

\subsubsection{Seleção Através de Índice}

Esta forma de pesquisa fornece ao usuário um índice análogo ao existente na literatura impressa (referimo-nos, por exemplo, aos livros que normalmente apresentam, em seu início, a relação de todos os capítulos, seções, sub-seções, etc. do volume). $\mathrm{O}$ sistema hipertexto, neste caso, associa a cada elemento do índice uma ligação que pode ser selecionada pelo usuário para acessar diretamente o conteúdo selecionado. Veja as figuras A.11 e A.18. 


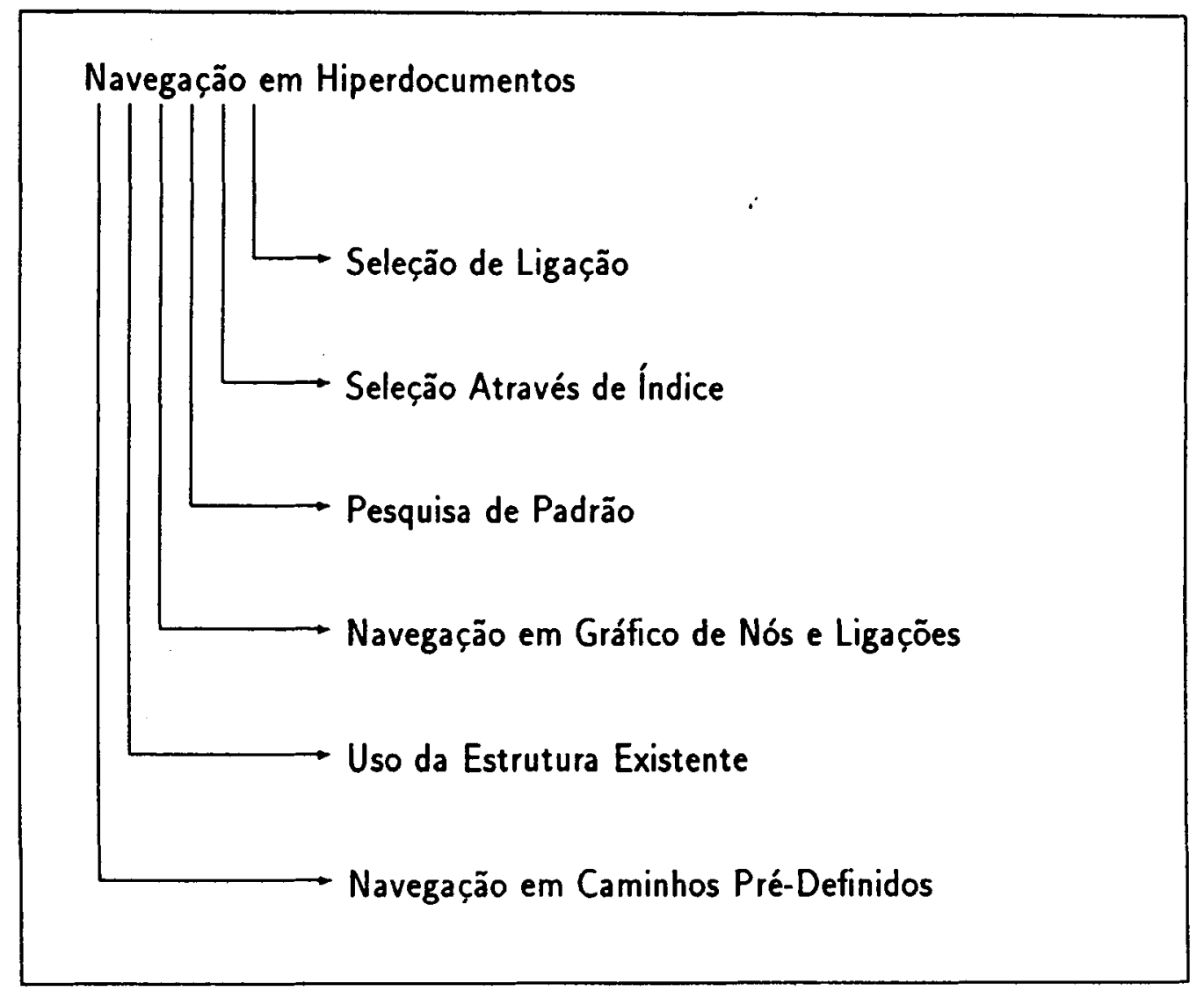


Algumas questões podem ser consideradas ao se optar por oferecer esse tipo de ferramenta aos usuários do sistema, entre elas:

Que regiâo deve cobrir cada índice? Pode existir um único índice para cada documento, como o citado acima, ou pode ocorrer que a hieraquia de índices seja dividida e apresentada de modo a existir um índice para cada nível da hieraquia. Por exemplo: um índice que cobre apenas os capítulos; um índice para cada capítulo que cobre, por sua vez, todas as seções existentes no capítulo; outro conjunto de índices para relacionar os subseções existentes em cada seção, e assim por diante.

Quando o índice é criado? Cada índice pode ser criado a partir da solicitação do usuário que, nesse caso, pode especificar inclusive a área da base que deseja visualizar, ou pode ser criado automaticamente pelo sistema quando da criação de um documento.

É possível editar um índice? Caso o sistema ofereça tal facilidade, o usuário pode reestruturar o documento movimentando e eliminando informações diretamente no índice.

Como manter a consistência entre o documento e seu índice durante a edição do documento pelo usuário? Pelo menos duas alternativas são possíveis: num primeiro caso, pode ser deixado sob responsabilidade do sistema manter a consistência do índice em relação ao documento editado. Uma segunda alternativa é deixar a cargo do usuário a solicitação de um serviço que realize a operação de verificação de consistência quando ele, usuário, julgar conveniente. Neste caso o sistema pode ter uma opção que é realizar a operação para verificação da consistência da base em situações estratégicas, como no momento em que o usuário encerra sua sessão no sistema, por exemplo.

\subsubsection{Pesquisa de Padrão}

Esta facilidade é de extrema importância uma vez que é utilizada para auxiliar o usuário a encontrar o que procura e a se localizar dentro da base de dados. A maioria dos sistemas procura fornecer algum tipo de pesquisa desse gênero a seus 
usuários, como fazem os editores de texto convencionais. Vários dos projetistas de sistemas hipertexto reconhecem que essa é uma ferramenta que precisa ser estudada profundamente. Existem muitos pontos que precisam ser definidos quando se decide que o sistema deve oferecer essa ferramenta. Alguns deles são discutidos a seguir.

Que tipo de padrão pode ser suportado? Existem variações que permitem a busca de palavras, textos e sentenças. Em alguns casos é permitido ao usuário utilizar máscaras para especificação do padrão e mesmo utilizar o conceito de expressões regulares na especificação.

Quão rápida deve ser o tempo de resposta a uma solicitação de pesquisa? Muita importância tem sido dada às pesquisas desta área. Existem pesquisas em andamento na área de algoritmos para buscas de padrão em grandes e pequenas bases de dados [Williams 87],[Raymond 88], com o objetivo de otimizar ao máximo o tempo gasto nas buscas.

Que extensões do processo de busca pode-se oferecer? Uma das extensões mais diretas é o suporte a busca implícita de sinôminos dos padrões pesquisados. Tal ferramenta permite ao usuário utilizar ao máximo seu conhecimento a respeito do assunto sobre o qual busca informaçóes. $\mathrm{O}$ oferecimento de tal facilidade implica o aumento da responsabilidade do sistema. Inúmeras pesquisas a respeito estão sendo desenvolvidas [Halasz 88], [Raymond 88].

Como a resposta da pesquisa deve ser apresentada ao usuário? Duas alternativas são comumente utilizadas. A primeira apresenta ao usuário um nó com ligações para os locais nos quais há ocorrência do padrão solicitado. Ao selecionar uma ligação, o usuário escolhe qual dos contextos encontrados deve ser apresentado para sua apreciação. Uma segunda alternativa consiste em deixar que o sistema apresente um-a-um os contextos encontrados, deixando ao usuário a escolha de quando continuar a navegação pelas diversas ocorrências encontradas.

Que escopos de busca oferecer? Normalmente permite-se ao usuário definir uma determinada região do documento na qual a busca deve ser realizada. Os mecanismos pelo qual o sistema permite ao usuário especificar a região de busca variam de acordo com a estrutura do documento suportada pelo sistema. Em alguns casos o usuário define uma estrutura hierárquica que delimita uma porção 
do documento. Outro mecanismo que pode ser utilizado para definir o escopo da busca é a especificação de algumas versões dos documentos nas quais a pesquisa deve ser realizada. Uma outra ferramenta oferecida por alguns dos sistemas atuais é a operação de filtro, através da qual o usuário seleciona um conjunto de nós que possuam as características especificadas no filtro [Delisle 86a, 86b].

Que outras funções de busca permitir ao usuário? Neste ponto consideramos condições especiais que podem ser utilizadas pelo usuário para especificar melhor $o$ objeto da pesquisa e a maneira pela qual a pesquisa deve ser realizada. $\mathrm{O}$ usuário pode fornecer, por exemplo, o número de vezes que o padrão deve ser encontrado. $O$ usuário pode também realizar restrições a respeito da diferenciação entre as letras maiúsculas ou minúsculas que constróem o padrão. 0 sistema pode oferecer mecanismos para a construção de padrões mais complexos com 0 auxílio de operadores lógicos do tipo AND, OR e NOT.

\subsubsection{Navegação em Gráfico de Nós e Ligações}

Diversos sistemas oferecem, como mecanismo de pesquisa e visualização da base, uma visão gráfica chamada browser gráfico. No browser os documentos são representados por seus títulos: os títulos são associados aos nós de um grafo cujas arestas representam as ligações que estão embutidas no conteúdo dos nós. Além de servir como instrumento de navegação e edição, os browsers gráficos constituem um mecanismo de grande importância no que diz respeito ao auxilio oferecido ao usuário sobre sua localização na base de nós. Veja as figuras A.4, A.7, A.11 e A.13, onde são apresentados vários browsers.

Este aspecto de localização na base de nós é de muita importância em sistemas que permitem a construção de documentos com um número arbitrário de nós, estejam esses nós relacionados de modo estritamente hierárquico ou não.

Os sistemas atuais permitem, normalmente, a definição de vários niveis de escopo para a geração da visão gráfica e admitem também que o usuário realize edições no documento relacionado ao grafo, através da criação e eliminação de nós e arestas. 


\subsubsection{Uso da Estrutura Existente}

Alguns sistemas oferecem mecanismos para que as informações possam ser aninhadas em estruturas bem determinadas [Delisle 86a], [Halasz 88]. As estruturas são definidas através de nós especiais cujo conteúdo representa: (a) um conjunto de nós, comuns ou especias e (b) as ligações que relacionam esses nós na base de dados. Veja a figura A.10.

Essas estruturas podem ser utilizadas pelo usuário para pesquisar na base sem ter que passar pelos conteúdos dos nós que armazenam as últimas instâncias da informação.

\subsubsection{Navegação em Caminhos Pré-Definidos}

Um mecanismo suportado por alguns sistemas é a especificação de caminhos que podem ser utilizados como padrão para uma navegação na base. Tais caminhos podem ser definidos por um usuário para uso próprio ou para utilização por outros usuários que realizam pesquisas no hiperdocumento, no caso de ensino, por exemplo. Os caminhos podem ser definidos também dinamicamente pelo próprio sistema, como é o caso daqueles sistemas que guardam todo o trajeto, ou parte dele, executado pelo usuário, para facilitar-lhe a volta pelo mesmo caminho, se assim o desejar.

\subsection{Criação de Hiperdocumentos}

A elaboração de quaisquer documentos, através de um sistema hipertexto, é uma questão polêmica.

Correntes distintas avaliam o fato de ser ou não sempre melhor para o autor utilizar um sistema hipertexto para escrever um documento. Contra a idéia existe, por exemplo, o argumento de que o autor é obrigado a estruturar precocemente suas idéias. Tal argumento é válido apenas em relação aos sistemas que exigem tal estruturação por parte do usuário. Outro argumento contrário critica a necessidade do usuário ser obrigado a criar o documento utilizando pouca quantidade de informação em cada nó do documento. Este argumento também não é válido para todos os sitemas existentes, uma vez que vários deles não limitam a quantidade de informação que pode estar contida em cada nó. 


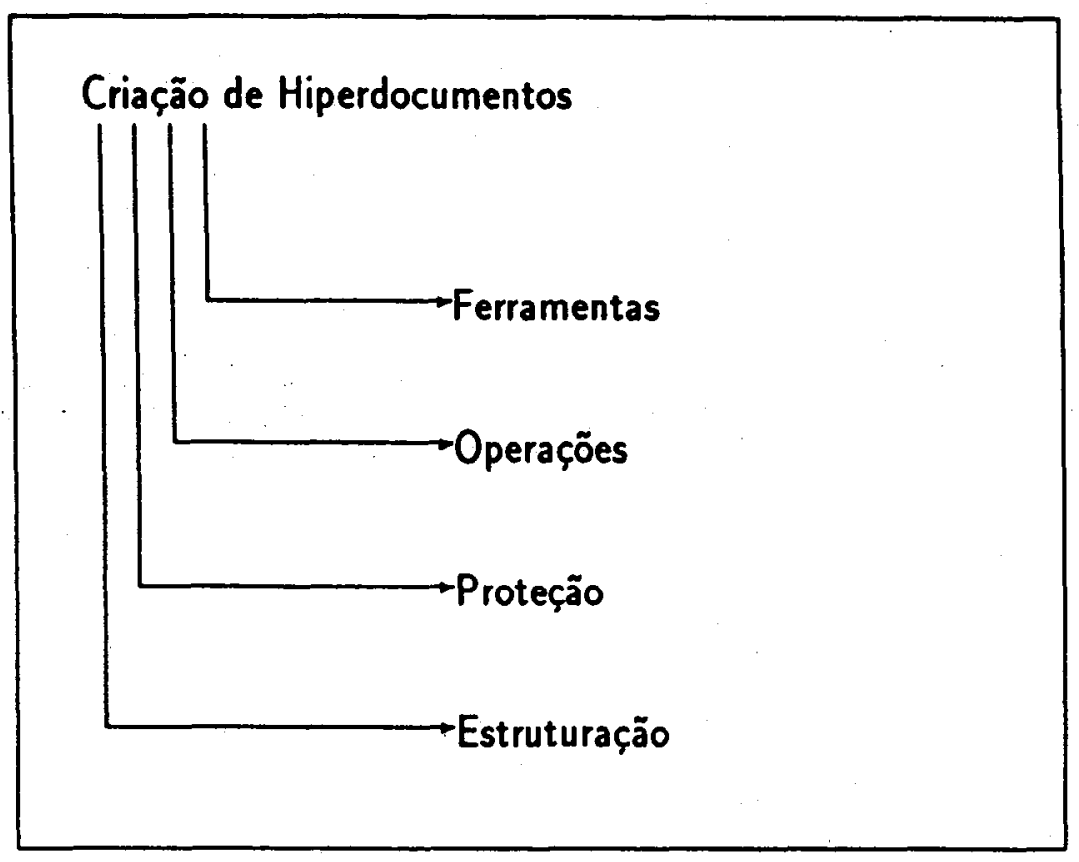

Já a favor existe, entre outros, o argumento de que o autor é auxiliado na tarefa de estruturar suas jdéias a respeito do tema que pretende escrever. Este argumento, por sua vez, é válido em relação aos sistemas que não obrigam o usuário a seguir uma estrutura rígida na construção de seu documento. Outro argumento a favor é o fato de sistemas hipertexto permitirem máxima flexibilidade e liberdade ao autor; em relação a criação do documento. Discutimos a seguir os temas Ferramentas, Operaçōes, Proteção e Estruturação.

\subsubsection{Ferramentas}

As ferramentas para a criação de hiperdocumentos devem contribuir nos processos de edição e navegação. Elas podem ser distintas, para cada uma dessas tarefas, ou integradas.

Akscyn defende que a integração das operações de edição e navegação numa única ferramenta imprime velocidade ao trabalho de criação [Akscyn 88] . Outro argumento favorável à integração é que ela facilita muito o aprendizado e a operação do sistema que, desta forma, pode ser utilizado em uma grande gama de aplicações. 


\subsubsection{Operaçōes}

Independentemente de estarem divididas em aplicações distintas ou não, as operações básicas oferecidas pelos sistemas atuais são praticamente as mesmas. Apresentamos a seguir uma lista dessas operações, acompanhadas de uma descrição sucinta de suas funções.

Criação: reunidas nesta classe encontram-se as operações que criam elementos do hipertexto, sejam eles ligações, conteúdos dos nós ou estruturas auxiliares como, por exemplo, um nó com uma visão gráfica da base ou com a indexação de parte do documento. Uma política normalmente adotada é o salvamento implícito das estruturas criadas pelo usuário, no momento em que ele termina de manipulá-las, ao selecionar outro nó, por exemplo.

Alguns sistemas oferecem ferramentas diferentes para tipos distintos de dados. Os autores desses sistemas utilizam o argumento de que tal política, além de facilitar a implementação, facilita a extensão do sistema sempre que novos dispositivos de armazenamento e tratamento da informação (som, imagem animada, etc.) forem tornando-se disponiveis.

Outros autores implementam uma única ferramenta para a manipulação de tipos diferentes de informação e defendem essa política argumentando que ela facilita a utilização de operações semelhantes sobre tipos distintos de dados, o que auxilia o aprendizado e a utilização do sistema.

Eliminação: nesta classe encontram-se operações análogas às existentes na classe anterior, mas referentes à operação de eliminação.

Movimentação: Oferecidas pela maioria dos sistemas, esta operação permite ao usuário reestruturar o documento, com certa facilidade, sempre que julgar necessário.

Obtenção / Associação de atributos e versões: estas operações estão presentes nos sistemas que permitem a associação de atributos e versões aos componentes do documento. 
Seleção de parte do documento: a operação de seleção é oferecida com o objetivo básico de permitir que o usuário especifique uma porção de um documento pertencente à base de nós. 0 usuário pode desejar especificar essas porções por vários motivos, entre eles: (a) definir uma região do documento que deve servir como destino de uma ligação, (b) especificar uma porção do documento que deve ser copiada em outra região qualquer, (c) solicitar a impressão da porção selecionada, etc.

\subsubsection{Proteção}

Nas situações em que o sistema suporta múltiplos usuários simultaneamente, é necessário fornecer esquemas através dos quais os usuários possam ser protegidos uns dos outros. Quando o sistema hipertexto associa cada nó a um arquivo, - sistema normalmente utiliza a proteção a nível de nós dos hiperdocumentos. Nos casos em que o sistema hipertexto utiliza o sistema de arquivos do sistema operacional, ele normalmente aproveita o mecanismo de proteção oferecido por esse sistema de arquivos.

Os sistemas hipertexto fornecem geralmente as mesmas classes de acesso aos seus usuários. Para isso podem utilizar ferramentas já implementadas a nível de sistema de arquivos ou de sistemas gerenciadores de bases de dados, ou construir seus próprios mecanismos. Os métodos através dos quais os sistemas hipertexto implementam essas classes se baseiam em duas premissas:

1. A cada nó da base associa-se o dono desse nó (que é normalmente seu criador);

2. A cada usuário que pretende utilizar o nó associa-se um código de acesso que estabelece quais os direitos de acesso do usuário sobre aquele nó.

Entre os direitos de acesso aos nós, encontramos normalmente:

Apenas-leitura: o usuário pode apenas consultar o conteúdo do nó.

Anexação: além de poder consultar o conteúdo do nó, o usuário pode inserir no nó ligações que estabelecem conexões com outros nós, sobre os quais também possui o direito de anexação.

Escrita: o usuário que possui esse direito sobre um nó pode realizar quaisquer operações sobre ele, inclusive a operação de eliminação. 


\subsubsection{Estruturação}

Alguns sistemas obrigam o usuário a estabelecer, desde o início da geração de seu documento, uma hierarquização do conteúdo, como é o caso do Neptune [Delisle 86a] e do NoteCards [Halasz 88].

A estruturação procura ajudar o autor do hiperdocumento a organizar suas idéias e relacioná-las à medida em que for produzindo o hiperdocumento. Possui o inconveniente de obrigar $o$ autor a organizar, algumas vezes precocemente, suas idéias.

\subsection{Adaptação de Documentos}

Encontramos na literatura referências às pesquisas atualmente realizadas no sentido de se criarem mecanismos, simples e eficientes, de transporte dos documentos, construídos na maneira tradicional, para os padrôes de hiperdocumentos [Raymond 88].

As pesquisas nesta área são de extrema importância e necessitam culminar em mecanismos realmente de pouca complexidade, dado o volume de documentos, produzidos durante a história da humanidade, que seriam de grande valia se fossem transformados em hiperdocumentos.

\subsection{Controle de Versões}

Uma das características mais importantes dos sistemas hipertexto é o controle automático de versões. Essa característica torna-se imprescindível quando o sistema é utilizado como suporte a projeto auxiliado por computador e automação de escritório, entre outras aplicações.

Entre os sistemas existentes atualmente, alguns se propõem a ser uma ferramenta para apoio a CAD e para tanto possuem suporte ao controle de versões dos documentos por eles gerados. É o caso do Neptune [Delisle 86a], do Dynamic Design [Bigelow 88] e do KMS [Ackcyn 88]. Outros sistemas, apesar de não suportarem diretamente o controle de versões, possuem características que permitem ao usuário realizar com certa facilidade tal controle, como o sistema Intermedia [Yankelovich 88]. 
Algumas das facilidades fornecidas diretamente para controle de versões são:

- controle de versão embutido em cada operação, que faz com que sempre se manipule diretamente uma versão específica de um determinado elemento do hiperdocumento;

- geração automática de versões sempre que o conteúdo de um nó é alterado;

- seleção de uma determinada versão através de um comando específico.

\subsection{Trabalho Cooperativo}

Vários autores dos sistemas estudados se preocupam em fornecer um mecanismo para que grupos de usuários possam trabalhar de forma cooperativa na geração e na utilização de hiperdocumentos.

Uma das alternativas para a implantação desse mecanismo é a utilização das facilidades oferecidas pelos sistemas operacionais multi-usuários. Isso poderia ser feito relacionando os nós a arquivos distintos controlados pelos sistema de arquivos do sistema operacional. Poderia-se permitir, desse modo, que os usuários tivessem acesso simultâneo a um hiperdocumento, deixando a cargo do sistema operacional o impedimento de acessos conflitantes.

Outra alternativa é implementar todo o controle de acesso aos hiperdocumentos no próprio sistema hipertexto.

Cada uma das alternativas tem suas limitações, vantagens e desvantagens. Cabe ao projetista analisar essa questão levando em consideração, entre outros, os seguintes pontos: qual o tamanho do grupo que se deve suportar (poucos, vários ou muitos elementos) e que tipo de acesso deve-se permitir a usuários distintos de um mesmo hiperdocumento (um escreve e os outros lêem, por exemplo). 


\section{Capítulo 5}

\section{Soluções Adotadas nos Principais Sistemas}

Entre os diversos sistemas atuais que apresentam características de hipertexto, selecionamos quatro para um estudo mais detalhado: Hypertext Abstract Machine, Intermedia, NoteCards e Knowledge Management System. Escolhemos esses sistemas porque, analisando-os, é possivel reconhecermos muitos dos aspectos discutidos anteriormente e, além disso, podemos ter uma visão global de como tais aspectos são efetivamente combinados para a construção de um sistema real. 


\section{Soluçōes Adotadas nos Principais Sistemas}

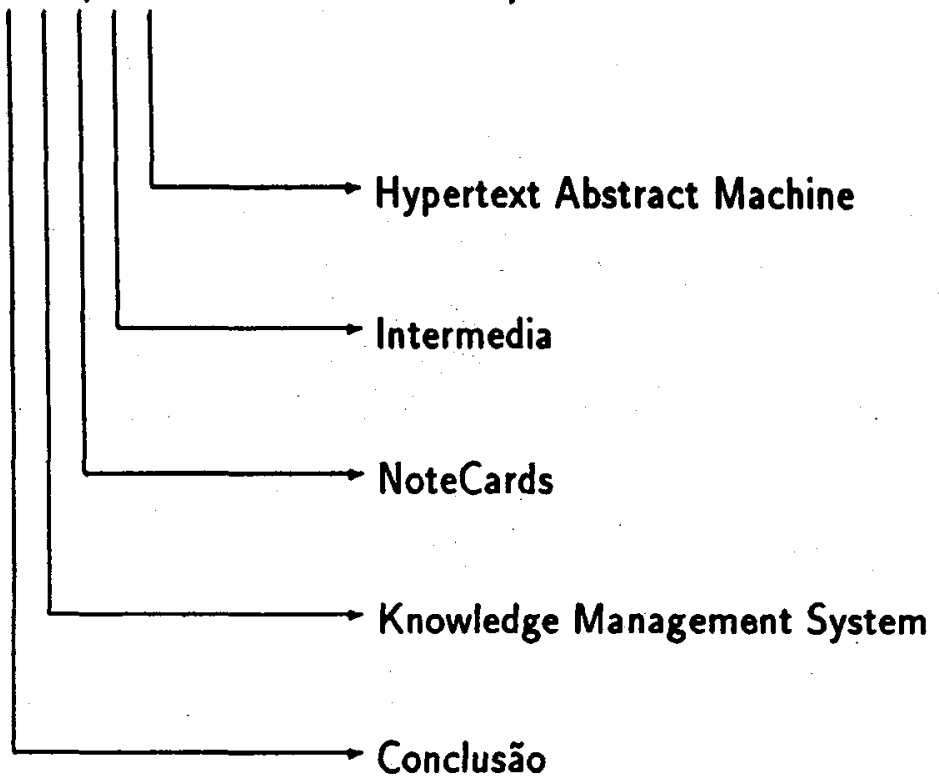

\subsection{Hypertext Abstract Machine}

O sistema Hypertext Abstract Machine, HAM, foi utilizado inicialmente pela equipe de Norman Delisle para a construção do Neptune, um sistema hipertexto projetado para aplicações em CAD (Computer Aided Design) [Delisle 86a]. 0 Neptune foi construído por Delisle e sua equipe nos laboratórios da Tektronics. James Bigelow trabalha com o HAM no projeto do sistema Dynamic Design, um sistema hipertexto para CASE (Computer Aided Software Engineering) [Bigelow 88]. Brad Campbell e Joseph Goodman apresentam em [Campbell 88] alguns aspectos gerais do HAM e alguns exemplos de sua utilização.

O HAM é um sistema baseado em transações. Ele oferece funções de hipertexto para programas de aplicação, ou seja, é um sistema para uso por aplicações e não por usuários. Os sistemas de aplicação são escritos de modo a utilizarem as funções do HAM para obter o resultado desejado. Exemplos de sistemas de aplicação que utilizam o HAM são o Neptune e o Dynamic Design. A figura 5.1 mostra a arquitetura de um sistema de hipertexto genérico construído com o HAM, segundo Campbell e Goodman.

O modelo de armazenamento do HAM baseia-se em 5 objetos; grafos, contextos, nós, ligações e atributos. O HAM mantém a história de cada um desses 


\section{Interface com o Usuário \\ Aplicações \\ Hypertext Abstract Machine \\ Sistema de Arquivos Hospedeiro}

Figura 5.1: Sistema Hipertexto com HAM [Campbell 88]

objetos, permite que sejam acessados através de um mecanismo de filtro e pode admitir restriçōes de acesso, pois implementa um mecanismo de segurança de dados.

\subsubsection{Os Objetos do HAM}

Um grafo do HAM contém contextos, nós, ligações e atributos, que são organizados hierarquicamente da seguinte forma:

Grafo: um grafo é o objeto de mais alto nível e contém, normalmente, toda a informação referente a um tópico geral, como, por exemplo, as informações a respeito de um projeto de software. Um grafo contém um ou mais contextos.

Contextos: os contextos particionam os dados dentro do grafo. Podem ser utilizados para suportar configurações, trabalho privativo ou árvores de histórias de versões. Cada contexto tem um contexto pai e zero ou mais contextos filhos. Quando um grafo é criado, um contexto raiz inicia a árvore. Esse conceito é bastante discutido no artigo de Norman Delisle e Mayer Schwartz [Delisle 86b].

Nó: um nó contém informações arbitrárias que podem ser armazenadas como texto ou como blocos binários de tamanho fixo. Ele pode ser classificado como tipo arquivado, não arquivado ou anexação.

Quando um nó do tipo arquivado é atualizado, uma nova versão do nó é criada utilizando o novo conteúdo. Versões anteriores de um nó desse tipo podem ser recuperadas. 
Entretanto quando um nó do tipo não arquivado é atualizado, seu conteúdo é substituído pelo novo conteúdo.

No caso da atualização de um nó do tipo anexação, o novo conteúdo é anexado ao conteúdo anterior.

Ligação: uma ligação define um relacionamento entre um nó fonte e um nó destino e pode ser seguida em qualquer direção. Uma ligação entre contextos relaciona dois nós em contextos diferentes e é útil para o compartilhamento de dados entre dois contextos. A generalidade fornecida pelos atributos das ligações (veja Atributos a seguir) permite aos projetistas de aplicação definirem suas próprias noções de tipos de ligação ou esquemas de âncoras das ligações.

Atributos: os atributos podem ser relacionados a contextos, nós e ligações. Os valores de atributos podem ser cadeias de caracteres, valores numéricos ou de tipos definidos pelo usuário.

Pares (atributo,valor) determinam a semântica dos objetos do HAM. Eles podem representar propriedades específicas da aplicação dos objetos ou conter informações que auxiliam na descrição do objeto.

\subsubsection{Navegação}

O mecanismo de pesquisa do sistema permite que uma pesquisa seja realizada sobre as versões de um nó. Isso é feito por meio das operações especiais fornecidas pelo HAM (veja operações do $H A M$ no próximo item) que incluem funções como pesquisa de cadeia de caracteres no conteúdo de nós.

\subsubsection{Criação}

Para utilizar o HAM, Delisle e sua equipe projetaram uma interface na qual as operações do HAM são agrupadas em sete categorias: operaçōes de criação, operações de remoção (retém a informação histórica do objeto), operações de destruição (libera todo espaço utilizado pelo objeto), operações de alteração, de obtenção de dados, operações de filtro e operações especiais (como pesquisa e gerenciamento, por exemplo). 
As operações do HAM são abordadas detalhadamente no apêndice existente em [Delisle 86b].

\subsubsection{Controle de Versōes}

O sistema HAM fornece um mecanismo de controle de versões automático. A história de um objeto é atualizada toda vez que o objeto é modificado. Isso ocorre porque as operações de manipulação dos objetos requerem a especificação da versão sobre a qual a operação deve ser realizada. Deste modo, pode-se obter quaisquer das versões existentes dos objetos. $O$ sistema fornece também um mecanismo para a destruição de versões indesejadas.

\subsubsection{Trabalho Cooperativo}

O HAM é projetado para ser utilizado por múltiplos usuários num ambiente de rede de computadores.

A segurança dos dados de um nó é controlada através de um mecanismo de lista de controle de acesso. A atracação de um objeto a uma lista é opcional. Uma entrada dessa lista consiste do nome de um usuário ou de um grupo de usuários e de um conjunto de permissões. As permissões disponiveis são: acesso, anotação, atualização e destruição.

\subsection{Intermedia}

O sistema Intermedia é uma ferramenta projetada para suportar tanto ensino como pesquisa num ambiente universitário.

Esse sistema está sendo desenvolvido no Institute for Research in Information and Schorlarship, IRIS, da Brown University, desde 1985, aproximadamente. Nicole Yankelovich, Norman Meyrowitz e Andries van Dam apresentaram em 1985 um relato das experiências realizadas na Brown a respeito de sistemas hipertexto até aquela data [Yankelovich 85]. Além de uma introdução aos sistemas FRESS, The Eletronic Document System e BALSA, os autores discutem a respeito de documentos eletrônicos e apresentam os princípios do sistema Intermedia.

A versão atual do Intermedia foi construida utilizando-se a filosofia de pro- 
gramá̧ão orientada a objetos, como é mostrado em [Yankelovich 88].

Algumas questões relativas ao projeto de sistemas hipertexto, e em particular ao Intermedia, são discutidas por L. Nancy Garret, Karen Smith e Norman Meyrowitz em [Garret 86].

Nicole Yankelovich, George Landow e Peter Heywood apresentam em alguns dos cursos que foram preparados utilizando o Intermedia [Yankelovich 87].

As figuras A.3 e A.4 correspondem a imagens deste sistema.

\subsubsection{O Nó}

O Intermedia é um sistema composto por diversas ferramentas integradas, chamadas aplicações. Até 1988 o sistema Intermedia era composto por 5 aplicações [Yankelovich 88]:

InterText: um editor de textos que possui facilidades para definição e formatação de textos;

InterDraw: um editor gráfico que permite a criação de ilustrações em duas dimensões;

InterPix: um visualizador de imagens obtidas através de varreduras;

InterSpect: um visualizador de objetos tri-dimensionais que converte arquivos, que contêm representação de pontos de dados tri-dimensionais, em representaçôes gráficas tri-dimensionais;

InterVal: um editor que permite ao usuário organizar interativamente as informações dentro de seqüências de tempo.

Através desses editores, os usuários podem criar e modificar nós de tamanho arbitrário, que contenham informação do tipo relacionado.

\subsection{2 Âncoras e Ligações}

No Intermedia, as funcionalidades de hipertexto estão integradas a cada uma das aplicações, de modo que a criação e seleção de uma ligação são operações que podem ser misturadas com as ações de edição de documentos. 
Âncora: uma âncora pode estar relacionada a qualquer área dentro de uma aplicação, como uma sequêencia de caracteres ou uma combinação de objetos gráficos, por exemplo.

Marcas de âncora e ligação: o sistema utiliza uma combinação de marcas especiais, icons, e destaca a área da âncora para mostrar as ligações. Cada âncora tem uma marca especial, independente do número de ligações nela atracadas. Nos documentos gráficos, as marcas especiais indicam a existência das âncoras e suas extensões são destacadas visualmente.

Âncora com várias ligações: nas situações em que a uma única marca estejam relacionadas mais que uma ligação, o sistema apresenta uma lista das ligaçōes relacionadas àquela âncora, no instante em que o usuário acionar um comando para seguir ligações. Dessa maneira, ele pode optar pela ligação desejada.

Ligações: as ligações podem relacionar dois documentos de quaisquer tipos, e são bidirecionais.

Tipos de ligação: no projeto do sistema, especificou-se que deveriam ser implementados diversos tipos de ligações. $\mathrm{O}$ sistema permite que os usuários relacionem a cada ligação as seguintes informações adicionais: título, palavras-chave e pares de valores (palavras-chave,valor) definidos no sistema. Entre os dados que são relacionados, automaticamente, a cada ligação estão a data e hora de criação e o nome do criador.

\subsubsection{Controle de Versōes}

O sistema permite que os usuários agrupem as ligações em contextos separados chamados webs. Isso fornece várias visōes diferentes de um mesmo documento. $\mathrm{O}$ Intermedia não possui controle automático de versões, entretanto o usuário pode criar versões distintas de documentos utilizando o conceito de visões oferecido pelo web. 


\subsubsection{Trabalho Cooperativo}

É permitido o acesso simultâneo de vários usuários ao mesmo documento. São suportados três categorias de acesso aos documentos: leitura, anotação (inserção de ligações) e escrita. Com esses direitos de acesso, os usuários trabalham cooperativamente.

\subsection{NoteCards}

O NoteCards é um sistema hypertexto projetado para auxiliar as pessoas a trabalharem com idéias. Frank G. Halasz, um dos projetistas do sistema, afirma [Halasz 88]:

O NoteCards ... foi desenvolvido para suportar a tarefa de transformar uma coleção caótica de pensamentos não relacionados em uma interpretação ordenada e integrada de idéias e suas interconexões.

Os usuários aos quais o sistema pretende auxiliar são pesquisadores e outros profissionais engajados na tarefa de analisar informações, construir modelos, formular argumentos ou, de modo geral, processar idéias.

O sistema fornece ao usuário uma rede de cartões eletrônicos de anotação interconectados por ligações tipadas. Esta rede serve como um meio no qual o usuário pode representar coleçōes de idéias relacionadas. O NoteCards possui facilidades para visualizar, modificar, manipular e navegar através da rede de cartões e ligações.

As figuras de A.9 a A.13 correspondem a imagens deste sistema.

\subsubsection{O Nó}

O sistema implementa dois tipos de nós:

Notecard: é o nó do sistema NoteCards, que seus autores dizem ser um generalização eletrônica do cartão de papel de $3 \times 5$ polegadas, utilizado normalmente para anotações. Cada notecard possui um título e contém uma quantidade arbitrária de alguma informação editável, como uma peça de 
texto ou um gráfico, por exemplo. Os cartões são representados na tela utilizando-se janelas de padrão do ambiente Xerox Lisp. Existem vários tipos de notecards, que são diferenciados parcialmente pela natureza da informação que contêm. 0 sistema oferece um conjunto padrã̃o de tipos de cartões e fornece facilidades para adição de novos tipos.

Filebox: é um tipo especial de cartão, utilizado para organizar ou categorizar grandes coleções de notecards. 0 sistema pretende auxiliar o usuário, ao encorajá-lo a utilizar uma estrutura hierárquica para categorizar as informaçôes. Um filebox é um cartão no qual outros cartões, inclusive outros fileboxes, podem ser colocados. Aliás, o sistema exige que cada notecard, inclusive os fileboxes, estejam colocados em um ou mais fileboxes. Os fileboxes podem ser utilizados, também, para navegação (veja 5.3.3).

Como citamos anteriormente, esta exigência de estruturação nem sempre auxilia a tarefa do usuário.

\subsubsection{A Ligação}

As ligações são utilizadas para interconectar cartões individuais em redes ou estruturas de cartões relacionados. As ligações são tipadas e bidirecionais. $\mathrm{O}$ usuário escolhe o tipo da ligação de modo a especificar a natureza do relacionamento sendo representado.

As ligações têm, como âncora fonte, um ponto específico no conjunto de informações do nó e são ancoradas no cartão destino como um todo.

\subsubsection{Navegação}

O usuário pode selecionar as ligaçōes embutidas nos notecards e, além disso, selecionar os nomes dos notecards diretamente nos fileboxes.

Como alternativa, o usuário pode requisitar ao sistema a criação de um browser gráfico sobre uma sub-rede de nós e, então, navegar diretamente sobre ele.

Neste caso o browser gráfico é, na realidade, um notecard que contém um diagrama estrutural de uma rede de notecards. Os cartões dessa rede são representados por seus títulos, colocados dentro de retângulos, e as ligações da rede 
são indicadas por arestas que conectam esses retângulos. São utilizados diferentes padrões de arestas para representar os direfentes tipos de ligações.

Os diagramas contidos nos browsers são computados pelo sistema a pedido do usuário e, uma vez criados, são tratados como cartões normais. 0 sistema suporta dois modos de edição sobre os browsers. No primeiro modo, o usuário edita a estrutura do browser $e$ as operações são transportadas para a rede de nós automaticamente. No segundo modo, a edição do browser não implica a transformação da rede de nós.

Finalmente, o NoteCards fornece uma facilidade de pesquisa que permite localizar todos os cartões que satisfazem a uma especificação do usuário, como por exemplo, uma cadeia de caracteres no título do cartão ou do texto.

\subsubsection{Controle de Versões}

O sistema NoteCards não possui mecanismo automático de controle de versões. Cada cartão e ligação existem apenas em uma versão, que é atualizada quando alterada. Com isso, a gama de aplicações que podem ser suportadas pelo sistema torna-se limitada. Os autores do sistema comentam, por exemplo, que o sistema nunca foi utilizado para manutenção de software devido, em parte, ao fato de não suportar controle automático de versões. Eles defendem que para atividades como autoria de documentos e processamento de idéias - atividades para as quais o sistema foi projetado - a falta de mecanismos para controle de versóes não é relevante.

\subsubsection{Trabalho Cooperativo}

Halasz comenta que

Infelizmente o NoteCards foi projetado originalmente para ser um sistema mono-usuário. $O$ trabalho cooperativo foi visto como uma ocorrência fora do sistema, através de conversação face-a-face, correio eletrônico,...

Ele comenta ainda que, na prática, os usuários do sistema realizam tarefas inerentemente colaborativas em grupos de duas a dez pessoas. Esses usuários, segundo Halasz, têm trabalhado muito a fim de vencer as limitações do sistema no que diz respeito a esses aspectos. 


\subsection{Knowledge Management System}

O sistema KMS foi criado para ser a versão comercial do sistema ZOG desenvolvido na Carnegie-Mellon University, que por sua vez foi projetado para ser um sistema de propósito geral, com suporte a trabalho cooperativo.

Entre as aplicações que já foram exploradas pelo grupo que desenvolveu o KMS estão: publicação eletrônica, manuais on-line, correio eletrônico, auxílio on-line para outros sistemas de software, gerenciamento de projeto, análise de questões, modelamento financeiro e contabilidade, interface de usuário com materiais em vídeo-disco, interface de usuário com outros programas, engenharia de software, etc.

As informações sobre o sistema KMS foram obtidas no artigo de Robert Akscyn, Donald McCraken e Elise Yoder [Akscyn 88]. Outro artigo interessante referente ao KMS foi escrito por Elise Yoder [Yoder 89].

As figuras A.1 e A.2 correspondem a imagens deste sistema.

\subsubsection{O Nó}

O nó do sistema KMS tem a estrutura de um frame [Minsky 75], que corresponde a um espaço de trabalho do tamanho da tela. 0 usuário pode colocar nesse frame qualquer combinação de ítens de texto, imagens e gráficos. Cada um dos ítens pode ser ligado a outro frame ou utilizado para invocar um programa. Uma característica importante do frame é sua natureza espacial: todo o espaço do tamanho da tela de um frame existe sempre, não importa se existem ou não objetos incluidos nele. Ou seja, uma vez criado, um frame existe, mesmo estando vazio.

O tamanho de um frame é fixo (1132 x 805 pixels) e esse é o único tipo de nó suportado pelo sistema.

Apesar dos frames poderem conter qualquer combinação de dados, existem fortes convenções para o seu formato. Essas convenções têm sido utilizadas há mais de uma década com o objetivo de auxiliar o usuário a buscar as informações. A figura A.2 mostra algumas dessas convenções, como por exemplo: as ligações do tipo hierárquica e de execução de programas ficam no lado esquerdo na janela; as ligações de anotação são colocadas na porçẫo inferior direita da tela (veja a seção 5.4.2 a seguir). 
Apresentação do nó na tela: a tela da estação de trabalho é dividida normalmente em duas janelas, cada uma delas mostrando a metade esquerda de um frame (a metade direita é mostrada através de uma solicitação do usuário). Segundo seus autores, esse tamanho é suficiente para uma página de bom material. Os frames que ocupam toda a tela são utilizados principalmente para diagramas complexos.

\subsection{2 Âncoras e Ligações}

A âncora de uma ligação no KMS é sempre um item textual, o qual fornece semântica à ligação. $O$ texto de um item pode variar de um caractere até todo o texto do frame mas, usualmente, utiliza-se uma linha de texto como sendo o item âncora da ligação.

Toda ligação tem como âncora destino um frame inteiro. Portanto temos somente ligações ponto-a-nó no sistema KMS.

As fontes para ligação no KMS são, como vimos, ítens textuais. O KMS fornece três tipos de ligação: hierárquica, de anotação e de execução de programas.

Os ítens de ligação são identificados por símbolos especiais colocados junto ao início do texto do item. No caso de uma ligação hierárquica, esse símbolo é um pequeno círculo vazio. No caso de ligação de anotação, o símbolo é o mesmo círculo acompanhado do caractere @. Um tipo especial de ligação é a que invoca a execução de programas. Nesse caso, o símbolo que indica a existência da ligação no item textual é o pequeno círculo cheio.

Os autores do sistema encorajam os usuários a criarem seus documentos com uma estrutura fortemente hierárquica, sobre a qual expõem, entre outras, as seguintes vantagens: o usuário localiza-se mais facilmente nesse hiperdocumento do que num documento não hierárquico; o sistema fornece ferramentas que trabalham sobre hierarquias de frames, como por exemplo pesquisa de padrão, visualização linear de um conjunto de frames e geração de hardcopy de uma hierarquia; - usuário pode utilizar ligações de anotação para realizar referências cruzadas, por exemplo, e essas ligações são tratadas de modo adequado pelos utilitários do sistema; etc. 


\subsubsection{Navegação}

Os usuários navegam de frame a frame selecionando um item ligado com o cursor e pressionando o botão esquerdo do mouse. Os autores do KMS procuram tirar proveito da interface do usuário através do mouse e afirmam que cerca de $90 \%$ das operações de interação direta do usuário são realizadas com apenas um comando no mouse, após ter o usuário posicionado o cursor convenientemente (o cursor é sensivel ao contexto). 0 projeto do sistema KMS deu grande ênfase à velocidade da navegação. É possível acessar o frame selecionado pela ligação e mostrá-lo na janela da tela em um tempo médio menor que um segundo.

O KMS oferece outra forma de visualizar o conteúdo da base de dados: uma visão linear de uma hieraquia de frames. Com essa visão, os usuários podem criar documentos formatados tanto para material on-line como para hardcopy.

O sistema não fornece browser gráfico pois seus autores consideram que os custos envolvidos na sua manutenção não justificam sua existência. Eles argumentam que o browser não é de tanta utilidade em sistemas cuja informação está organizada de modo fortemente hierárquico e onde os tamanhos dos documentos não são grandes demais.

Os autores argumentam, ainda, que o fato do sistema fornecer respostas muito rápidas, às solicitações de seleção de ligação, serve para auxiliar o usuário a se localizar na base de nós. Em seus estudos, a equipe que desenvolveu o KMS concluiu que o tempo de resposta a uma requisição de acesso através de uma rede de computadores deve ser, em média, menor que 0.25 segundos. Akscyn apresenta resultados atuais nos quais mostra que valores próximos a essa média estão sendo obtidos inclusive para frames localizados remotamente.

O outro mecanismo fornecido pelo KMS, para busca na base de dados, é um programa que permite a pesquisa de cadeia de caracteres dentro de qualquer hierarquia de frames. 0 resultado da pesquisa é apresentado na forma de um frame, no qual ligações levam aos frames onde houve sucesso na pesquisa.

\subsubsection{Criação}

Nao existe separação entre as operações de edição e navegação. Um usuário pode manipular diretamente o conteúdo de um frame a qualquer instante. Isso é feito movendo-se o cursor do mouse para o local desejado na tela e pressionando-se seus botões, no caso de navegação, ou digitando no teclado, no caso de edição. 
A criação de um frame é feita de maneira simples, colocando-se o cursor do mouse sobre um item não ligado e apertando-se o botão esquerdo do mouse. Note que é o mesmo procedimento utilizado para selecionar ligaçōes já existentes, de modo que a criação pode ser sentida como uma forma especial de navegação. Quando os usuários navegam para fora de um frame, que tenham modificado, as alterações realizadas são gravadas automaticamente.

\subsubsection{Controle de Versões}

O sistema KMS suporta controle de versões sobre hierarquias de frames e possui um programa utilitário que pode congelar todos os frames de uma hierarquia como pertencentes a uma versão particular. Quando um frame congelado for posteriormente alterado, seu conteúdo congelado é salvo automaticamente num novo frame que, por sua vez, é colocado no topo de uma lista encadeada de frames que representam as versões anteriores. É permitido aos usuários seguirem as ligações de modo a buscar uma versão específica de um frame, mas o sistema implementa esse controle para ser utilizado, principalmente, por seus programas que realizam controle de versôes.

\subsubsection{Trabalho Cooperativo}

Desde o início, os sistemas ZOG e KMS foram projetados para suportar uma comunidade de usuários de modo que eles pudessem desenvolver projetos em grupo e partilhar, efetivamente, dados de uma base de conhecimento composta de artigos, planos, relatórios e memorandos.

Múltiplos usuários podem trabalhar simultaneamente num projeto comum: os usuários podem visualizar facilmente o que os outros estão fazendo, inserir comentários, imprimir qualquer porção hierárquica a qualquer momento, etc. Não existe administração da base de dados: os usuários desenvolvem a base de dados de acordo com o senso comum e as normas do grupo.

A respeito da implementação da base de dados, sabemos que o KMS utiliza o sistema de arquivos da rede de estações de trabalho SUN, de modo a obter acesso aos frames que residam remotamente. Existe um servidor de arquivos mestre que guarda a localização de todos os conjuntos de frames. Todos os servidores de arquivos que contêm alguma porção da base de dados do KMS mantêm automaticamente cópias reserva da localização das informações, para serem utilizadas no caso do arquivo mestre ser danificado. 
Pára proteção dos dados, o sistema KMS implementa esquemas de proteção a nivel de frames. Cada frame tem seu proprietário e este pode proteger o frame de modo que outros usuários sejam impedidos de acessá-lo, ou possam fazê-lo apenas para leitura.

\subsection{Conclusão}

Como podemos verificar, após esta apresentação, as opiniões dos autores sobre o projeto de sistemas hipertexto muitas vezes divergem .

Os pontos comuns constituem a própria essência dos sistemas hipertexto nós, ligações e acesso não seqüencial aos mais diversos tipos de informação.

Já os pontos divergentes estão relacionados com a imensa flexibjlidade fornecida pela filosofia dos sistemas hipertexto.

A tabela 5.1 apresenta uma comparação entre os sistemas discutidos, em relação aos principais aspectos de projeto analisados neste capítulo. 


\begin{tabular}{|c|c|c|c|c|}
\hline & KMS & HAM & Intermedia & NoteCards \\
\hline $\begin{array}{l}\text { Objetivo } \\
\text { Principal }\end{array}$ & $\begin{array}{l}\text { Propósito } \\
\text { Geral }\end{array}$ & CAD & $\begin{array}{l}\text { Ensino e } \\
\text { Pesquisa }\end{array}$ & $\begin{array}{l}\text { Organização } \\
\text { de Idéias }\end{array}$ \\
\hline $\begin{array}{l}\text { Tamanho } \\
\text { do Nó }\end{array}$ & limitado & $\begin{array}{l}\text { não } \\
\text { limitado } \\
\end{array}$ & $\begin{array}{l}\text { não } \\
\text { limitado }\end{array}$ & $\begin{array}{l}\text { não } \\
\text { limitado }\end{array}$ \\
\hline $\begin{array}{l}\text { Nro de Nós } \\
\text { por Tela }\end{array}$ & fixo & $\begin{array}{l}\text { não } \\
\text { limitado } \\
\end{array}$ & $\begin{array}{l}\text { não } \\
\text { limitado }\end{array}$ & $\begin{array}{l}\text { não } \\
\text { limitado }\end{array}$ \\
\hline $\begin{array}{l}\text { Tipos de } \\
\text { Nó }\end{array}$ & fixo & \begin{tabular}{|l|} 
não \\
limitado
\end{tabular} & fixo & fixo \\
\hline $\begin{array}{l}\text { Tipos de } \\
\text { Âncora }\end{array}$ & textual & & $\begin{array}{l}\text { marca } \\
\text { especial }\end{array}$ & $\begin{array}{l}\text { marca } \\
\text { especial }\end{array}$ \\
\hline $\begin{array}{l}\text { Objetos } \\
\text { Ligados }\end{array}$ & $\begin{array}{l}\text { ponto-a- } \\
\text { nó }\end{array}$ & livre & livre & $\begin{array}{l}\text { ponto-a- } \\
\text { nó }\end{array}$ \\
\hline $\begin{array}{l}\text { Seleção de } \\
\text { Ligação }\end{array}$ & fácil & & regular & fácil \\
\hline $\begin{array}{l}\text { Navegação por } \\
\text { Seleção de } \\
\text { Ligação }\end{array}$ & sim & $\operatorname{sim}$ & sim & sim \\
\hline $\begin{array}{l}\text { Pesquisa } \\
\text { de Padrão }\end{array}$ & $\operatorname{sim}$ & $\operatorname{sim}$ & sim & $\operatorname{sim}$ \\
\hline Browser & กão & (xim & sim & $\operatorname{sim}$ \\
\hline $\begin{array}{l}\text { Caminhos Pré- } \\
\text { Definidos }\end{array}$ & nao & $\operatorname{sim}$ & sim & \\
\hline $\begin{array}{l}\text { Controle de } \\
\text { Versões }\end{array}$ & $\operatorname{sim}$ & $\operatorname{sim}$ & não & não \\
\hline $\begin{array}{l}\text { Criação de } \\
\text { HDs }\end{array}$ & fácil & & & \\
\hline $\begin{array}{l}\text { Proteção à } \\
\text { Informação }\end{array}$ & não & & & \\
\hline $\begin{array}{l}\text { Herança de } \\
\text { Contextos }\end{array}$ & não & $\operatorname{sim}$ & $\operatorname{sim}$ & não \\
\hline $\begin{array}{l}\text { Controle de } \\
\text { Percurso }\end{array}$ & $\operatorname{sim}$ & sim & sim & $\operatorname{sim}$ \\
\hline
\end{tabular}

Tabela 5.1: Aspectos de Projeto dos Sistemas Analisados campos em branco: informação não disponível HDs: Hiperdocumentos 


\section{Capítulo 6}

\section{Proposta e Implementação do Sistema Base para Hipertextos}

Nos capítulos anteriores procuramos ressaltar quais são os aspectos mais importantes a serem abordados no projeto de um sistema hipertexto, independentemente da aplicação a que se destinam (capítulo 4). Analisamos alguns dos principais sistemas hipertexto divulgados na literatura, mostrando de que maneira esses aspectos foram tratados tendo em vista o objetivo de cada sistema (capítulo 5).

Com base nesses estudos, realizamos uma detalhada e cuidadosa definição de cada um dos aspectos de projeto citados, avaliando-os, entretanto, de maneira conjunta. Com tal definição, chegamos à proposta do projeto de um sistema que tem todas as características básicas de hipertexto. $O$ sistema resultante pode ser utilizado para quaisquer aplicações cujos requisitos sejam atendidos por um sistema básico de hipertexto. A esse projeto denominamos $\mathrm{SBx}$, como referência a Sistema Base para Hipertextos. A descrição detalhada dessa proposta é tema do próximo capítulo.

O projeto SBx pode também servir de base para a definição de sistemas mais específicos, desde que realizadas as adaptações e complementações adequadas, as quais devem ser definidas por um levamento de requisitos necessários à aplicação.

Com o objetivo de verificar a viabilidade do projeto proposto, realizamos uma implementação na qual todos os pontos avaliados para o SBx foram considerados. Através dessa implementação, pudemos comprovar a validade da proposta e tivemos a confirmação de que os pontos nela definidos foram bastante acertados, de modo a estarmos, neste momento, satisfeitos com o projeto e implementação realizados. 


\subsection{Considerações Iniciais}

Entre os pontos iniciais da definição deste trabalho, decidimos pela realização de um sistema que rodasse em ambiente mono-usuário, para que pudesse ser utilizado em microcomputadores PC-compatíveis, devido à sua alta disponibilidade no Brasil.

Outro fator importante no desenvolvimento do trabalho foi a escolha da linguagem de implementação adotada: o Sistema de Programação Orientada à Objetos Smalltalk trouxe inúmeras facilidades e conseqũências ao resultado final do trabalho. Entre as principais, destacamos:

- a implementação de uma interface amigável com o usuário - ponto considerado de extrema importância no projeto - foi conseguida de maneira imediata com o uso dos recursos de menu e janelas disponíveis neste sistema;

- a implementação pode ser desenvolvida de forma modular,permitindo que cada fase vencida servisse de apoio à fase seguinte;

- o produto final pode ser facilmente expandido.

O sistema implementado admite dois tipos distintos de usuários, aos quais nos referimos como criador e usuário comum. Ao criador cabe gerar o hiperdocumento, sendo responsável tanto pela criação dos conteúdos dos nós como pela definição das ligações embutidas - e de todas as operações decorrentes dessas duas funçoes. Já ao usuário comum é permitido apenas navegar pelo hiperdocumento, sendo impossível realizar qualquer alteração no seu conteúdo.

Ao entrar no sistema, o usuário fornece seu nome e código de acesso, através dos quais o sistema identifica quando se trata de um criador ou de um usuário comum.

Implementamos uma extensão que está relacionada ao tratamento diferenciado entre os usuários comuns. $\mathrm{O}$ sistema utiliza os dados relativos a nome $\mathrm{e}$ código para obter qual o valor do escopo de acesso do usuário. Um criador tem acesso a toda informação existente no sistema, ao passo que um usuário comum tem acesso apenas ao conjunto de informaçōes diponíveis ao seu escopo. 0 uso de tal informação pelo sistema está discutido ao longo deste e do próximo capítulo sob o título de herança dé contextos.

Listamos a seguir os pontos básicos que nortearam a proposta de construção do SBx. Propusemos que o sistema fosse construído de modo a: 
- ser mono-usuário;

- não limitar o tamanho dos nós;

- possuir os tipos de ligação hierárquica e de referência cruzada;

- permitir ao usuário realizar operaçóes de consulta e de execução de programas;

- fornecer uma ferramenta de pesquisa limitada ao escopo do nó;

- permitir a apresentação de mais de um nó por tela;

- relacionar âncora e lígação numa correspondência um-a-um;

- ligar os nós em esquema ponto-a-nó;

- fornecer um browser simples;

- não exigir estruturação obrigatória do documento;

- suportar a existência de ciclos na navegação do usuário;

- não realizar controle de versões;

- fornecer uma interface amigável ao usuário;

- suportar tipos distintos de usuários para criação e navegação comum;

- fornecer ferramentas de auxílio a navegação que explorassem o percurso realizado pelo usuário;

- dar tratamento diferenciado aos usuários comuns.

Julgamos de interesse realizar um confronto entre o sistema SBx e os sistemas discutidos no capítulo 5 , no que diz respeito aos aspectos básicos de implementação. Essas informaçôes são apresentadas na tabela 6.1 , na qual podemos observar que o SBx pode ser classificado como um sistema hipertexto para utilização em ambientes mono-usuário. 


\begin{tabular}{|c|c|c|c|c|c|}
\hline & SBx & KMS & HAM & Intermedia & NoteCards \\
\hline $\begin{array}{l}\text { Objetivo } \\
\text { Principal }\end{array}$ & $\begin{array}{l}\text { Propósito } \\
\text { Geral }\end{array}$ & $\begin{array}{l}\text { Propósito } \\
\text { Geral }\end{array}$ & $C A D$ & $\begin{array}{l}\text { Ensino e } \\
\text { Pesquisa }\end{array}$ & $\begin{array}{l}\text { Organização } \\
\text { de Idéias }\end{array}$ \\
\hline $\begin{array}{l}\text { Tamanho } \\
\text { do Nó }\end{array}$ & $\begin{array}{l}\text { não } \\
\text { limitado }\end{array}$ & limitado & $\begin{array}{l}\text { nāo } \\
\text { limitado }\end{array}$ & $\begin{array}{l}\text { não } \\
\text { limitado }\end{array}$ & $\begin{array}{l}\text { não } \\
\text { limitado }\end{array}$ \\
\hline $\begin{array}{l}\text { Nro de Nós } \\
\text { por Tela }\end{array}$ & $\begin{array}{l}\text { não } \\
\text { limitado }\end{array}$ & fixo & $\begin{array}{l}\text { não } \\
\text { limitado }\end{array}$ & $\begin{array}{l}\text { não } \\
\text { limitado }\end{array}$ & $\begin{array}{l}\text { não } \\
\text { limitado }\end{array}$ \\
\hline $\begin{array}{l}\text { Tipos de } \\
\text { Nó }\end{array}$ & fixo & fixo & $\begin{array}{l}\text { não } \\
\text { limitado }\end{array}$ & fixo & fixo \\
\hline $\begin{array}{l}\text { Tipos de } \\
\text { Âncora }\end{array}$ & textual & textual & & $\begin{array}{l}\text { marca } \\
\text { especial }\end{array}$ & $\begin{array}{l}\text { marca } \\
\text { especial }\end{array}$ \\
\hline $\begin{array}{l}\text { Objetos } \\
\text { Ligados }\end{array}$ & $\begin{array}{l}\text { ponto-a- } \\
\text { nó }\end{array}$ & $\begin{array}{l}\text { ponto-a- } \\
\text { nó }\end{array}$ & $\begin{array}{r}: \\
\text { livre } \\
\end{array}$ & livre & $\begin{array}{l}\text { ponto-a- } \\
\text { nó }\end{array}$ \\
\hline $\begin{array}{l}\text { Seleção de } \\
\text { Ligação }\end{array}$ & fácil & fácil & & regular & fácil \\
\hline $\begin{array}{l}\text { Navegação por } \\
\text { Seleção de } \\
\text { Ligação }\end{array}$ & $\operatorname{sim}$ & sim & $\operatorname{sim}$ & sim & sim \\
\hline $\begin{array}{l}\text { Pesquisa } \\
\text { de Padrão }\end{array}$ & $\operatorname{sim}$ & sim & $\operatorname{sim}$ & $\operatorname{sim}$ & sim \\
\hline Browser & $\operatorname{sim}$ & กล̃o & sim & sim & sim \\
\hline $\begin{array}{l}\text { Caminhos Pré- } \\
\text { Definidos }\end{array}$ & sim & não & sim & $\operatorname{sim}$ & \\
\hline $\begin{array}{l}\text { Controle de } \\
\text { Versöes }\end{array}$ & não & sim & sim & não & กão \\
\hline $\begin{array}{l}\text { Criação de } \\
\text { HDs }\end{array}$ & fácil & fácil & & & \\
\hline $\begin{array}{l}\text { Proteção à } \\
\text { Informação }\end{array}$ & $\operatorname{sim}$ & กão & & & \\
\hline $\begin{array}{l}\text { Herança de } \\
\text { Contextos }\end{array}$ & $\operatorname{sim}$ & não & $\operatorname{sim}$ & $\operatorname{sim}$ & não \\
\hline $\begin{array}{l}\text { Controle de } \\
\text { Percurso }\end{array}$ & sim & $\operatorname{sim}$ & $\operatorname{sim}$ & $\operatorname{sim}$ & sim \\
\hline
\end{tabular}

Tabela 6.1: Aspectos de Projeto: SBx e outros Sistemas campos em branco: informação não disponível

HDs: Hiperdocumentos 


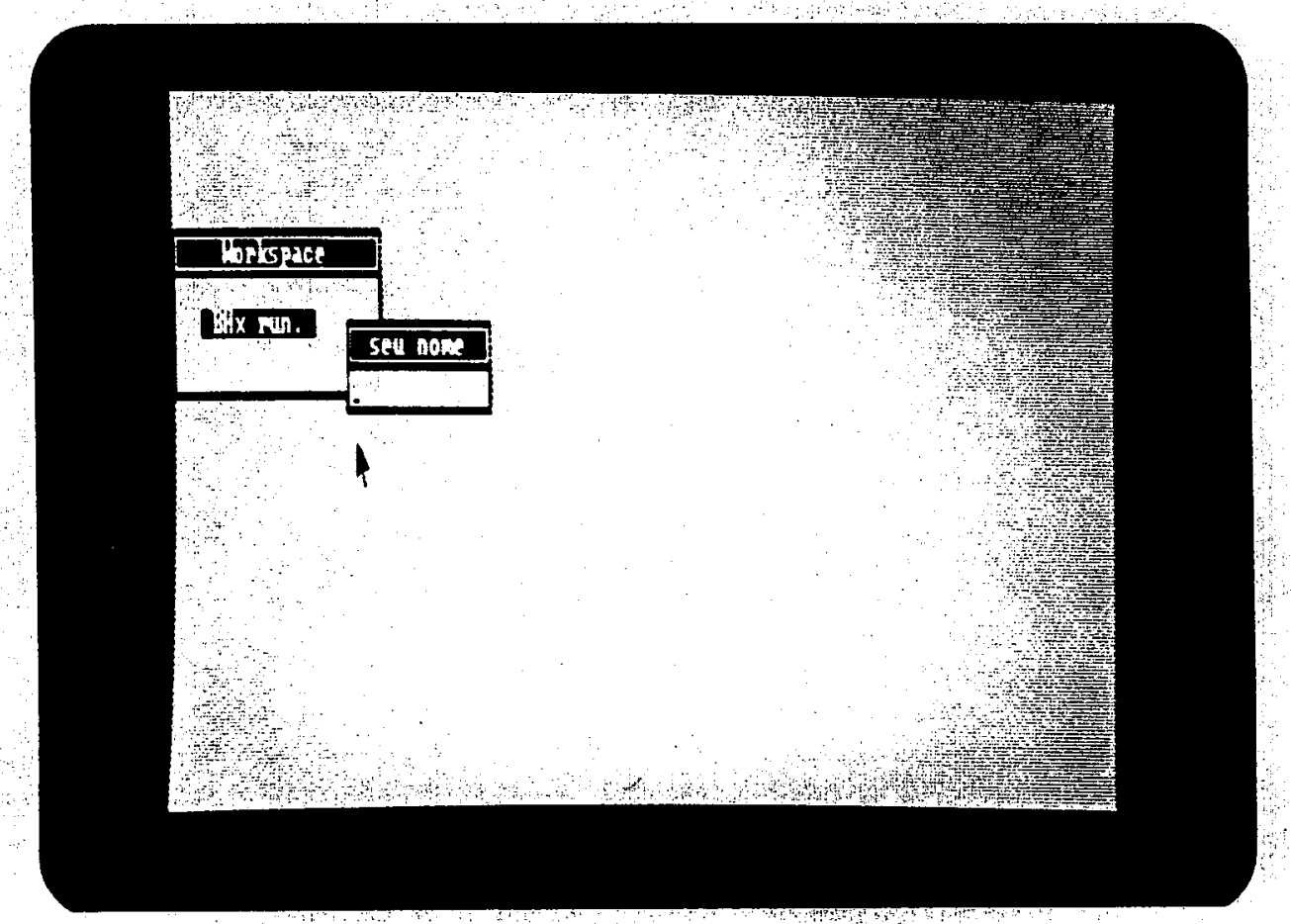

Figura 6.1: 0 sistema aguarda a identificação do usuário.

\subsection{Exemplo de Interação com o Sistema Im- plementado}

A seguir apresentamos um exemplo simples, a fim de mostrar a interface com o usuário e o funcionamento do $\mathrm{SBx}$. No próximo capítulo apresentamos detalhadamente os aspectos relevantes do projeto.

O exemplo utiliza um conjunto pequeno de nós, cujo conteúdo foi gerado de modo ilustrar facilmente a realização dos diversos tipos de navegação permitida pelo sistema. $O$ conteúdo dos nós do hiperdocumento do exemplo, algoritmos estruturados, foi obtido a partir de [Farrer 85].

Considerando que o sistema já se encontra no ar, vamos mostrar como o usuário tem acesso aos hiperdocumentos existentes. $\mathrm{O}$ usuário deve, inicialmente, fornecer sua identificação, através da qual o sistema verifica o seu tipo de usuário. Esses passos são indicados nas fotos 6.1, 6.2 e 6.3.

O sistema apresenta uma janela na qual estão apresentados os nomes dos hiperdocumentos disponíveis para navegação. $O$ usuário deve selecionar então um dos hiperdocumentos, como mostra a foto 6.4 .

Após a seleção de um hiperdocumento, o nó raiz correspodente é apresentado 


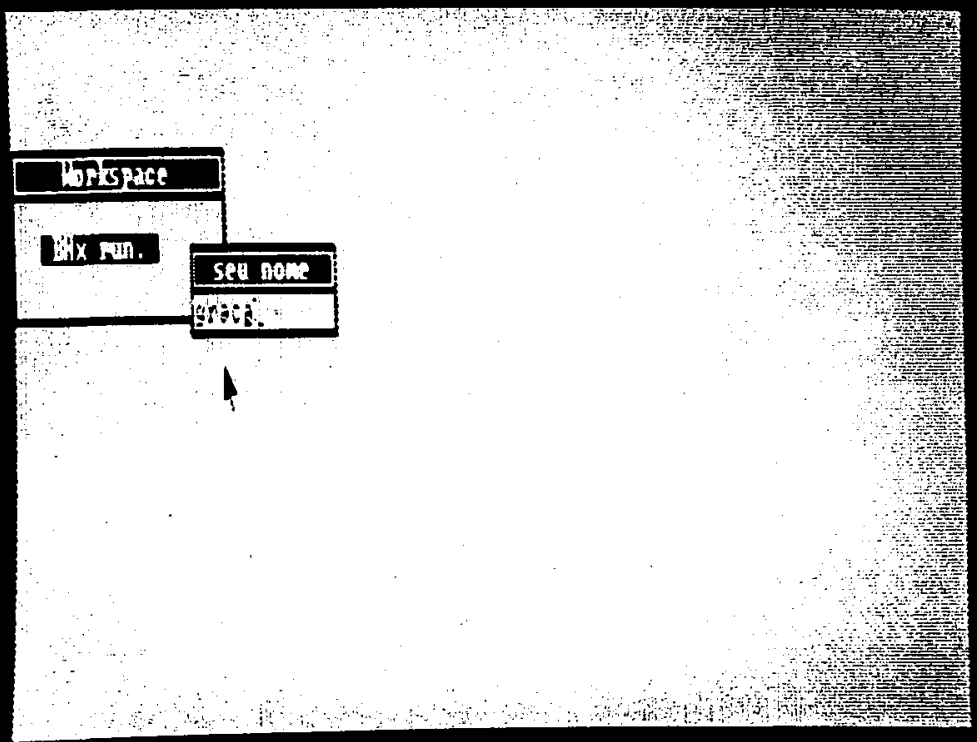

Figura 6.2: 0 usuário fornece seu nome...

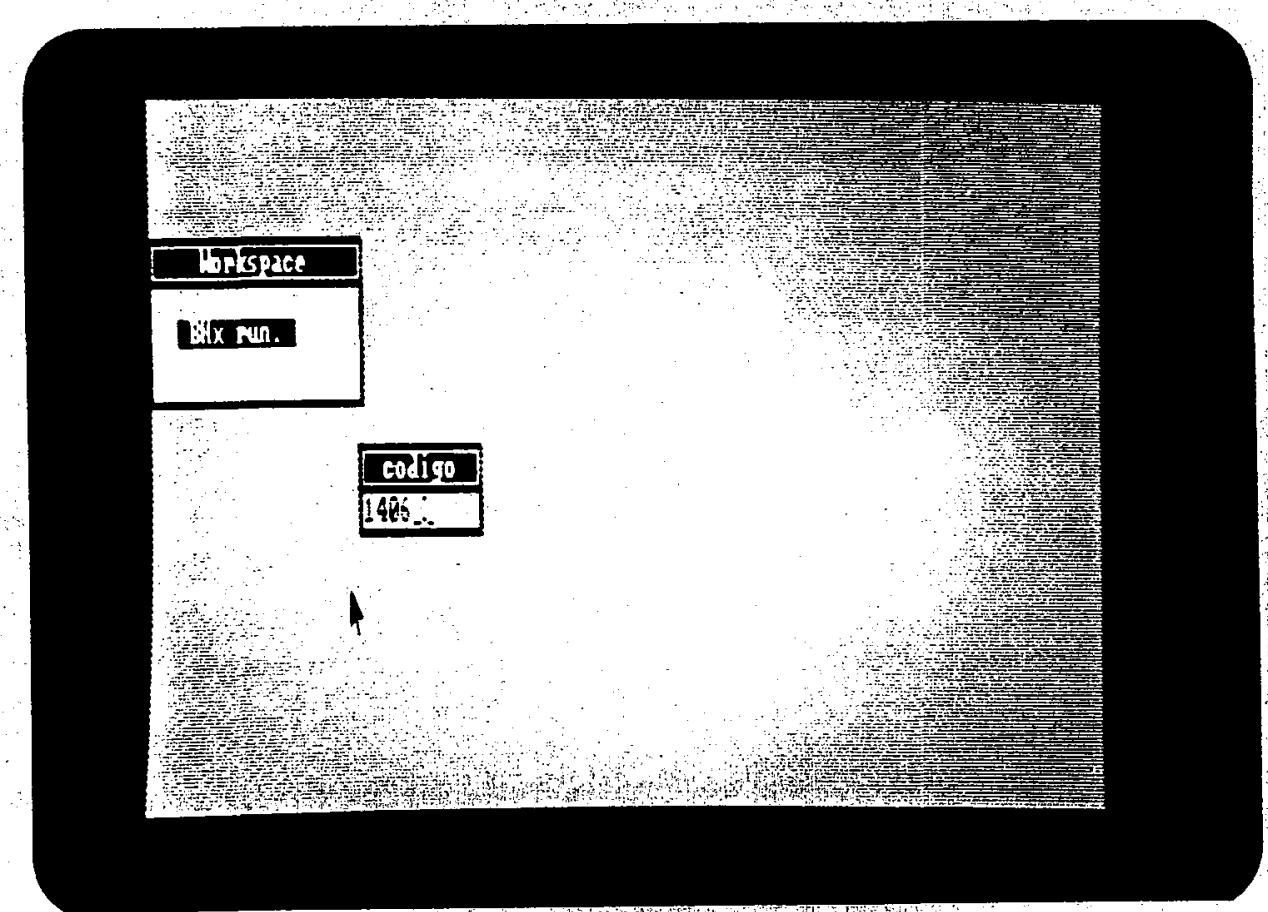

Figura 6.3: ...e código de identificação. 


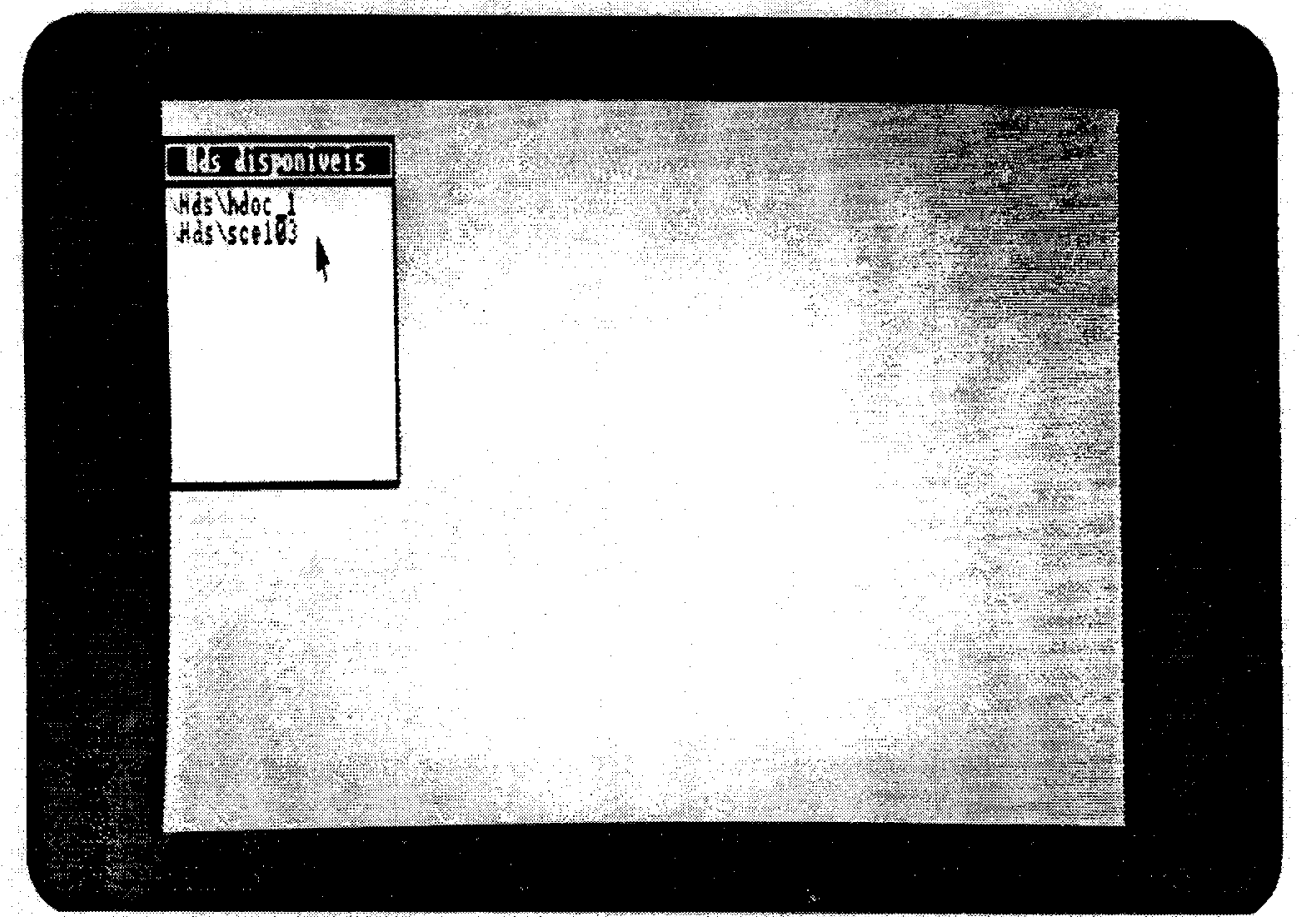

Figura 6.4: $\mathrm{O}$ usuário seleciona o hiperdocumento sce103.

ao usuário através de uma nova janela, e a janela com o nome dos hiperdocumentos é retirada, como pode ser observado na foto 6.5 . O nó raiz é um nó comum de texto.

O nome do arquivo relacionado a cada nó é utilizado como seu título e é colocado no campo de topo da janela (na foto, o título do nó raiz é raiz). O campo do título pode estar na cor preta ou branca. Quando o campo de um título está na cor preta significa que esse nó está ativado, caso contrário está desativado. As âncoras estäo representadas por caracteres especiais concatenados à esquerda de ítens do texto.

O usuário, a seguir, seleciona uma ligação. Ele coloca o cursor sobre a palavra Atribuição, que possui um caractere especial à sua esquerda, e atjva o comando seleção de ligação. Isso faz com que o nó correspondente atribuic seja trazido para a tela (veja a foto 6.6) em uma janela com características semelhantes à anterior. Observe que o nó anterior é desativado.

O usuário, a seguir, seleciona a âncora comando e o nó correspondente comando é trazido para a tela, como mostrado na foto 6.7

Uma extensão, implementada no sistema, é permissão para que o usuário veja o conteúdo dos nós visitados apenas selecionado-os na tela. Entretanto, esta operação é de visualização e não de navegação: para continuar a navegar, o usuário deve voltar ao nó corrente, cujo nome é indicado no nó que está sendo 


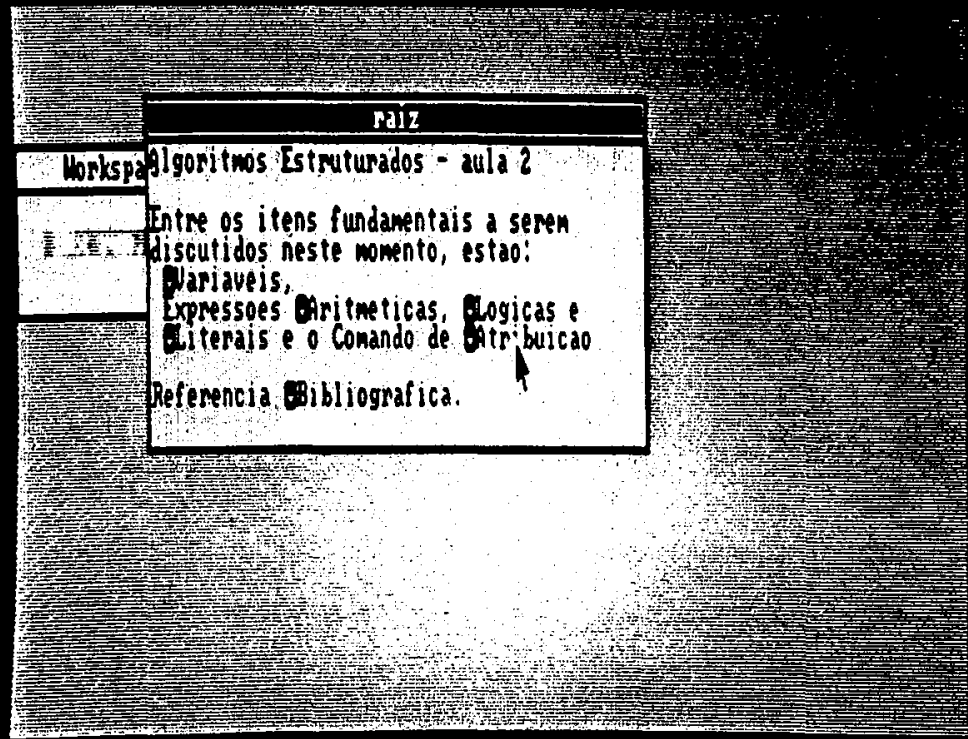

Figura 6.5: $\mathrm{O}$ nó raiz do hiperdocumento pedido é apresentado. $\mathrm{O}$ usuário seleciona Atribuição ...

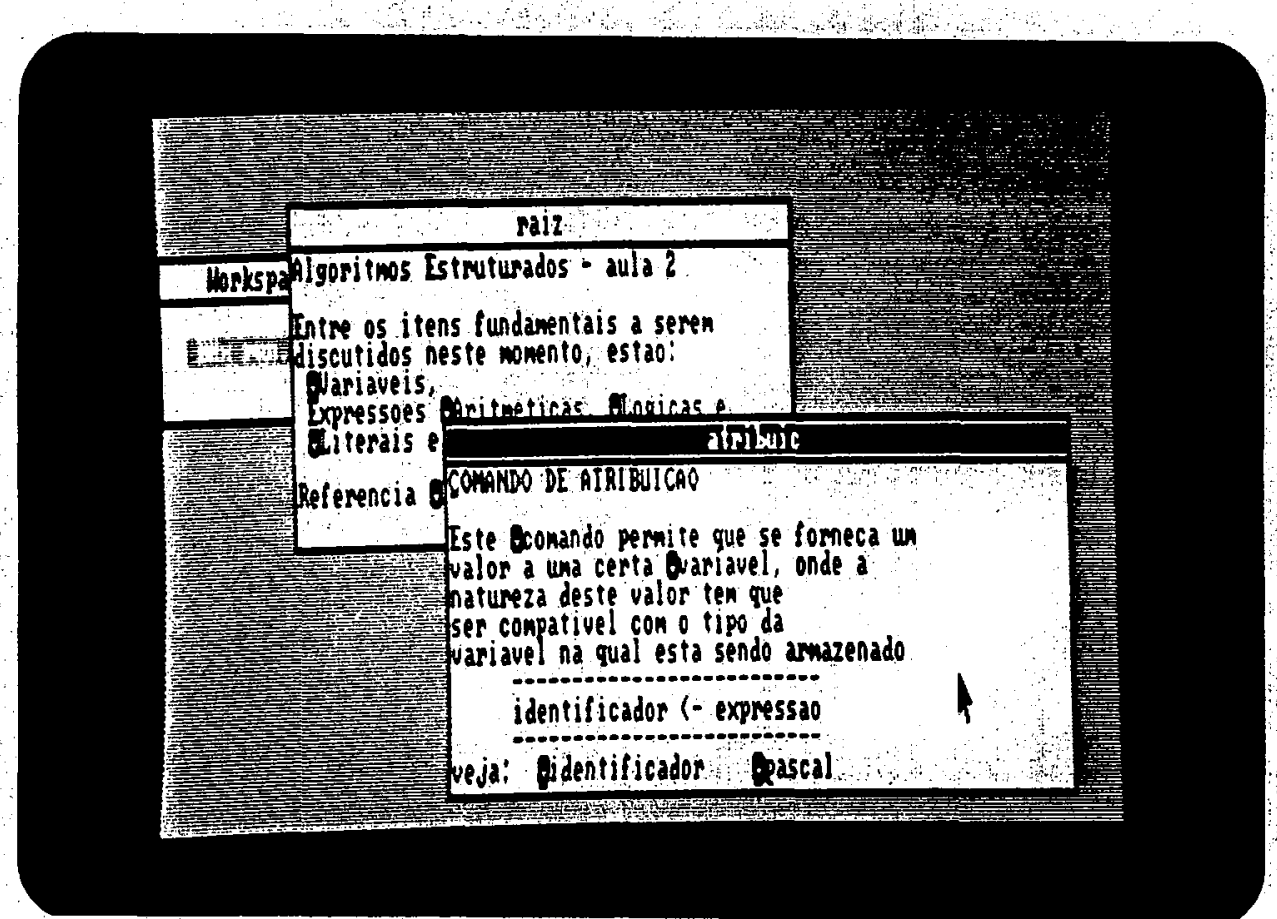

Figura 6.6: ...e o nó atribuic é trazido para a tela. $\mathrm{O}$ usuário seleciona comando ... 


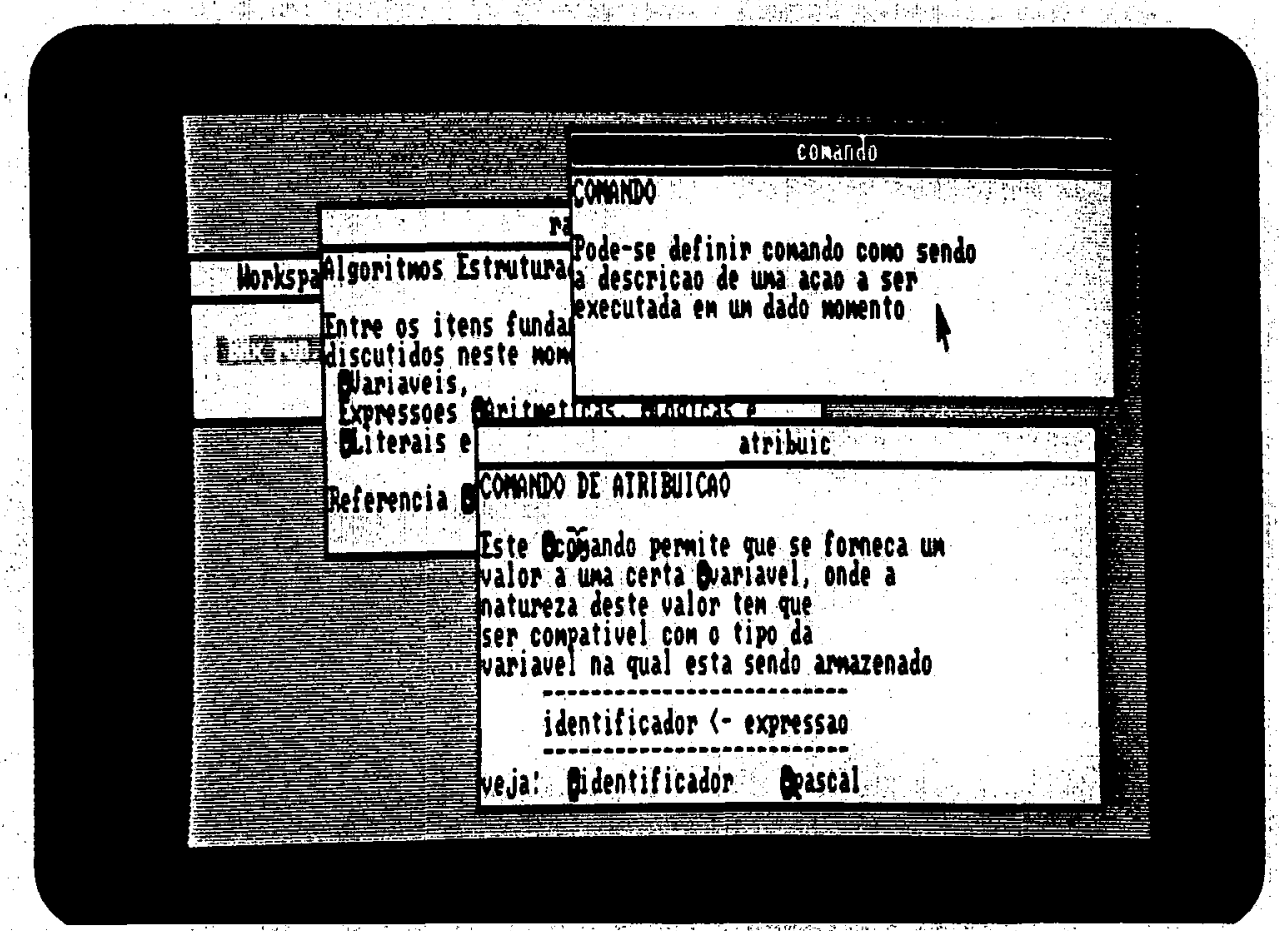

Figura 6.7: ...e o nó comando é trazido para a tela.

visualizado.

No exemplo, usuário ativa a janela do nó raiz para visualizar seu conteúdo e, a seguir, tenta realizar uma operação. O sistema avisa que o nó corrente é o comando (veja a foto 6.8). O usuário seleciona o nome do nó indicado e volta para o nó corrente, como indicado na foto 6.9 .

O usuário pode, estando num nó comum, requisitar um menu no qual está relacionado um conjunto de operações, como indicado na foto 6.10. Uma dessas operações é a de volta ao nó anterior, ou back.

Achamos conveniente manter os nomes de alguns comandos típicos de hipertexto, tais como back e go to, por verificarmos que já estão consagrados pelo uso.

No exemplo, o usuário, estando no nó comando, seleciona o comando back. O nó comando é retirado da tela e o nó anterior, no caso o nó atribuic, é ativado, como indicado na foto 6.11 .

O usuário executa a mesma operação e volta ao nó raiz (foto 6.12).

O sistema controla todo o percurso realizado pelo usuário. Utiliza essa informação para permitir ao usuário voltar, diretamente, para algum nó já visitado. O sistema, através do percurso realizado, também percebe a existência de ciclos. 


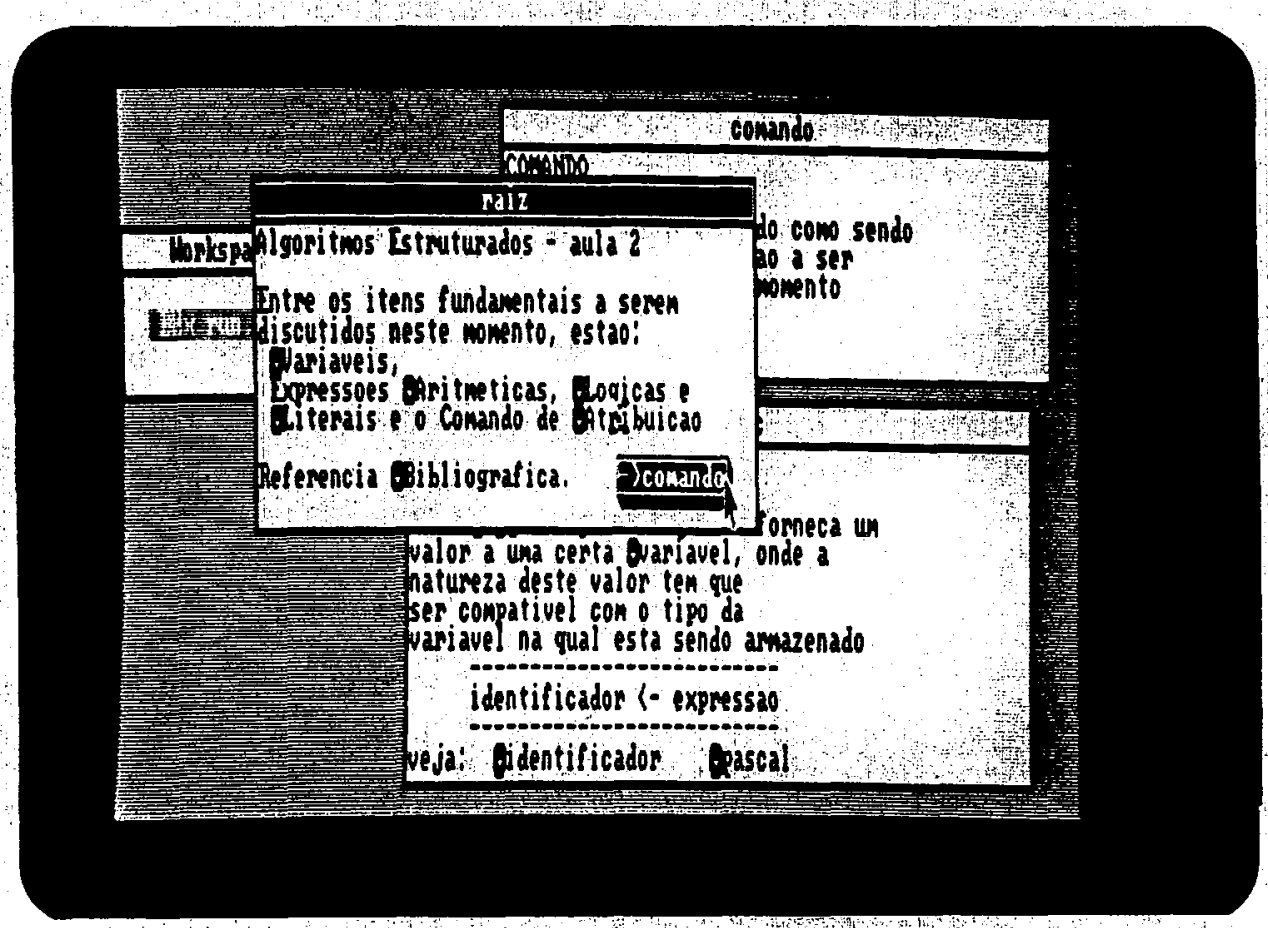

Figura 6.8: $\mathrm{O}$ usuário visualiza o nó raiz e, a seguir, tenta realizar uma operação. O sistema indica qual o nó corrente, o usuário seleciona o nome do nó indicado e então ...

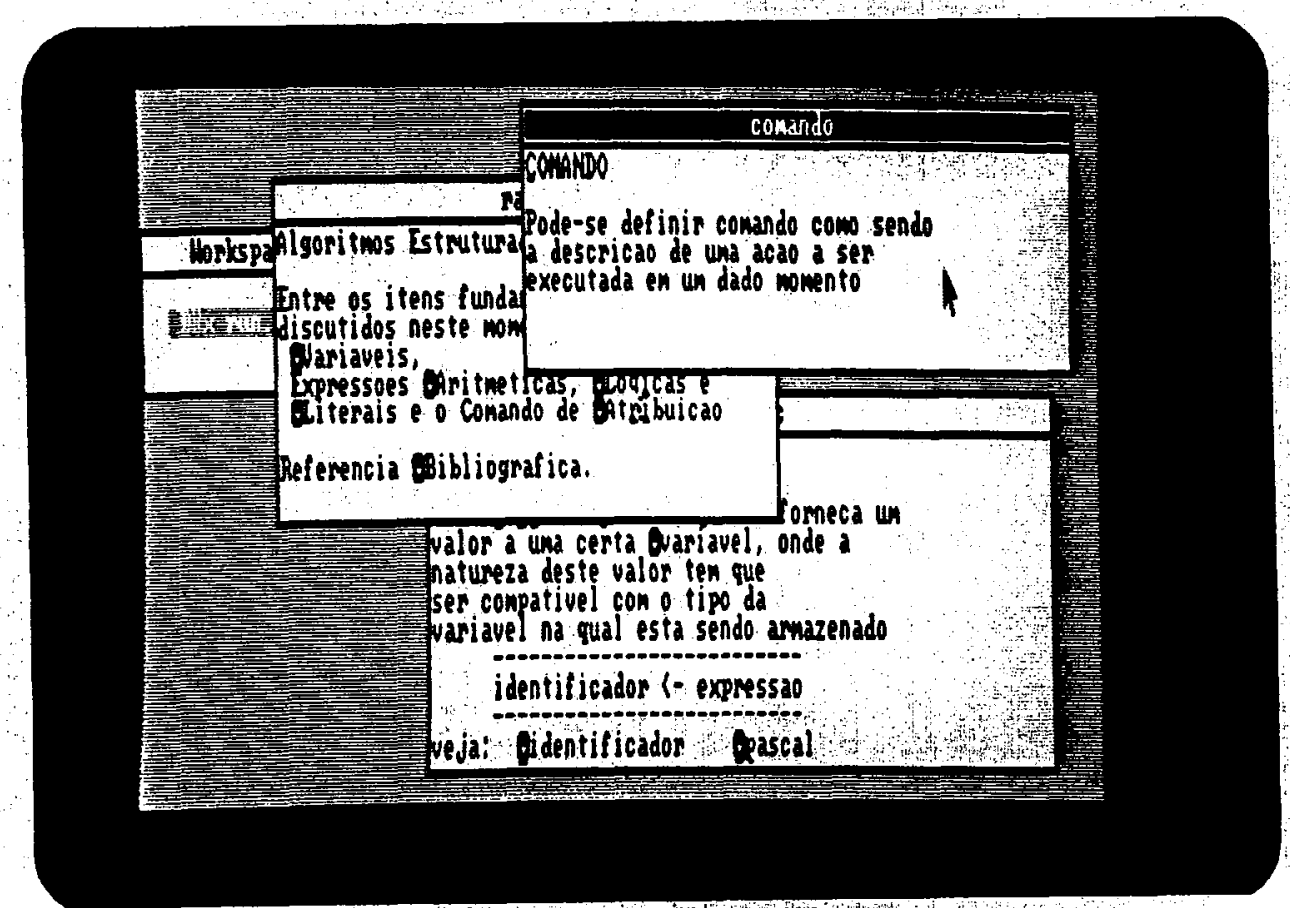

Figura $6.9: \ldots 0$ nó corrente torna-se ativo novamente. 


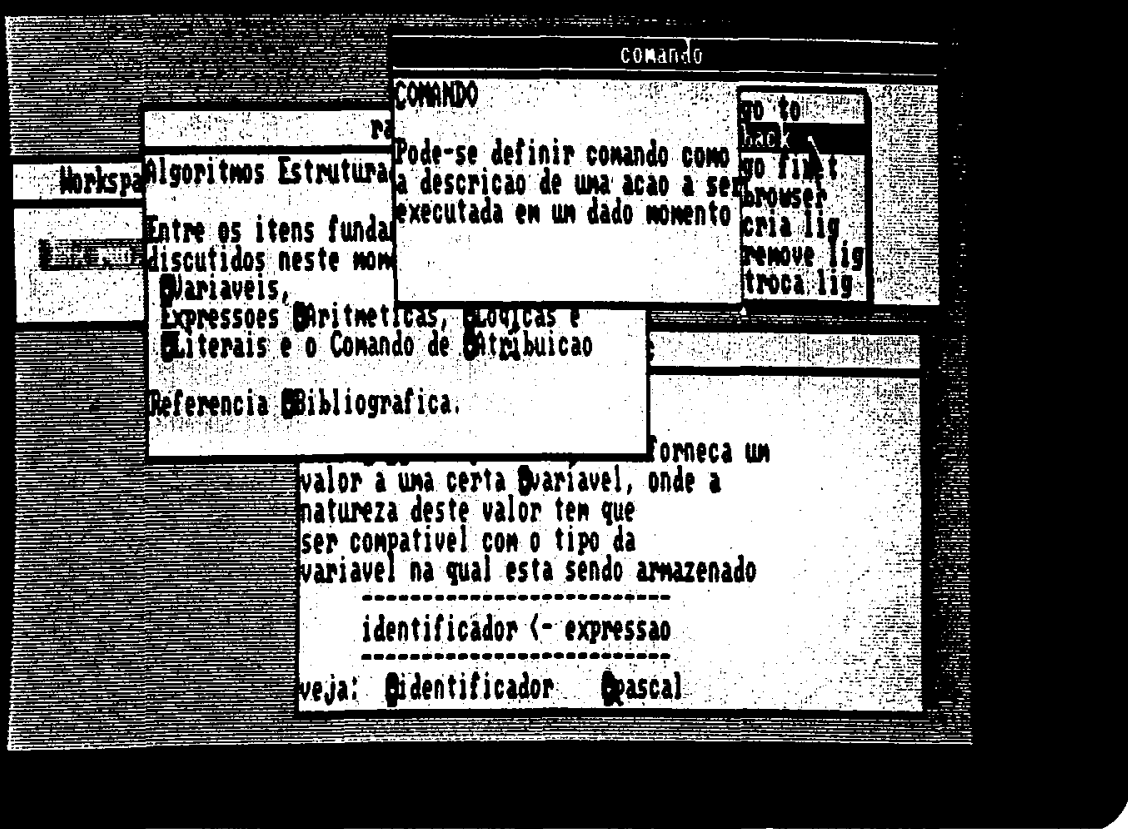

Figura 6.10: $O$ usuário requisita o menu de operaçóes e seleciona o comando back

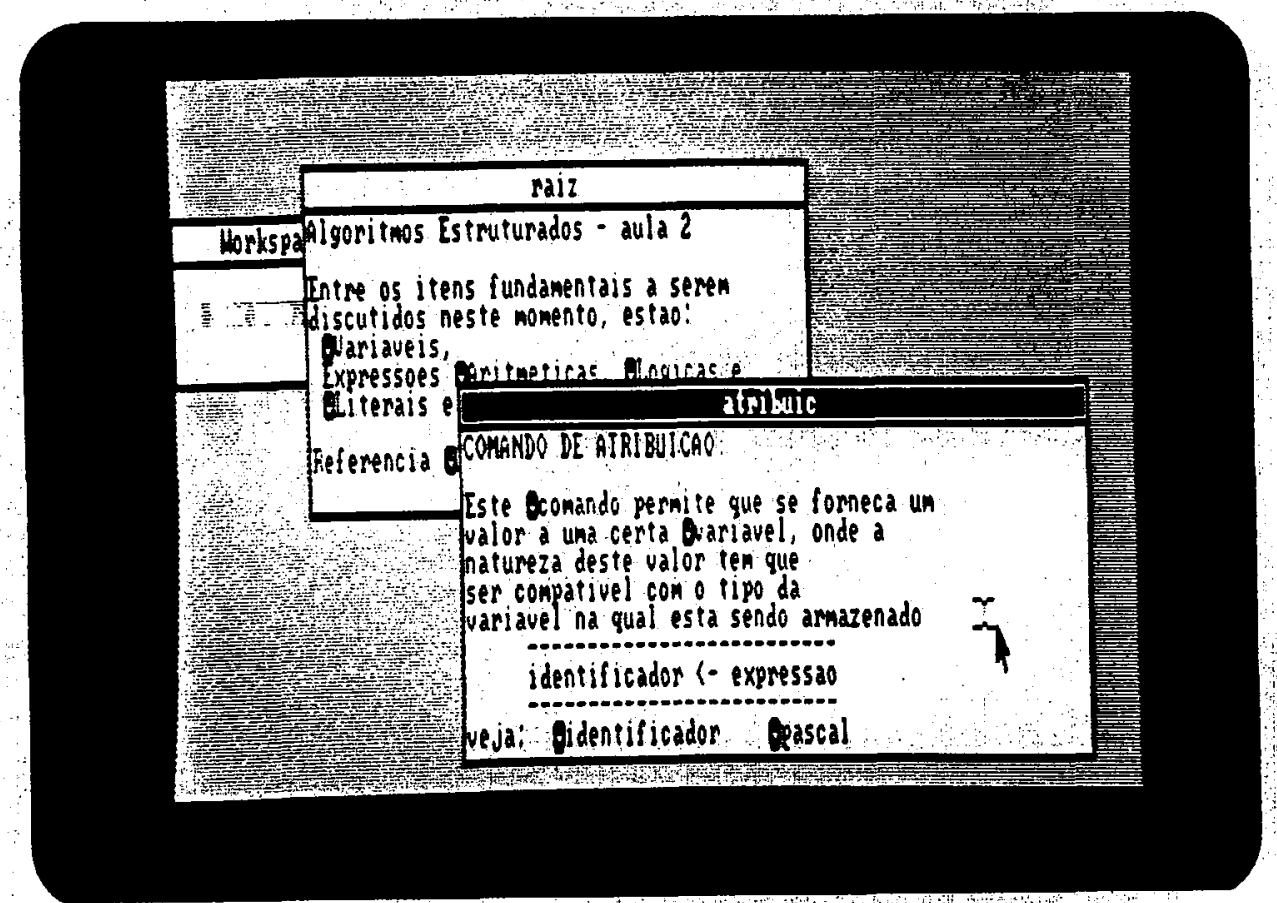

Figura 6.11: ...e o nó atribuic é ativado. 


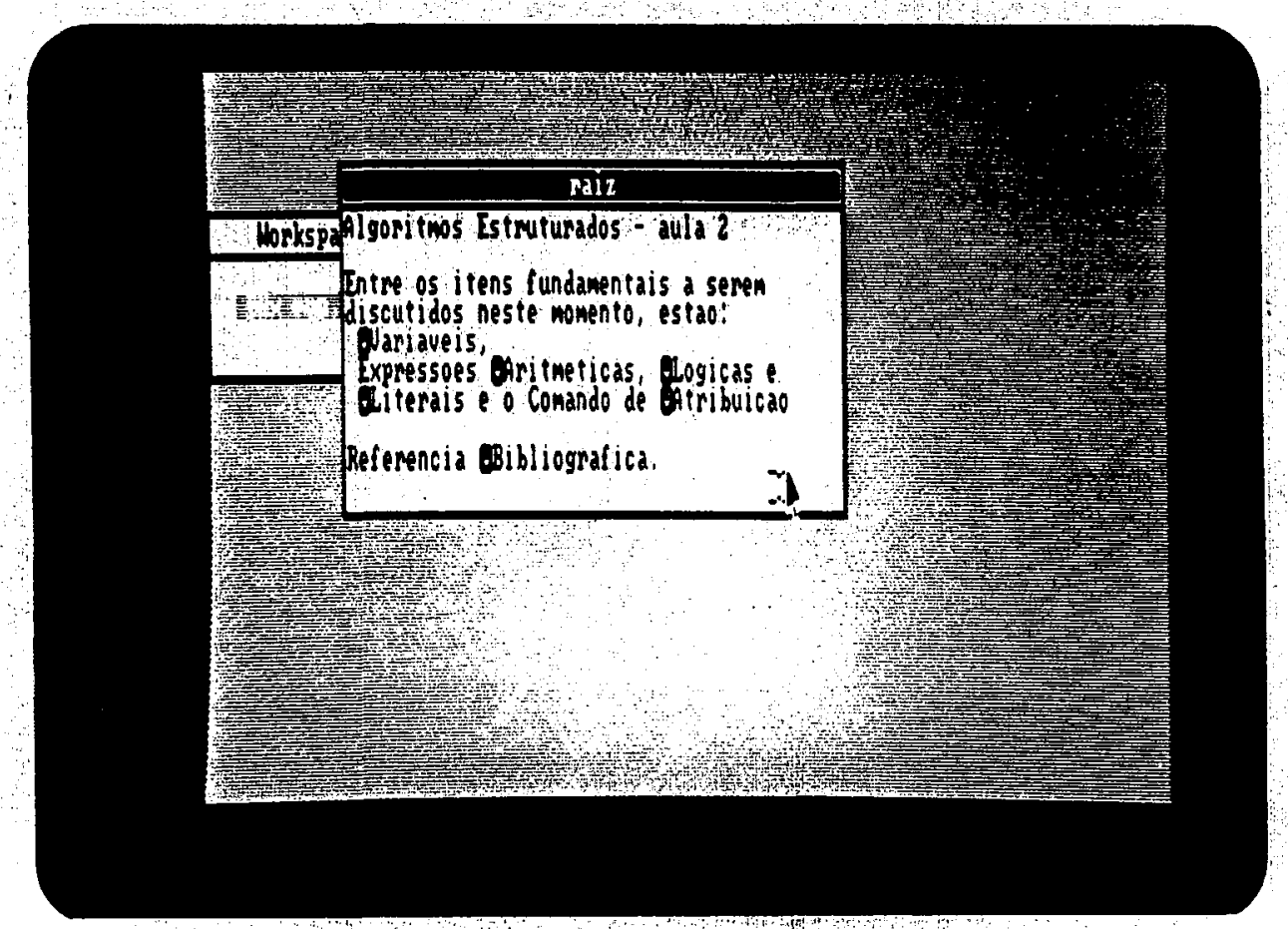

Figura 6.12 : 0 raiz é ativado.

Para exemplificar, o usuário seleciona, estando no nó raiz seleciona a âncora Atribuição o que faz que o nó atribuic seja carregado na tela, como indica a foto 6.13 .

O usuário, então, seleciona a âncora variável e seu nó é carregado, como mostra a foto 6.14 .

O usuário seleciona a âncora identificador, e o nó correspondente é carregado na tela (foto 6.15).

No nó identifi existe uma âncora variável que, por acaso, tem como destino - mesmo nó carregado a partir da seleção realizada no nó atribuic. Ao usuário selecionar essa âncora, o sistema verifica que o arquivo destino corresponde a uma âncora já carregada anteriormente. Nesse caso, em vez de carregar o nó correspondente ao destino na ligação, o sistema apenas ativa a janela correspondente e atualiza o percurso realizado.

No exemplo, o usuário seleciona a âncora variável e o nó variável anterior é selecionado (veja foto 6.16 ).

Neste momento, o usuário requisita o menu de operações especiais e ativa o comando go to, cuja função é permitir que o usuário retorne diretamente para qualquer nó dentro do percurso realizado. $O$ sistema, então, apresenta uma janela com uma lista de nomes de nós, que correspondem ao nós do percurso realizado 


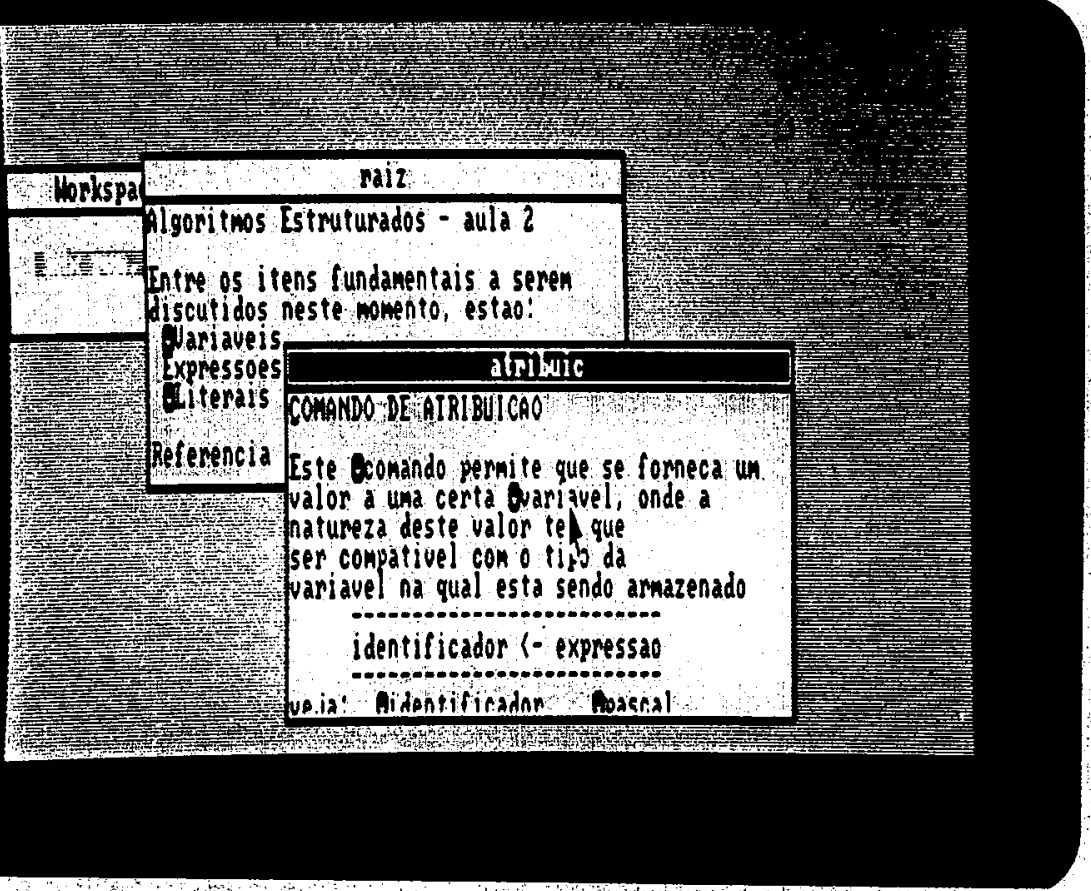

Figura 6.13: O usuário selecionou Atribuiçâo e seu nó foi carregado.

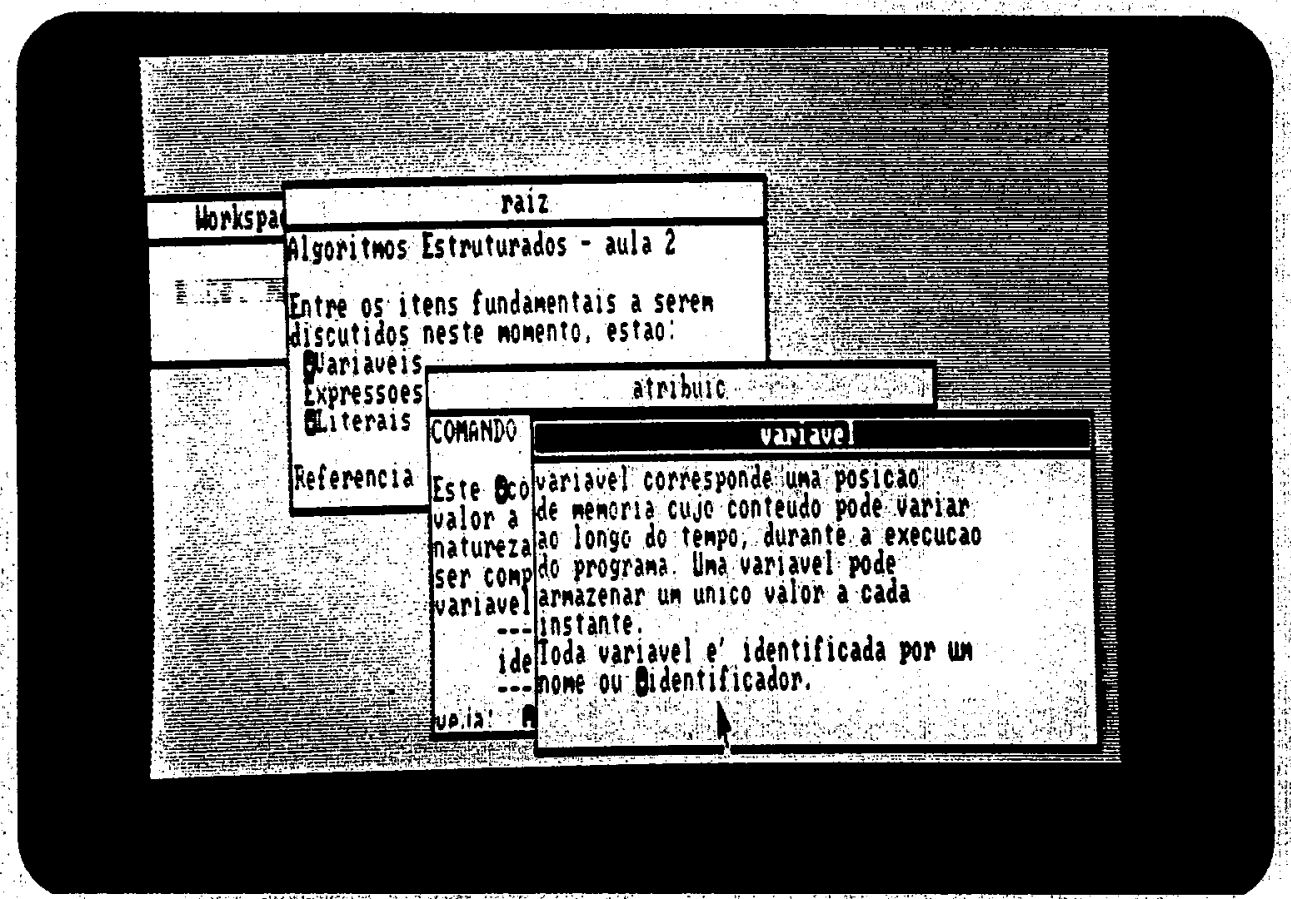

Figura 6.14. 0 nó variável foi carregado. 


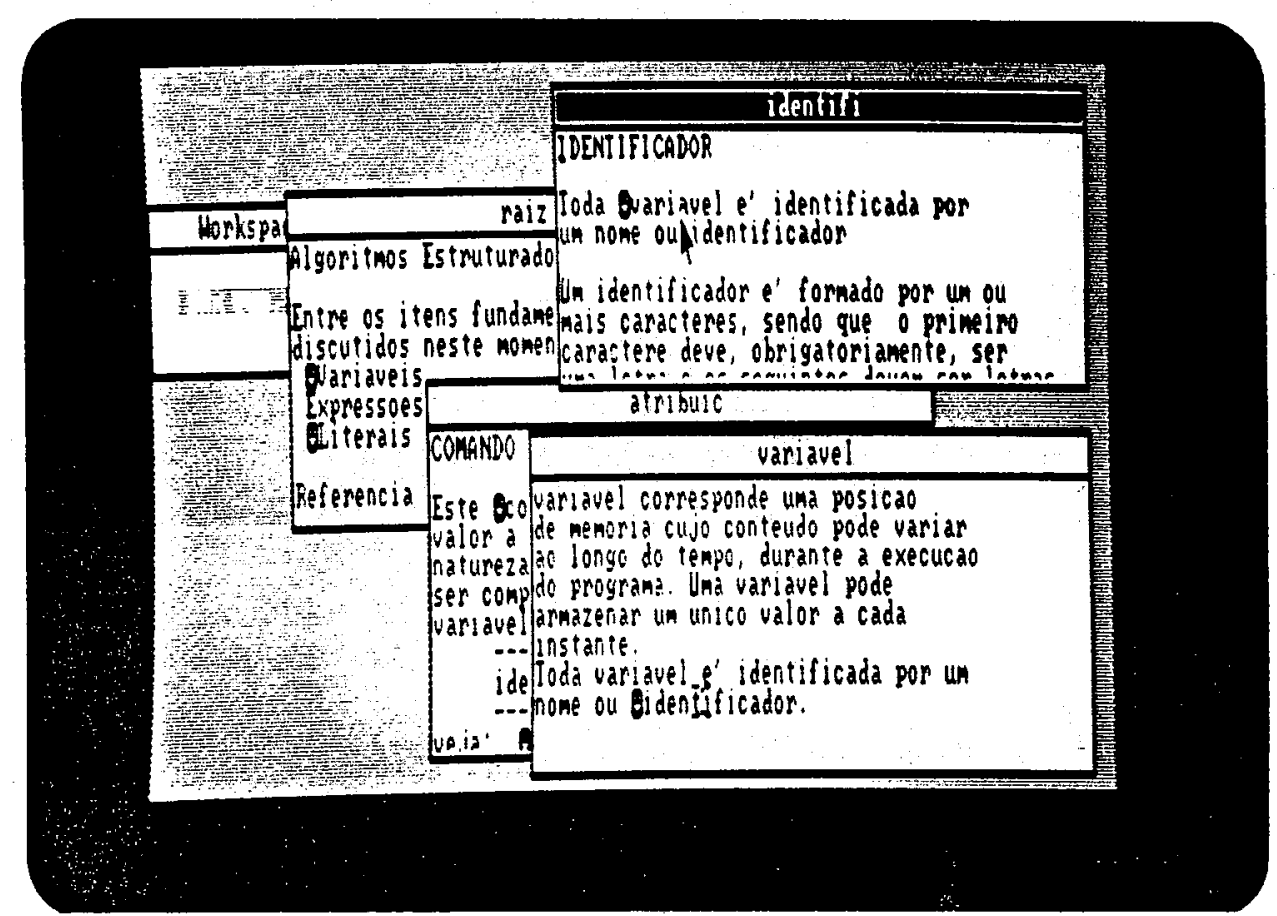

Figura 6.15: $\mathrm{O}$ nó identifi foi carregado na tela.

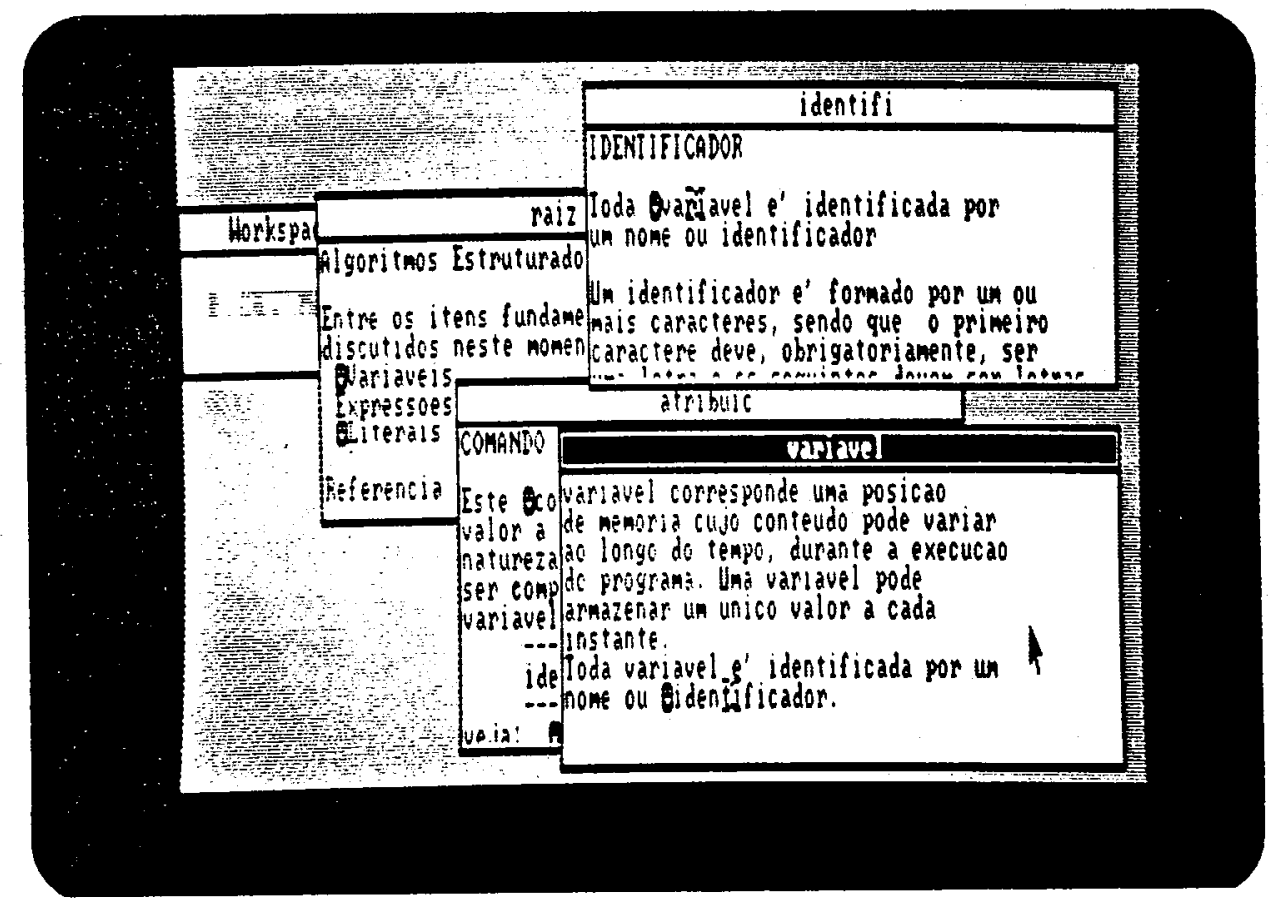

Figura 6.16: O nó variável foi reativado. 


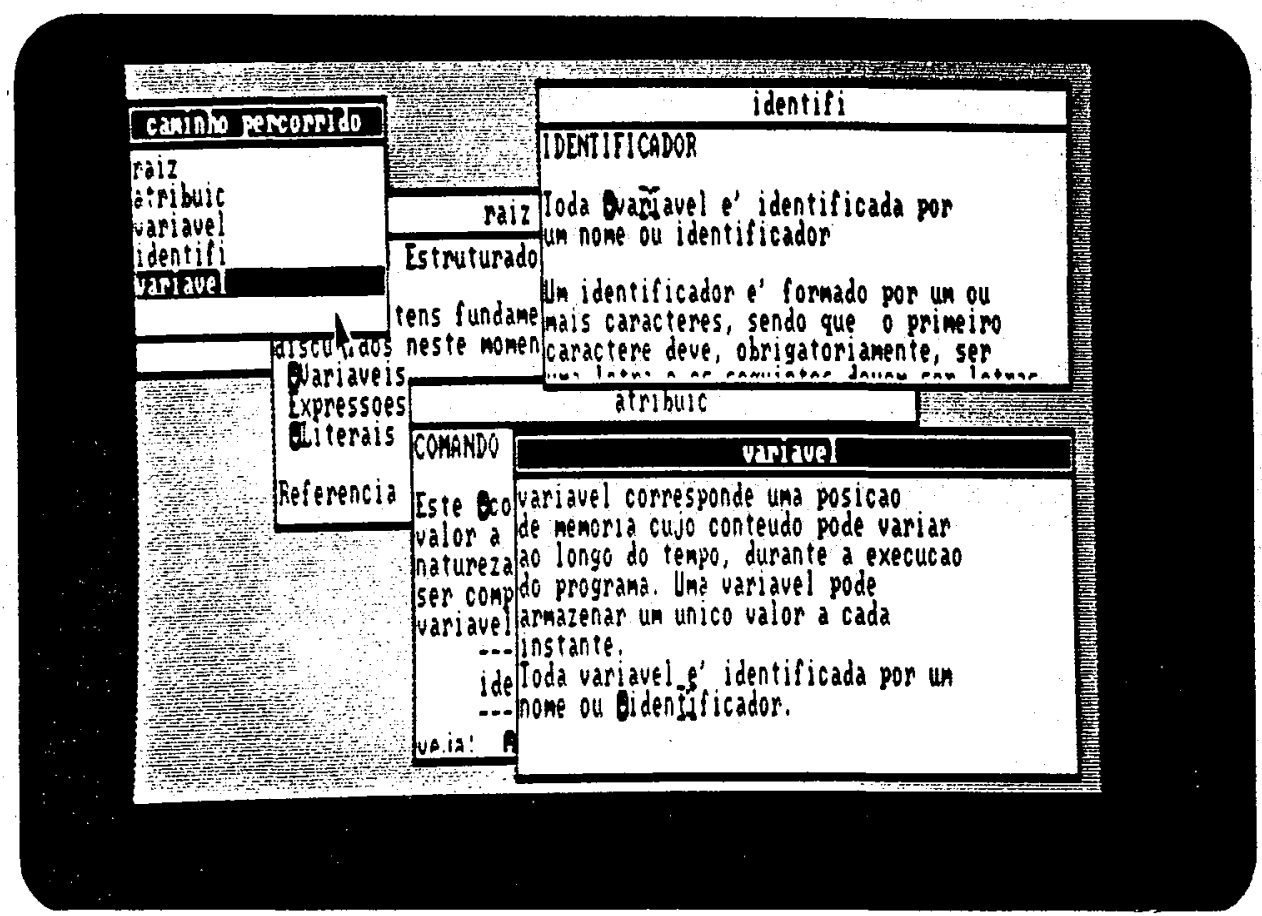

Figura 6.17: O sistema apresenta uma janela com o percurso realizado.

(como apresentado na foto 6.17).

O usuário pode selecionar qualquer um dos nós ou ativar um comando para desistir da operação (ação indicada na foto 6.18). Neste caso, o usuário seleciona o nome do nó atribuic, o que faz que ele retorne diretamente para aquele nó.

Outra função existente no menu de operações especiais é chamada browser como indicado na foto 6.19 .

O usuário então seleciona a função browser e o sistema coloca na tela uma janela com os nomes dos nós da vizinhaça do nó atribuic, como mostra a foto 6.20 .

A vizinhança do nó corrente corresponde a três gerações de nós, relativamente ao nó atual: seu nó pai, todos os seus irmãos (ele próprio é considerado neste caso) e todos os seus filhos e sobrinhos. De posse de uma janela desse tipo, o usuário visualiza sua posição dentro da porção do hiperdocumento. A janela do browser tem apenas função informativa, não sendo permitido ao usuário selecionar qualquer nó apresentado. A única operação disponível é a de retornar ao nó corrente, como indicado na foto 6.21 .

O usuário, a seguir, ativa o menu de comandos para requisitar a função back (foto 6.22 ).

Uma outra função existente no menu de comandos de um nó de texto é a go 


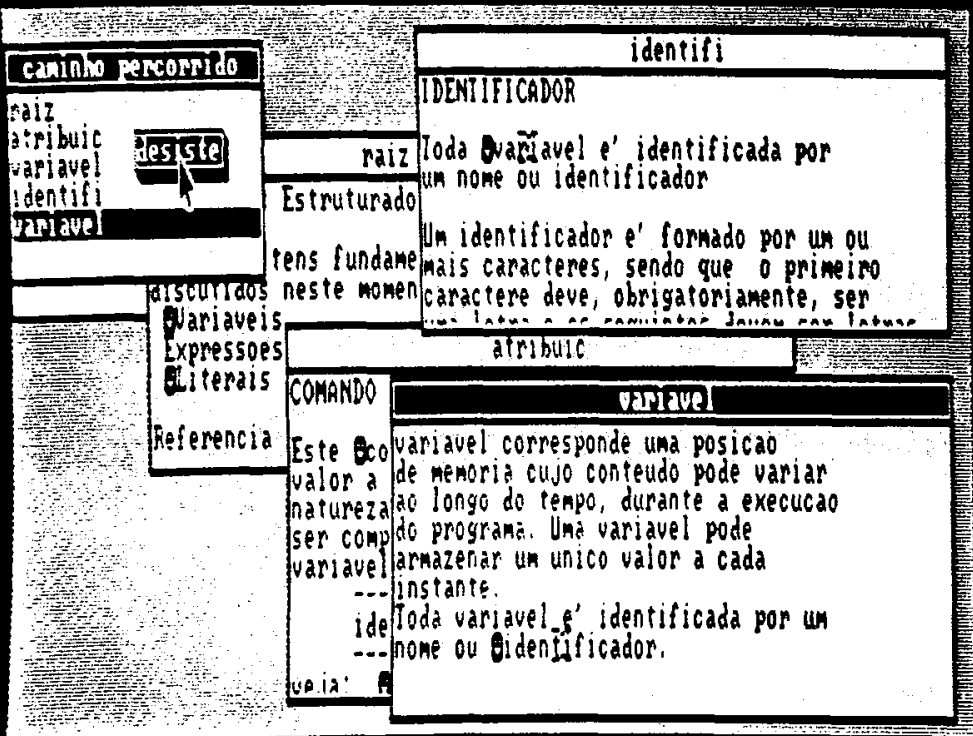

Figura 6.18: O usuário seleciona o nó atribuic.

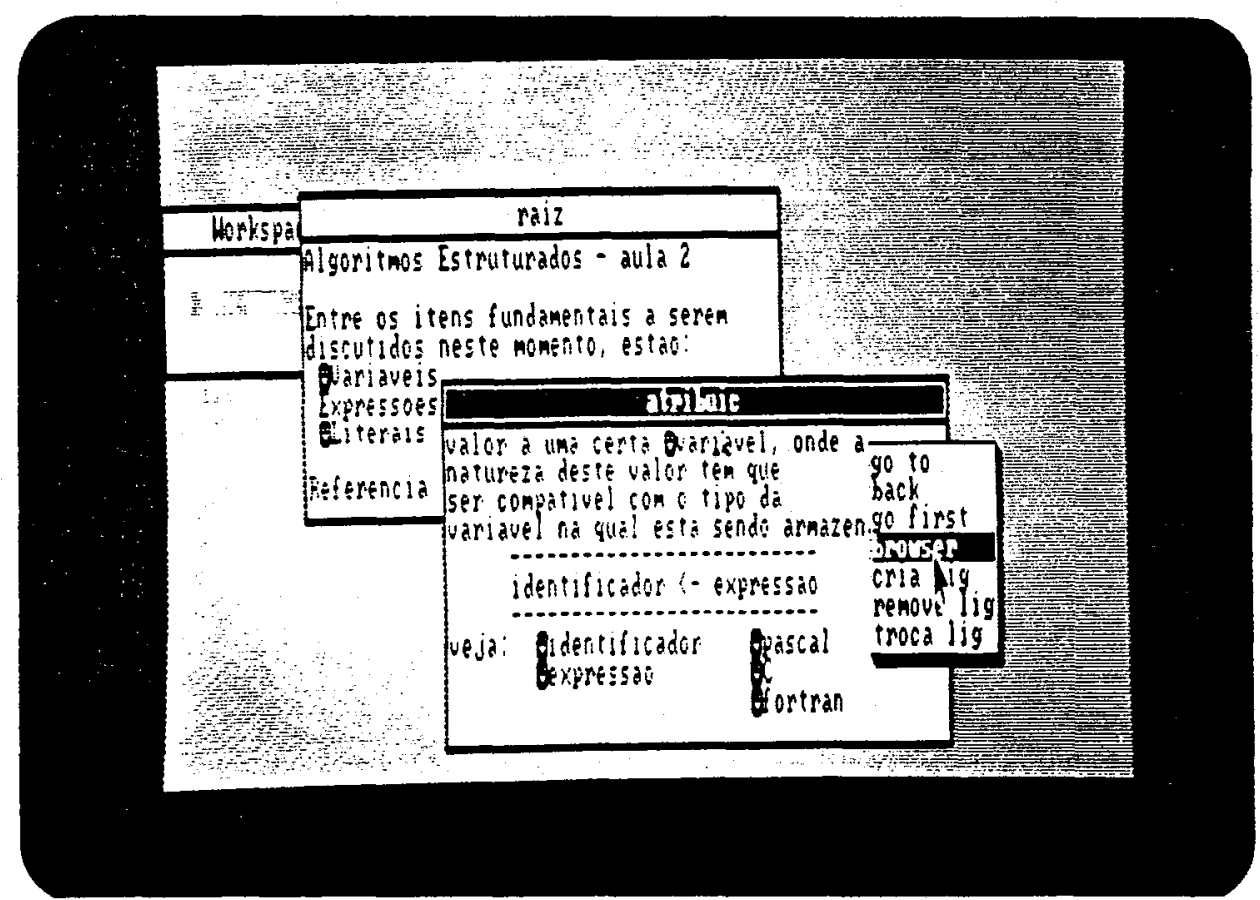

Figura 6.19: O usuário ativa o menu de operações para selecionar o browser. 


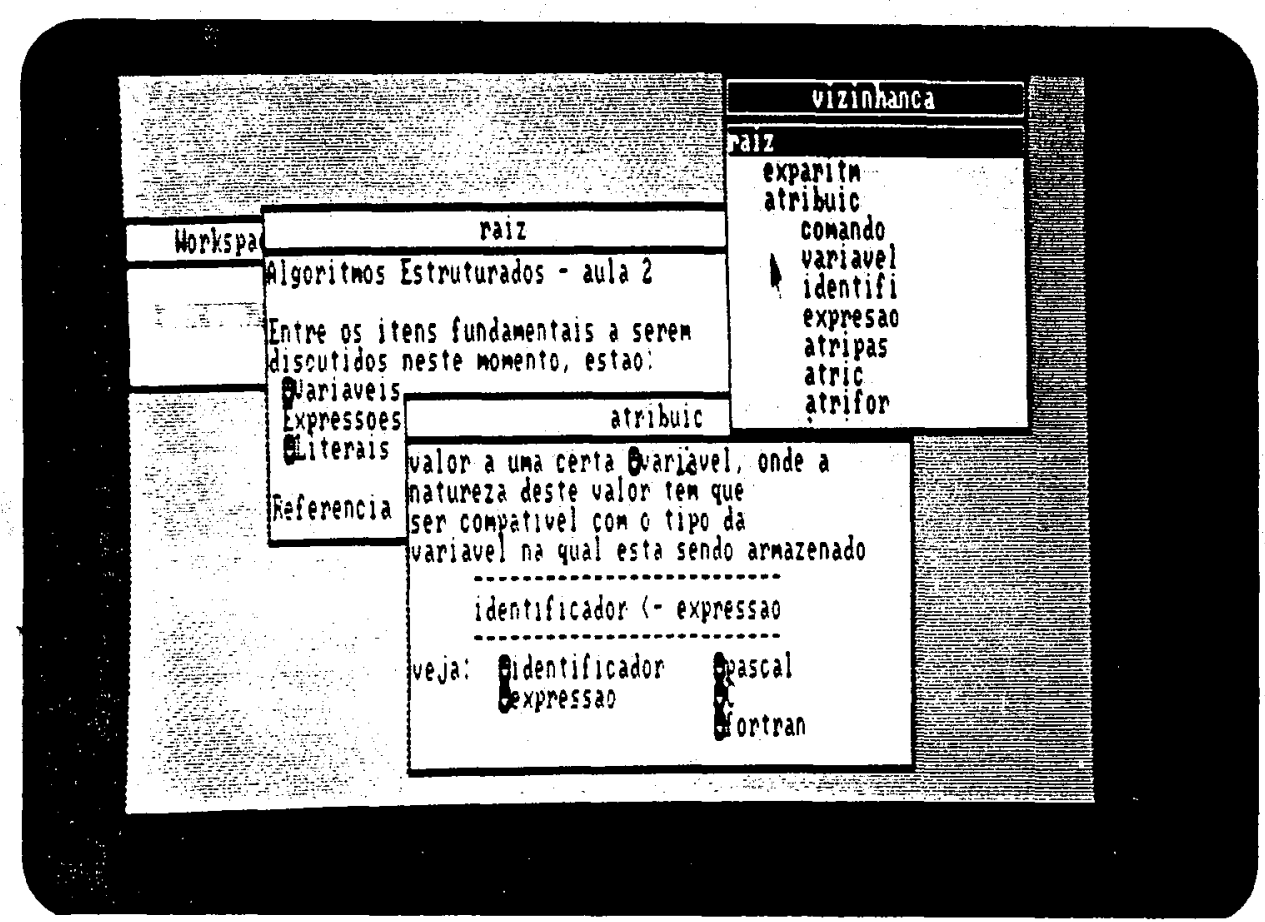

Figura 6.20: Janela com vizinhança do nó atribuic.

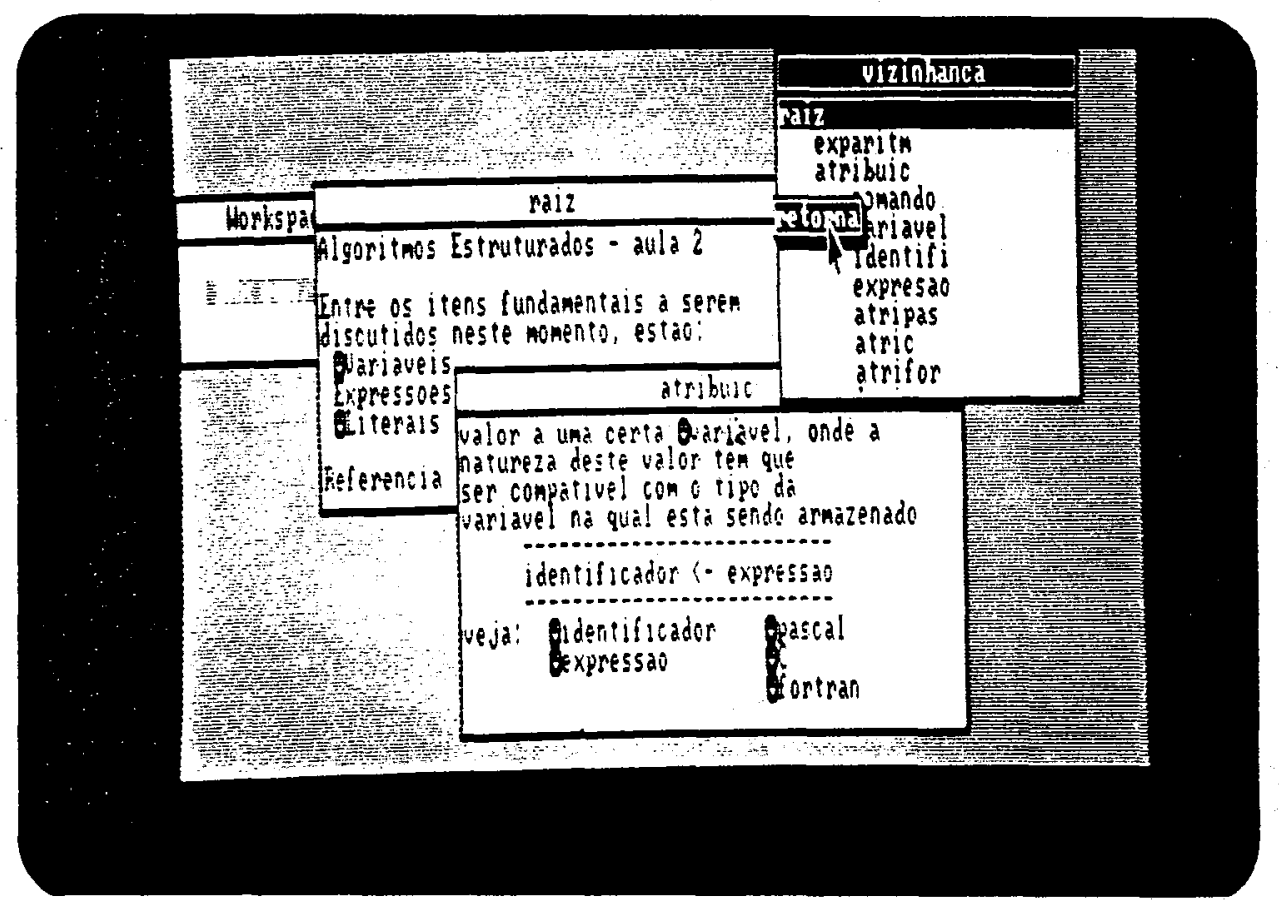

Figura 6.21: $\mathrm{O}$ usuário decide retornar ao nó corrente. 


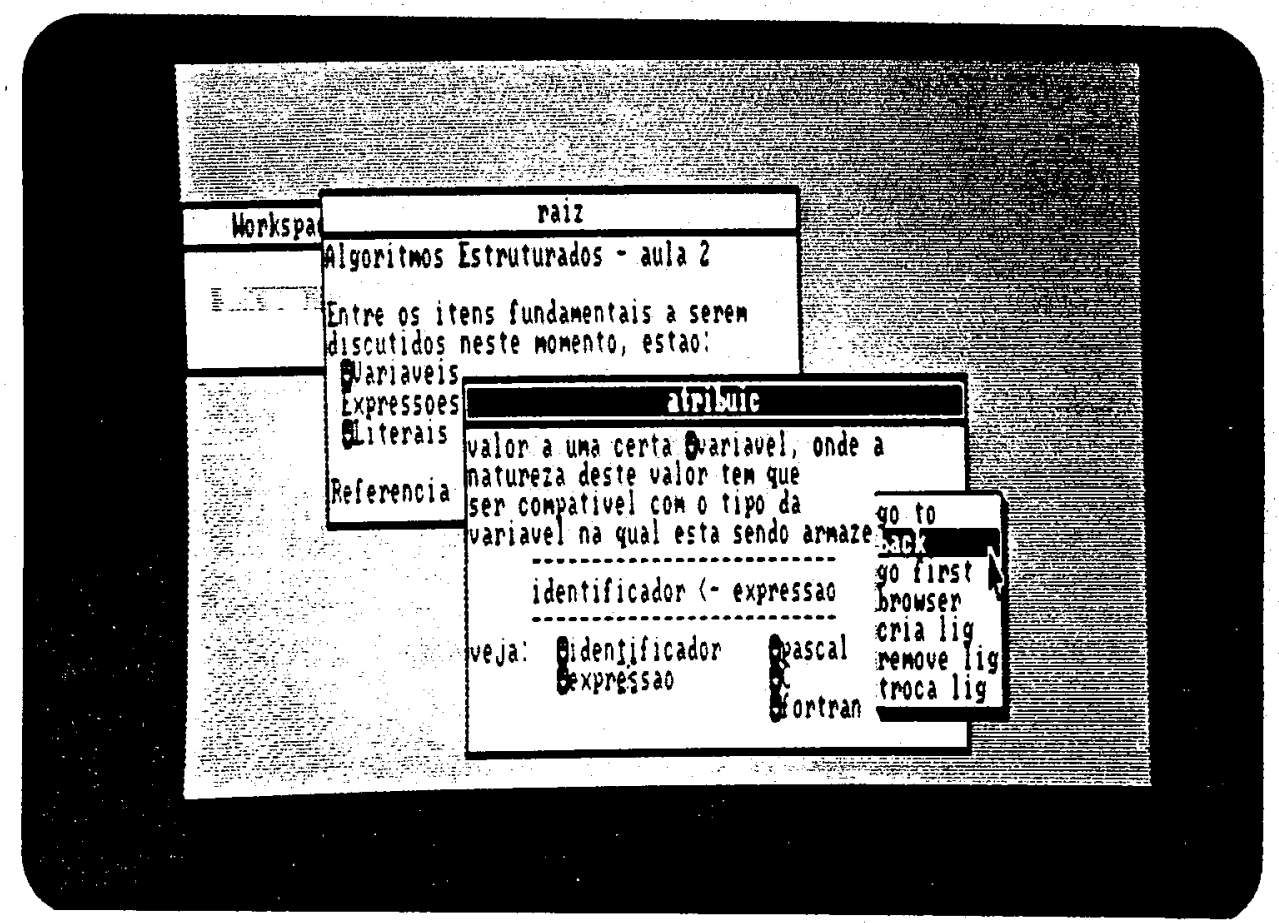

Figura 6.22: O usuário decide retornar ao nó raiz.

first, que faz com que o usuário volte, diretamente, ao nó raiz de seu percurso.

As outras funções constantes do menu de comandos são: cria lig, remove lig e troca lig. Essas funções são permitidas apenas ao usuário criador, e a seguir discutimos cada uma delas.

\section{Função cria lig.}

Indicada na foto 6.23. O usuário deve selecionar o item de texto corrente, que não pode corresponder a uma âncora, e requisitar esta função. O sistema então pede uma série de informações, necessárias ao estabelecimento da ligação, tais como nome do arquivo destino e tipo da ligação. Ao terminar a operação, o sistema acrescenta o caractere especial ao item de texto, indicando que ele agora é uma âncora.

\section{Função remove lig.}

Indicada na foto 6.24. Quando o usuário requisita esta operação, o sistema requisita a âncora que está relacionada com a ligação a ser removida e, a seguir, remove a ligação da âncora em questão dentro desse nó. $\mathrm{O}$ arquivo em disco, destino da ligação, permaneçe inalterado. Finalmente, a âncora é transformada num item 
normal de texto, através da eliminação do caractere especial a ela concatenado.

\section{Função troca lig.}

Indicada na foto 6.25. Com esta operação, o sistema permite que tanto a âncora como o arquivo destino sejam modificados. Para tanto, verifica primeiro qual das duas funções o usuário deseja realizar.

Para encerrar sua visita ao hiperdocumento, o usuário seleciona a função back, a partir nó raiz, que o leva de volta ao controle de entrada de usuários do sistema, como mostram as fotos 6.26 e 6.27 .

Para encerrar, vamos indicar quando e como o usuário pode realizar operações sobre hiperdocumentos como um todo.

Quando o usuário que entra no sistema é identificado como um usuário criador, o sistema tem disponível um menu de comandos especiais que pode ser utilizado antes da definição do hiperdocumento a ser visitado. As funções existentes nesse menu são comentadas a seguir.

Função cria $H d$.

Indicada na foto 6.28. Após selecionar esta função, o usuário recebe o pedido de fornecer o nome do hiperdocumento que deseja criar. Caso não exista, ele é criado pelo sistema que inicializa o nó raiz correspondente como sendo vazio e termina a operação, após atualizar a lista de hiperdocumentos disponíveis com o novo documento gerado.

Função remove $H d$.

Indicada na foto 6.29. O sistema pergunta qual o hiperdocumento o usuário deseja remover. A operação é realizada depois de algumas confirmações requisitadas ao usuário.

Função fim.

Indicada na foto 6.30. Essa função faz com que o sistema seja desativado, voltando o controle ao Smalltalk (foto 6.31). 


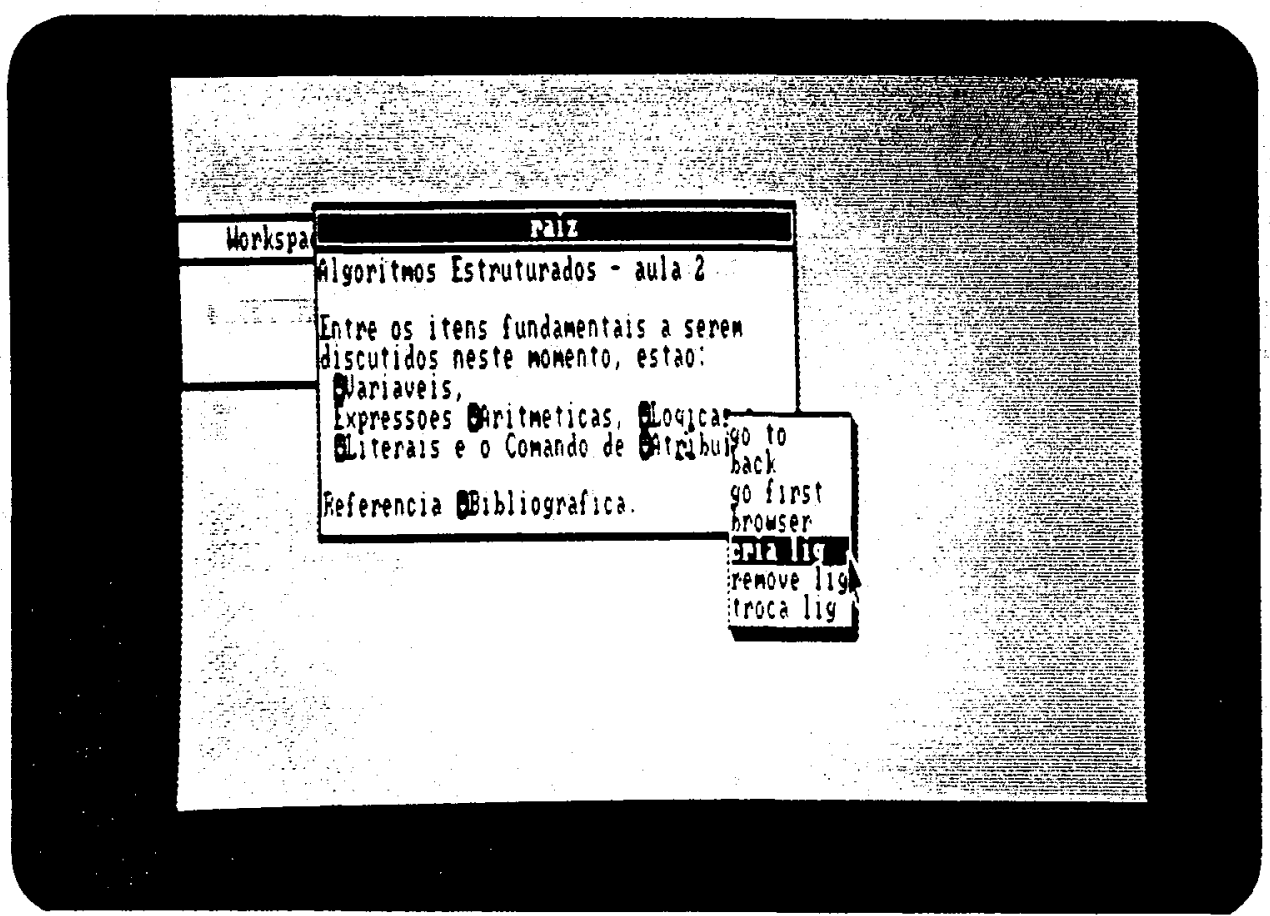

Figura 6.23: Função cria lig.

$\mathrm{Na}$ foto 6.32 , apresentamos o equipamento utilizado para a implementação. 


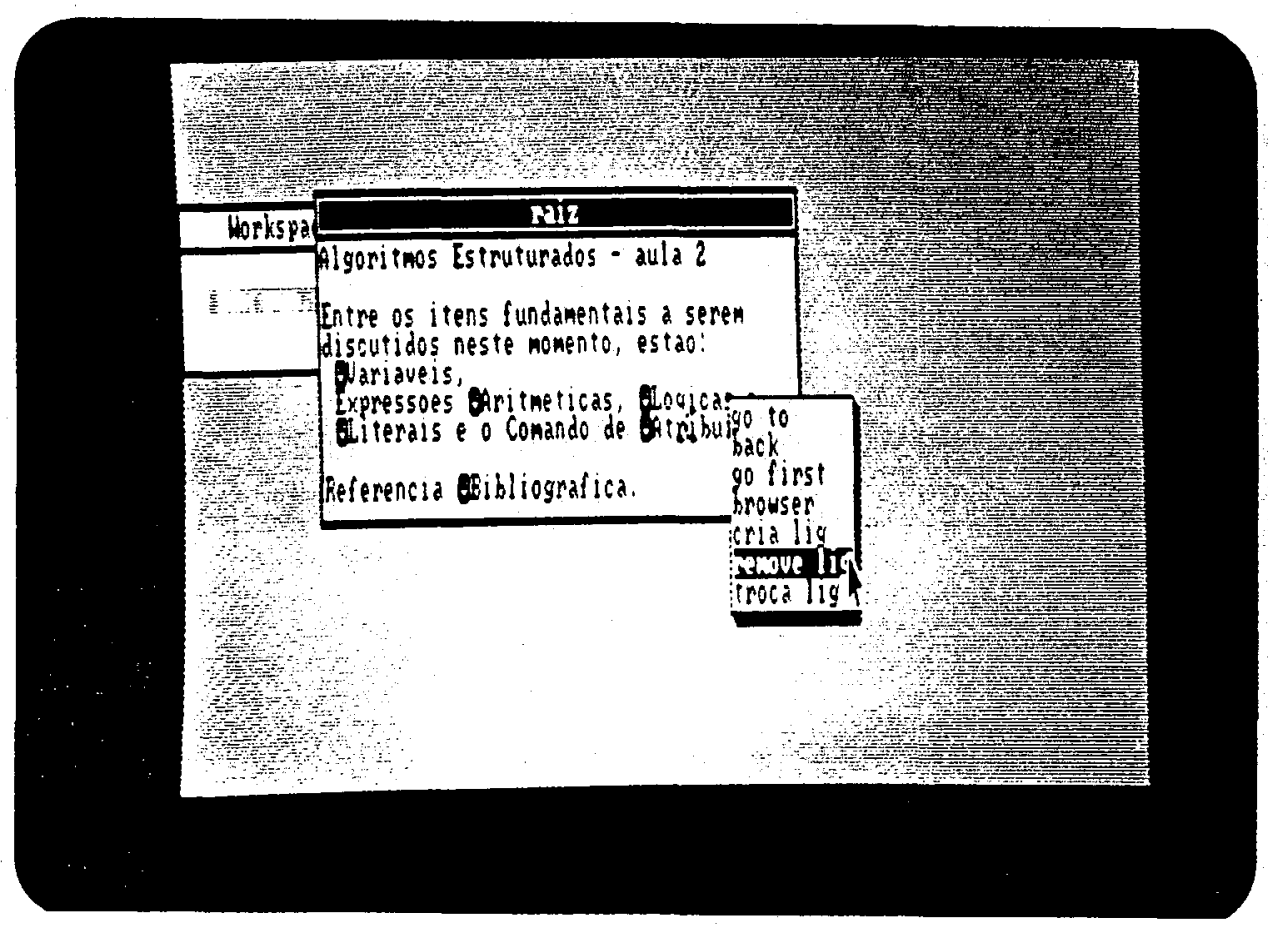

Figura 6.24: Função remove lig.

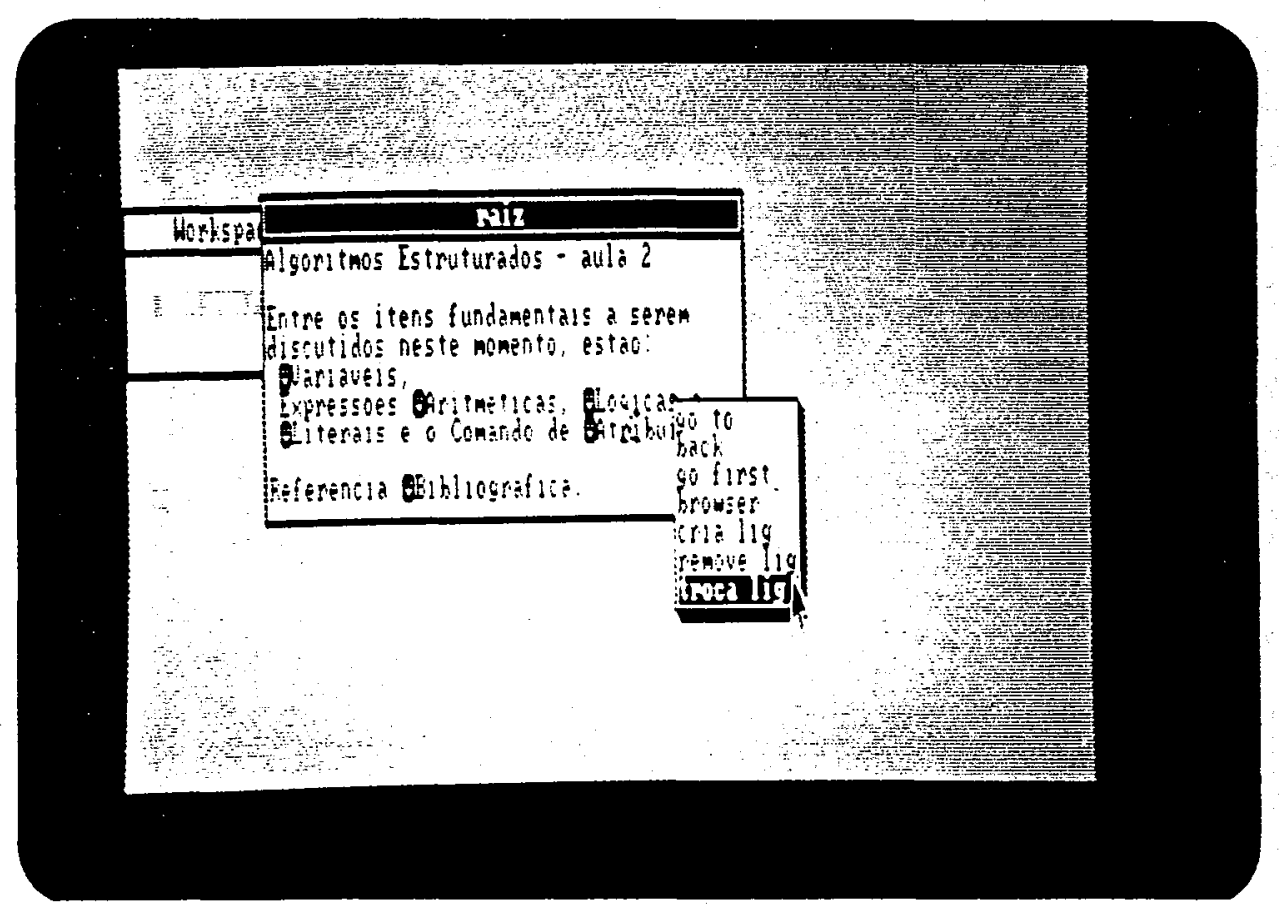

Figura 6.25: Função troca lig. 


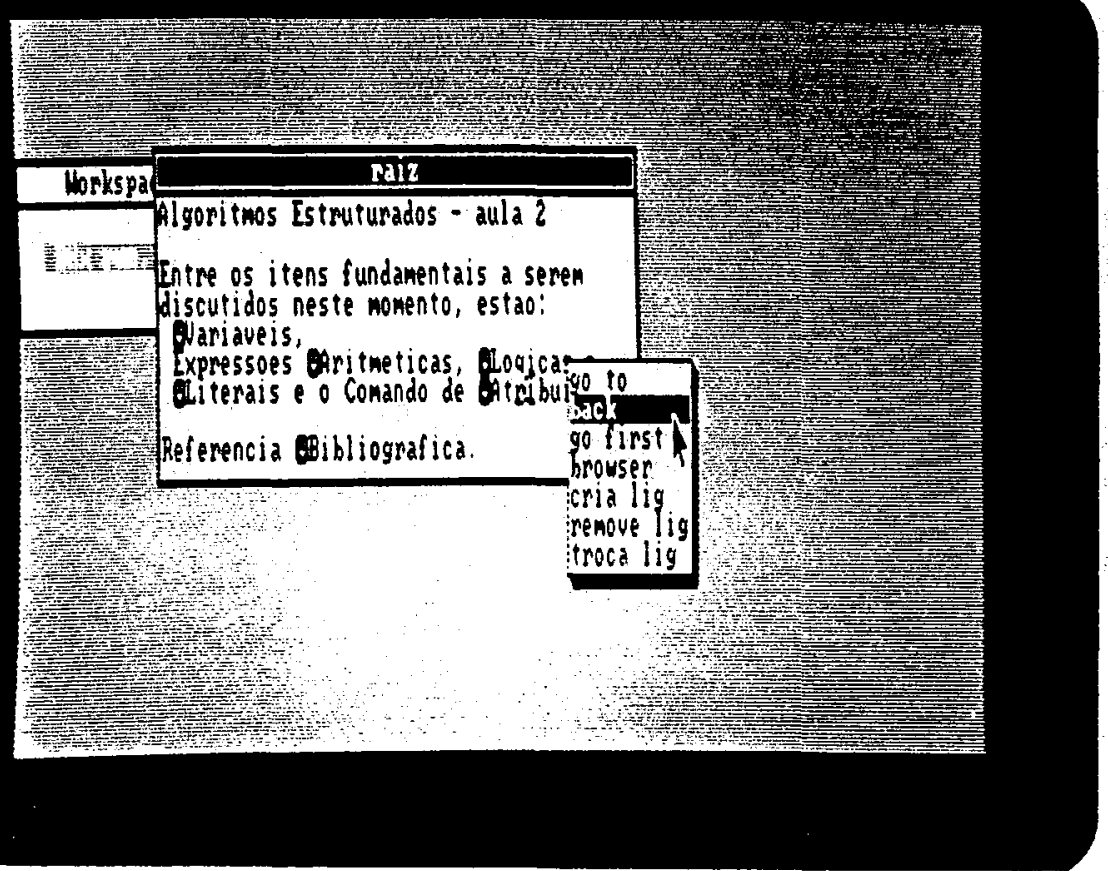

Figura 6.26: O usuário seleciona a função back no nó raiz ...

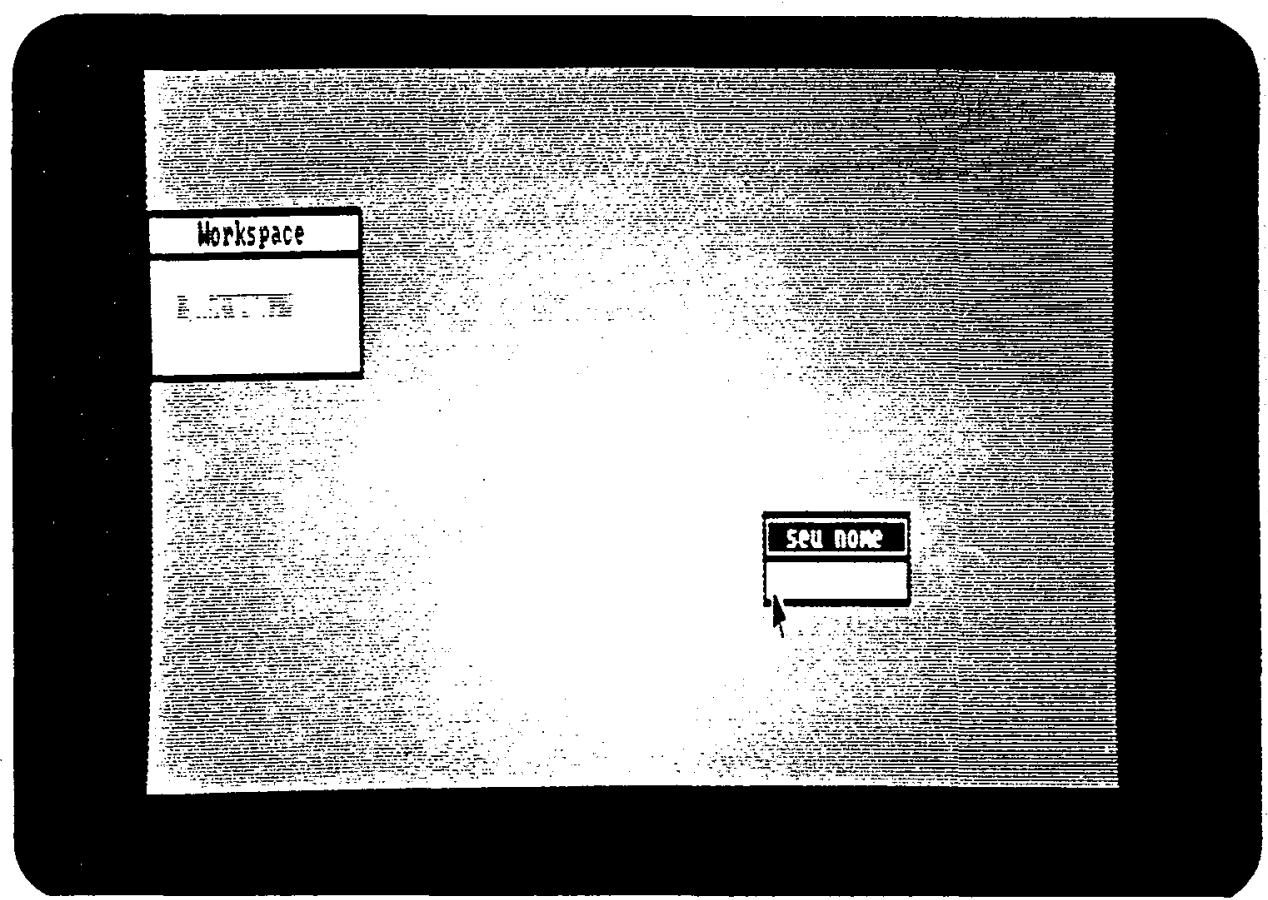

Figura 6.27: ...e volta ao controle de entrada de usuários. 


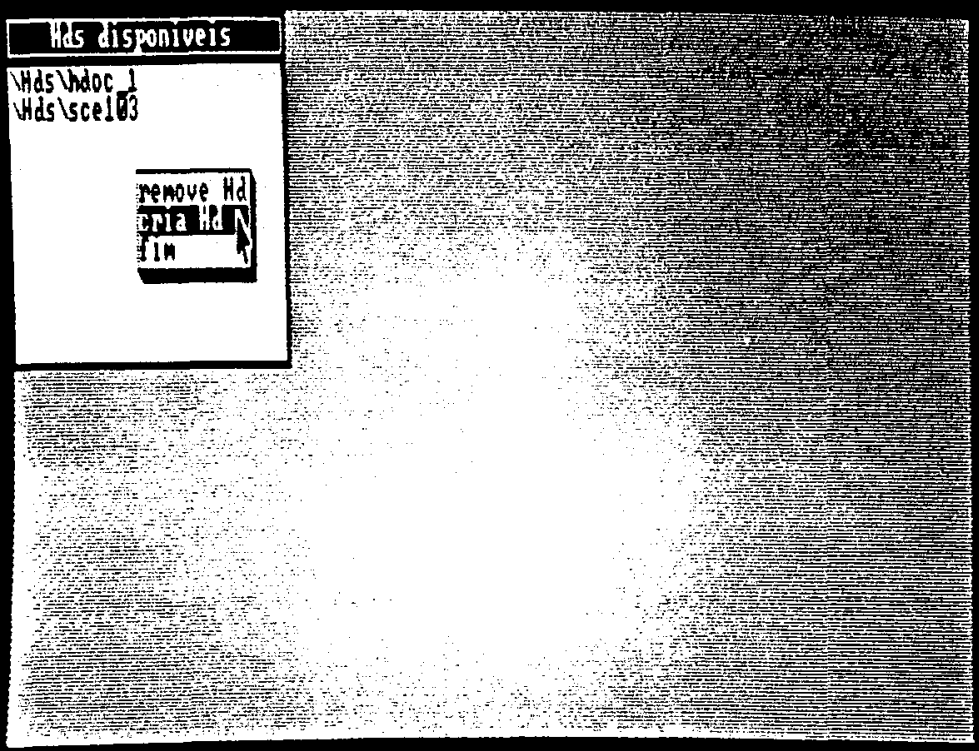

Figura 6.28: Funçao cria $H d$.

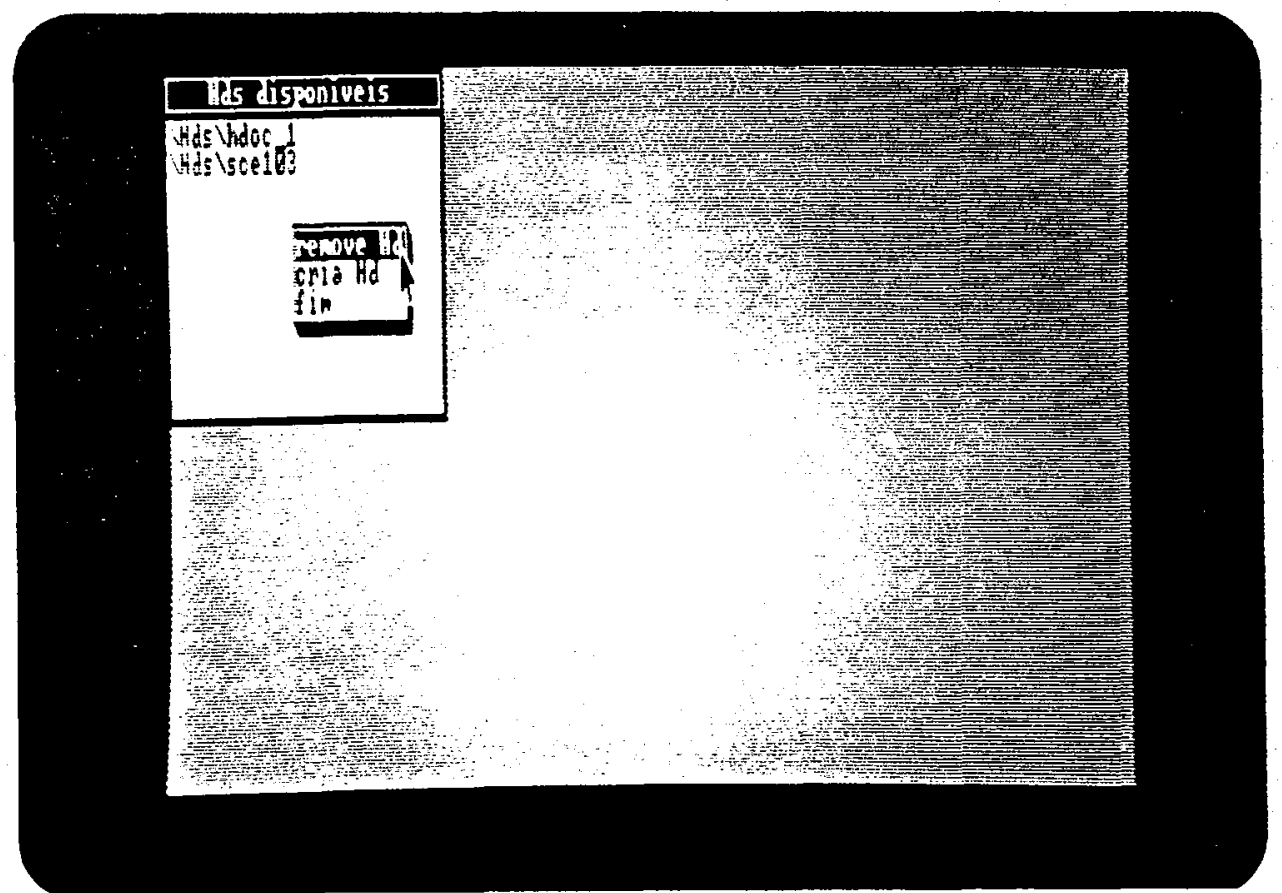

Figura 6.29: Função remove $H d$. 


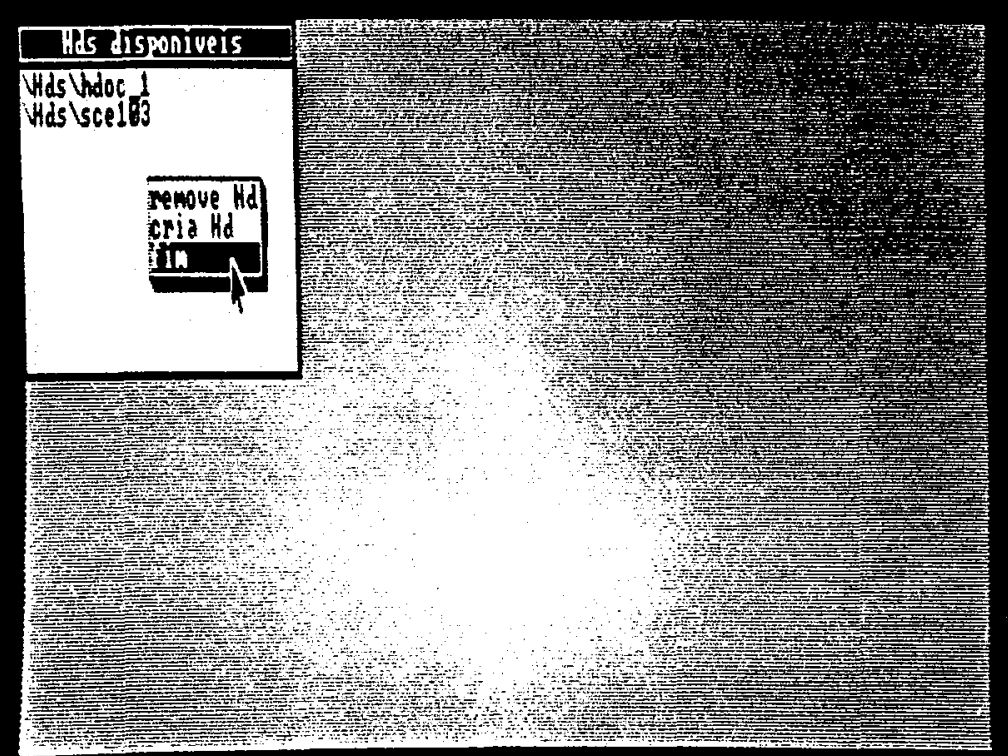

Figura 6.30: Funcão fim.

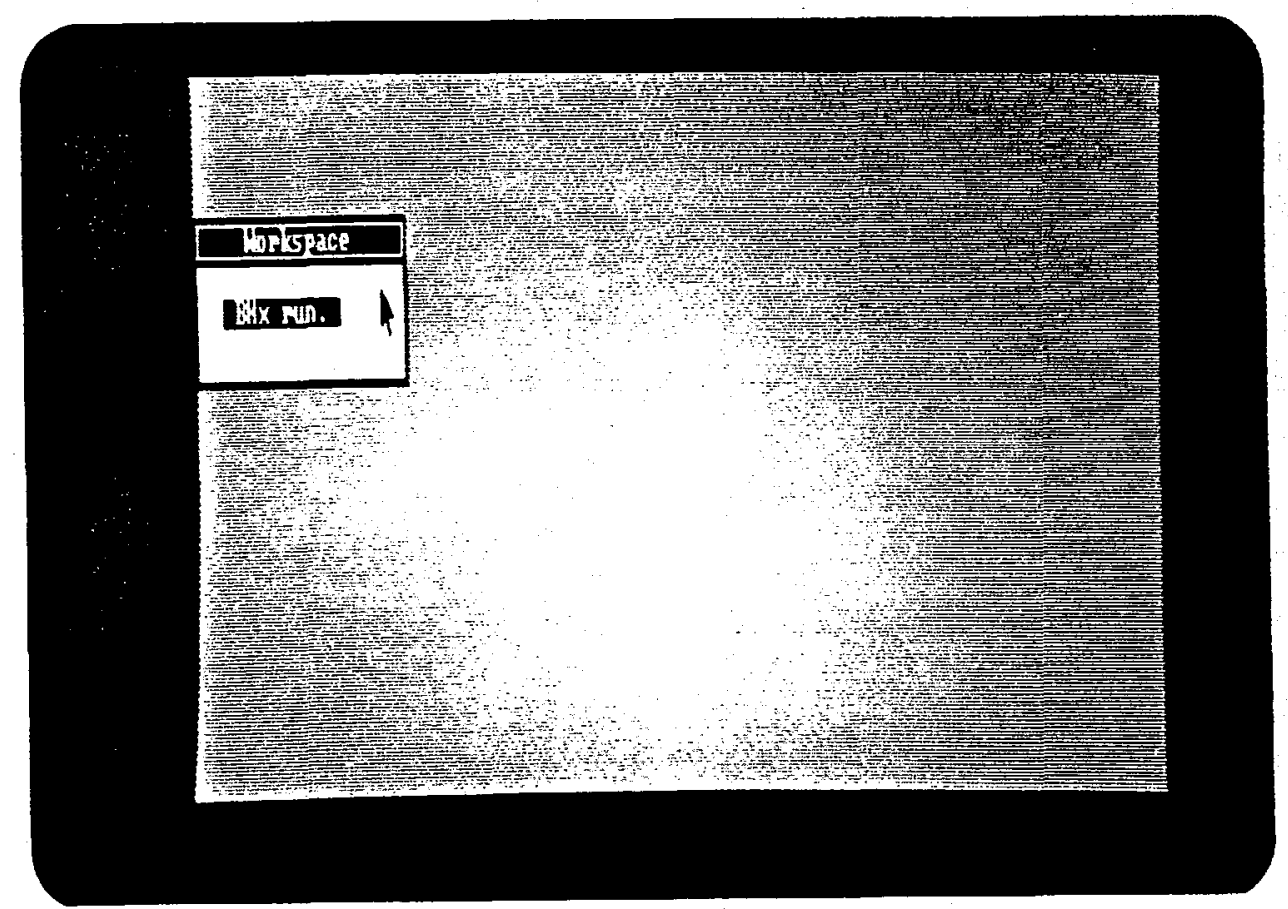

Figura 6.31: Controle devolvido ao Smalltalk. 


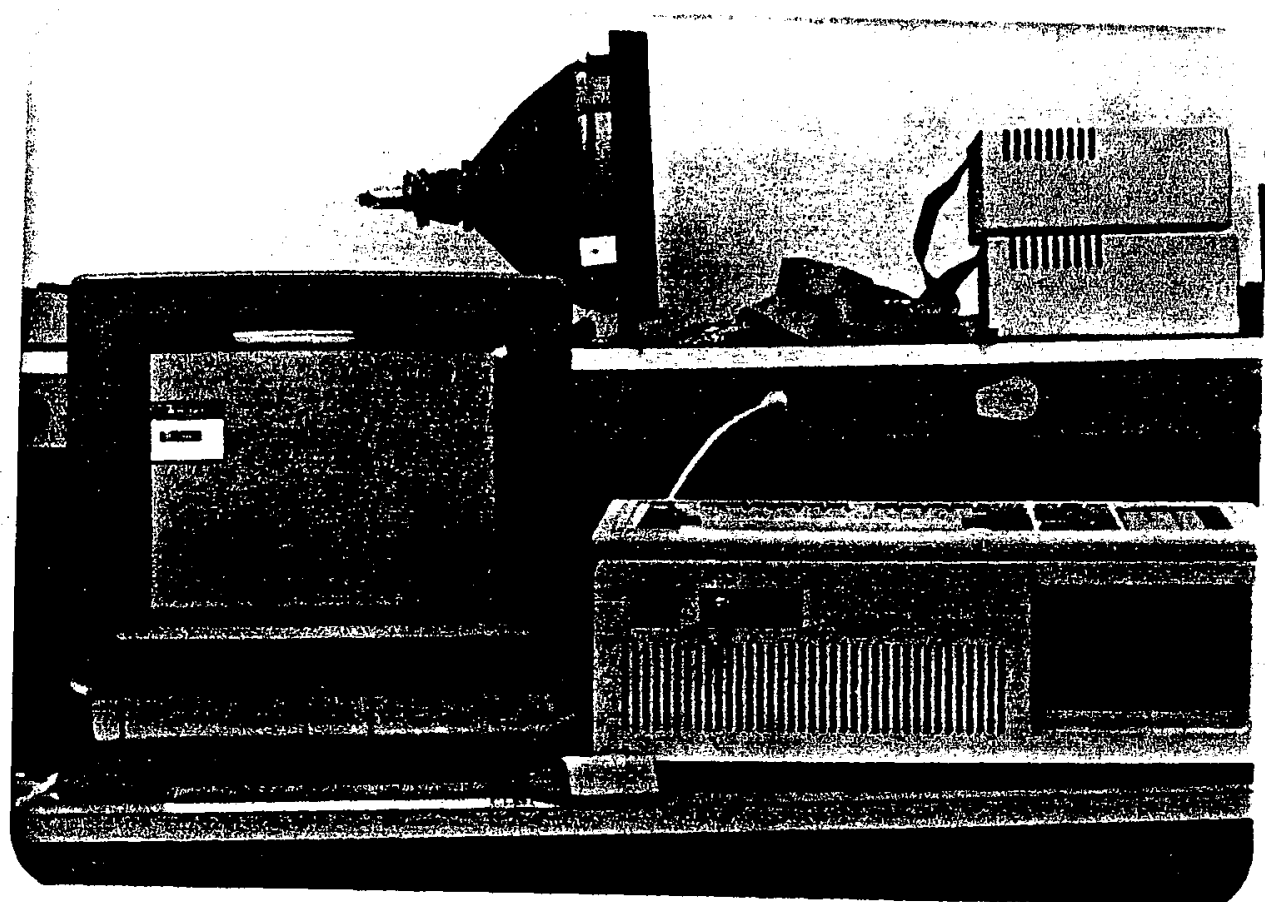

Figura 6.32: Equipamento utilizado - microcomputador ND 4000 AT; vídeo NEC/Multisync II e Witty Mouse. 


\section{Capítulo 7}

\section{Aspectos Relevantes ao Projeto do Sistema Base para Hipertextos}

Na primeira seção deste capitulo apresentamos o diagrama funcional do projeto SBx.

Nas seções seguintes mostramos como definimos, no projeto do sistema SBx, os aspectos relevantes discutidos anteriormente. Junto à apresentação de cada aspecto, tecemos algumas consideraçōes sobre o funcionamento do sistema. Além disso, em várias ocasiões, sugerimos possíveis extensões do sistema proposto, as quais estão resumidas no final do capítulo.

\subsection{Diagrama Funcional do Projeto}

O diagrama funcional do SBx, apresentado a seguir, é baseado no método proposto em [Yourdon 78], conhecido por Projeto Estruturado.

A tabela 7.1 apresenta a simbologia dos gráficos de estrutura utilizada, segundo a nomenclatura apresentada em [Rocha 87].

$\mathrm{Na}$ apresentação do diagrama utilizamos as abreviaturas Hd e HDs no lugar de Hiperdocumento e Arquivo de Hiperdocumentos, respectivamente.

Os detalhes do projeto e da implementação realizada encontram-se em [Pimentel $89 \mathrm{~b}]$. 


\begin{tabular}{|l|l|}
\hline \hline simbolo & significado \\
\hline$\square$ & módulo de função \\
$\longrightarrow$ & chamada \\
$\hookrightarrow$ & acoplamento de dados \\
$\cup$ & chamada interativa \\
$\bigcirc$ & chamada condicional $\star$ \\
\hline \hline
\end{tabular}

Tabela 7.1: Simbologia dos Gráficos

* para facilitar a criaçâo do diagrama dentro do processador gráfico utilizado, substituímos o símbolo $\diamond$ pelo $\bigcirc$. 

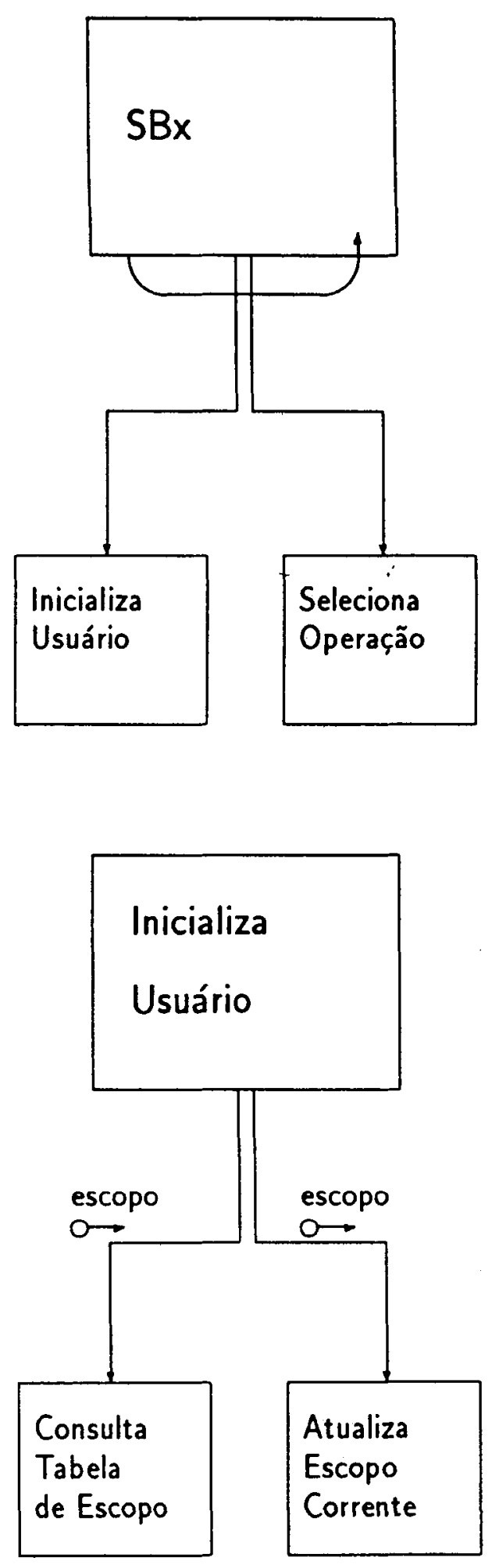

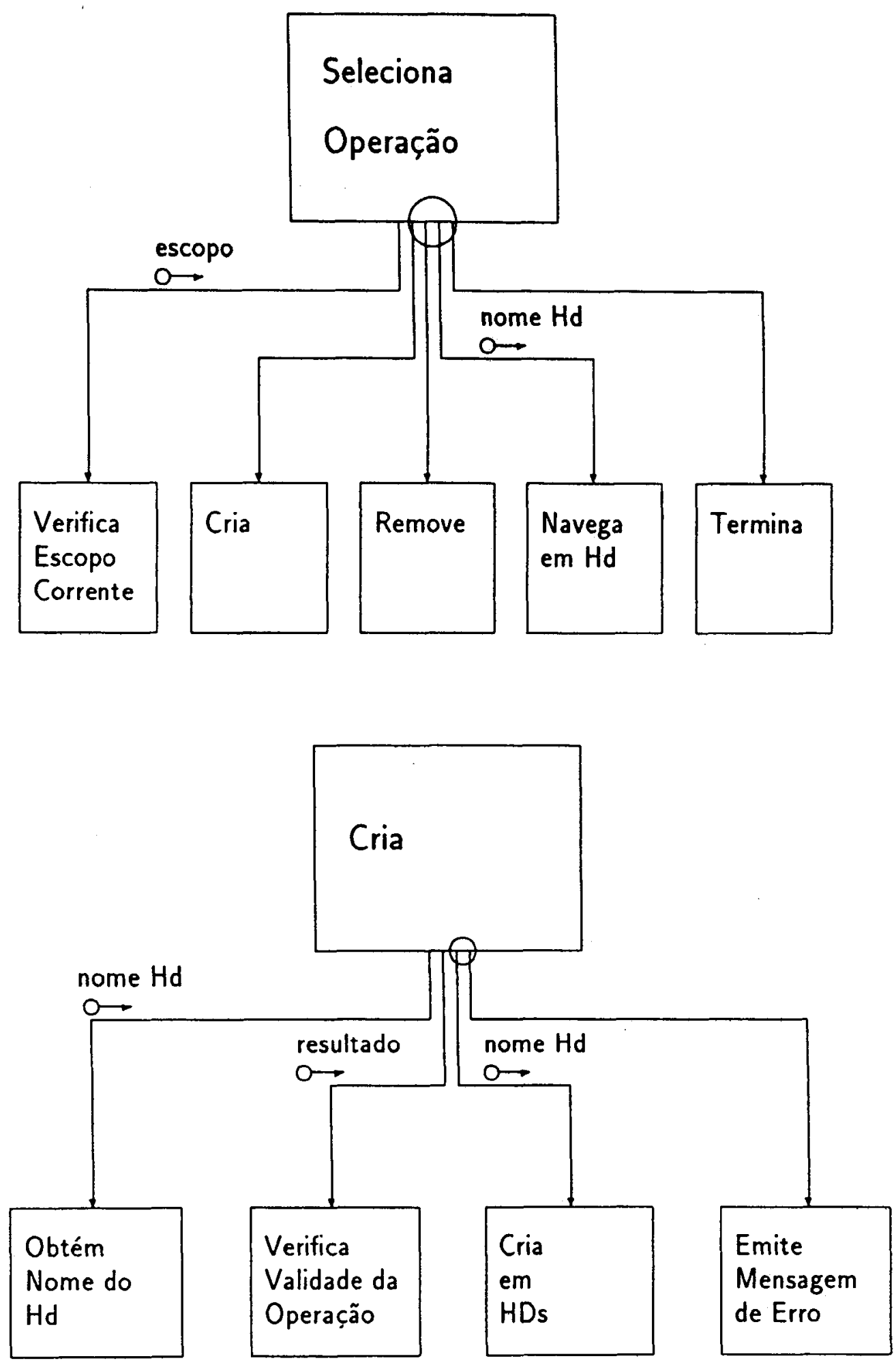

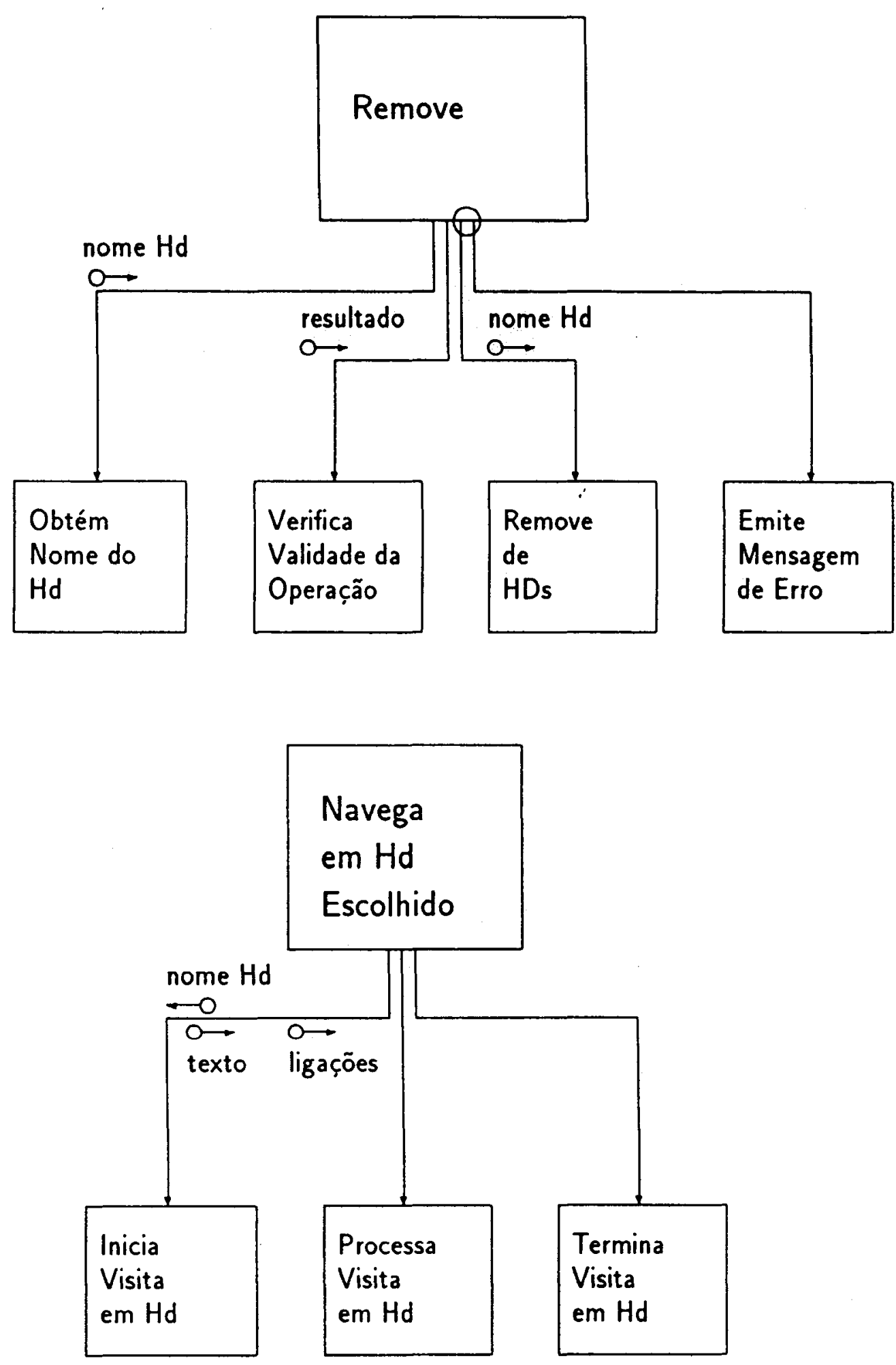

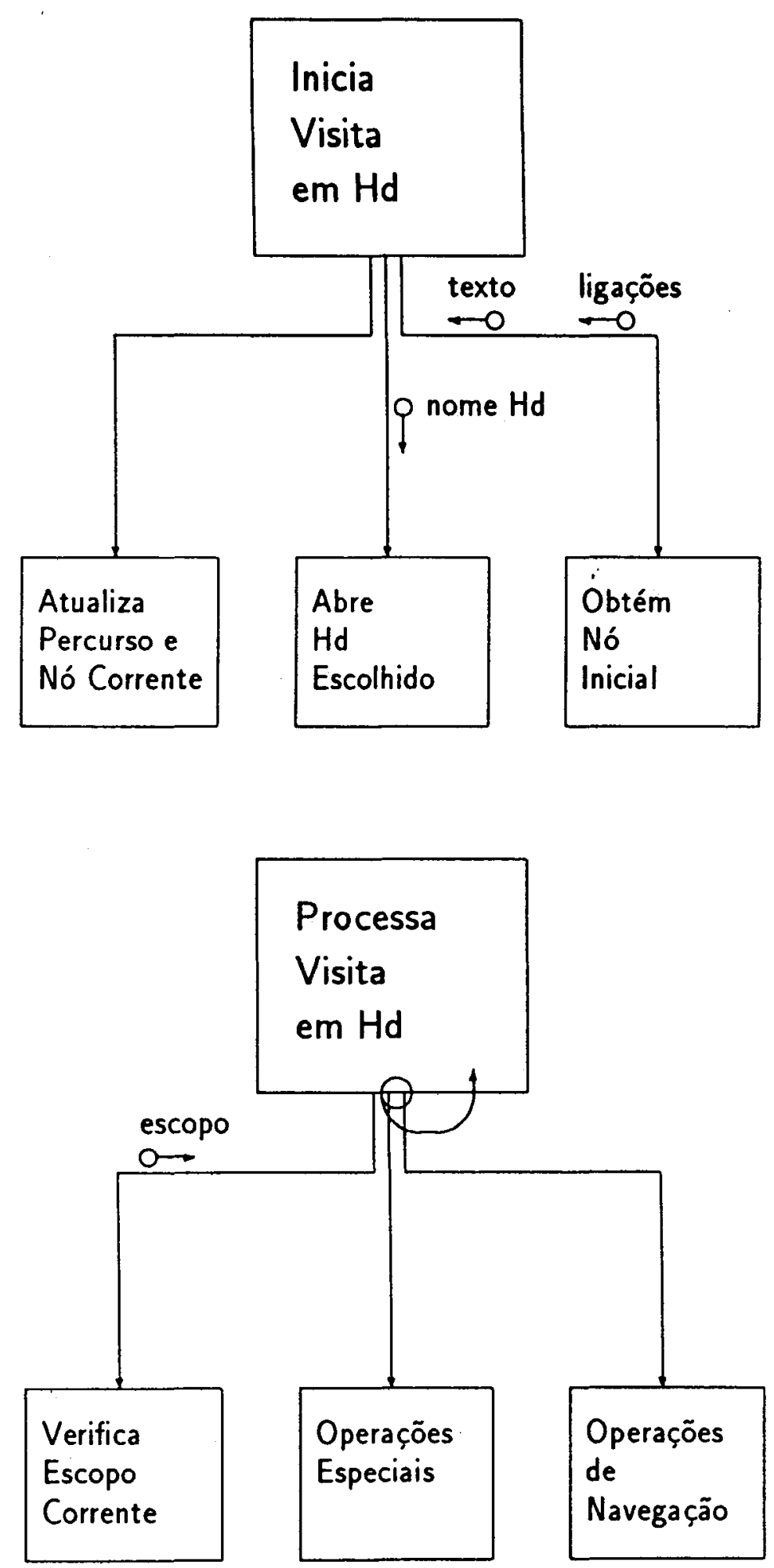

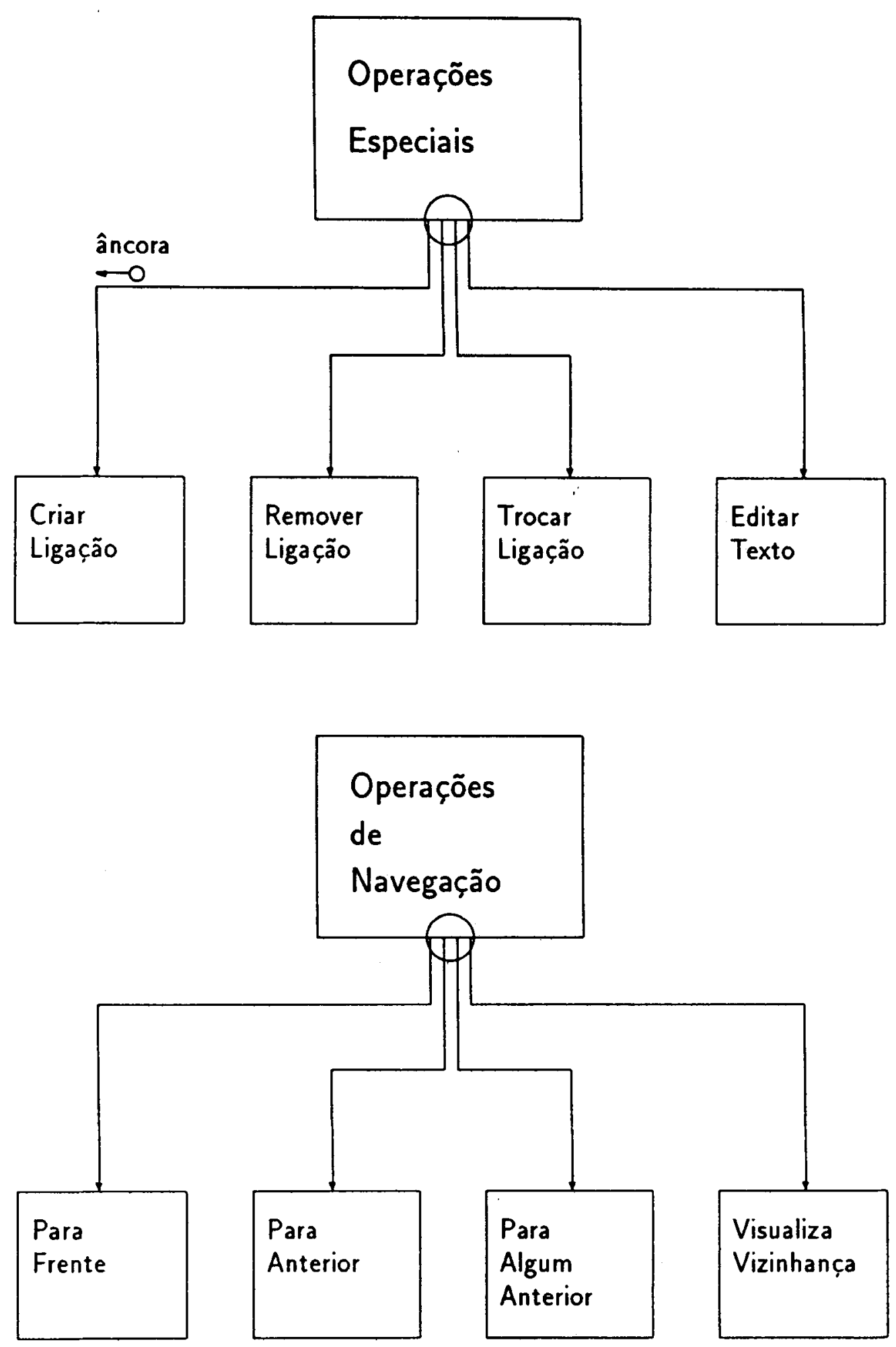
Mostramos nas próximas seções aspectos relevantes ao projeto do SBx.

\subsection{O Nó}

\subsubsection{O Tamanho do nó}

O SBx utiliza os arquivos do sistema operacional para o armazenamento e recuperação do conteúdo dos nós, utilizando o padrão ASCII (sem caracteres especiais dos editores de texto, por exemplo). Desta forma não restringimos o tamanho do nó, a menos do já imposto pelo sistema operacional (capacidade do dispositivo de armazenamento). Com isso, permitimos, inclusive, que documentos já existentes nesse padrão sejam aproveitados para a criação dos hiperdocumentos (veja discussão realizada na seção 7.6)

Utilizamos o recurso de janelas oferecido pela linguagem de implementação e permitimos a apresentação de mais que um nó por tela. Cada janela oferece ao usuário a visualização de parte do conteúdo de um nó. São permitidas, ao usuário comum, as seguintes operações sobre as janelas: rolamento do texto tanto na vertical como na horizontal; alteração da posição e do tamanho da janela. O SBx oferece uma ferramenta de pesquisa limitada ao escopo do nó, que é discutida na seção 7.4.2.

\subsubsection{Tipos de Nó}

Nossa implementação se enquadra na classificação dos sistemas que implementam um tipo de nó para cada tipo de informação. Implementamos três tipos diferentes de nó:

- Apresentação de texto e ligações embutidas: esse nó é utilizado pelo criador do hiperdocumento para armazenar informações de texto e especificar as ligações embutidas. Para um usuário comum, esse nó é utilizado para visualização do texto e execução de operações de navegação (veja item 7.4 para majores detalhes sobre navegação).

Para edição do conteúdo do nó utilizamos o editor de texto do sistema Smalltalk, que obedece ao padrão ASCII. Uma expansão possivel do SBx é a alteração do editor para o suporte de todos os caracteres existentes na língua portuguesa. 
- Apresentação do percurso percorrido: nesse nó é apresentada uma lista de todos os nós visitados pelo-usuário /, em ordem cronológica, durante os avanços efetivos na navegação (näa sendo apresentados os trechos já abandonados). O usuário pode selecionar qualquer nó da lista, requisitando ao $\mathrm{SBx}$ o seu retorno àquela posição de navegação. 0 item 7.4 .4 discute essa operação.

- Apresentação da viżinhança do nó: esse tipo de nó apresenta uma lista com os nomes dos nós que estão na vizinhança do nó corrente. A lista é disposta em três níveis: no primeiro nível é apresentado o nome do nó pai do nó corrente, no segundo nível são apresentados os nomes de todos os nós irmãos do nó corrente, e no terceiro nível são apresentados todos os nós filhos e sobrinhos do nó corrente. Esse nó serve ao usuário como um browser para vizualização de sua vizinhança, não sendo permitida nesta versão a seleção de nós no browser para navegação. $O$ item 7.4 .3 discute os aspectos de navegação envolvidos com esse tipo de nó.

A linguagem utilizada na implementação possui recursos para oferecimento de nós de conteúdo gráfico. Uma expansão do sistema estaria relacionada ao suporte, pelo SBx, desse tipo de informação.

Os diversos tipos de nós implementados foram oferecidos com os seguintes objetivos:

- conter tipos distintos de dados: um tipo único de nó com conteúdo tipo texto é suportado; outros tipos de dados devem ser implementados por tipos diferentes de nós.

- servir para fins distintos: cada tipo de nó implementado tem uma função específica dentro do sistema.

- permitir a extensão do sistema: quando novos tipos de nós forem implementados, eles poderão ser adicionados ao sistema com bastante facilidade, o que permite a expansão deste de forma modular.

\subsection{A Ligação}

Âncora e Ligação. Implementamos as âncoras como palavras dentro do texto, às quais permitimos relacionar uma ligação. Caso seja necessário um número major de ligações, o criador pode gerar um nó intermediário que contenha uma âncora para cada ligação destino desejada. 
Objetos Ligados. Permitimos que o criador relacione uma âncora a um nó destino como um todo. Para isso, o criador da ligação fornece o nome do arquivo que contém o conteúdo desejado. Portanto, temos os nós ligados num esquema ponto-a-nó. É possivel acrescentar o esquema de relacionamento ponto-a-ponto com certa facilidade, o que pode ser feito se a aplicação necessitar.

Direção da Ligação. Implementamos a ligação unidirecional, mas realizamos o controle de percurso do usuário, o que lhe permite retornar aos nós anteriores (veja as operações apresentadas no ítem 7.4.4).

\begin{abstract}
(b)
Vizunalização da Ligação. Implementamos o esquema de marca especial para indicar a existência de ligação. $\mathrm{O}$ usuário sabe que uma determinada palavra do texto possui uma ligação embutida ao visualizar um caractere especial concatenado à esquerda da palavra. Existem três caracteres especiais correspondendo aos três tipos de ligação implementados (veja Tipos de Ligação, a seguir). Não se permite que esses caracteres, que não são símbolos convencionais, sejam utilizados no texto para outros fins. Os caracteres especiais têm tamanho normal, mas o usuário não tem difữ uldades para seguir a ligação, uma vez que pode selecionar qualquer ponto da âncora, e não apenas o caractere especial. Por serem de tamanho normal, julgamos que os símbolos de ligação não congestionam o campo visual do usuário. Uma expansão que pode ser realizada é a opção de inibição momentânea dos caracteres especiais, de forma a permitir que o usuário veja apenas o texto do nó.
\end{abstract}

Operações sobre a Ligação. A única operação que o usuário comum pode realizar sobre uma ligação é segui-la, uma vez que não lhe é permitida nenhuma outra operação sobre o nó. Ao criador do hiperdocumento são permitidas outras operações que são discutidas na seção 7.5 .

Herança de Contextos. Implementamos um esquema de limitação da herança de contextos baseado no escopo do usuário. Cada ligação possui um escopo inicial e final de acesso. Esse escopo é utilizado pelo SBx quando o usuário seleciona uma ligação: ele só terá acesso às ligações existentes no nó destino, cujo escopo inicial e final sejam valores que limitam inferior e superiormente o escopo do próprio usuário. No item 7.4.1 comentamos este esquema. Procuramos, deste modo, implementar uma ferramenta que permita acesso diferenciado aos usuários, de forma bastante flexivel. 
Tipos de Ligação. Optamos por implementar três tipos de ligação: hierárquica, de referência cruzada e de execução. Caracteres distintos indicam o tipo de ligação relacionado a uma âncora.

- Os dois primeiros tipos são utilizados pelo criador do hiperdocumento para indicar, aos demais usuários, quando a informação encontrada no nó destino está hierarquicamente subordinada à informação do nó atual. Veja o item 7.4.3 para saber quando o $\mathrm{SBx}$ utiliza esses tipos distintos.

- Ao selecionar uma ligação do tipo executável, o usuário ativa a execução, pelo sistema operacional, do programa relacionado à ligação. A ligação do tipo executável é de extrema importância, se considerarmos o SBx como um sistema hypermedia: através da execução dos programas podemos relacionar nosso sistema de microcomputador à qualquer outro equipamento periférico, possivel de ser controlado por programas executáveis a partir do sistema operacional.

\subsection{Navegação}

\subsubsection{Seleção de Ligação}

A operação de seleção de ligação é tratada pelo SBx de modo diferente, dependendo do tipo de ligação selecionado.

Ligação Hierárquica ou de Referência Cruzada. Quando o usuário seleciona uma ligação desse tipo, o sistema realiza os seguintes passos:

- busca o arquivo relacionado à ligação;

- cria uma janela para a apresentação do conteúdo do arquivo, nas coordenadas indicadas pelo criador da ligação;

- desativa as ligações às quais o usuário não tem direito, através da verificação, no arquivo destino, de quais ligações têm escopo válido para o usuário corrente;

- atualiza o percurso realizado; 
- marca a janela anterior como válida apenas para visualização e não mais para navegação;

- coloca o conteúdo do nó na janela e marca essa janela como válida para navegação.

O nivel de detalhes apresentado permite visualizarmos os seguintes aspectos de navegação implementados no SBx:

1. Controle de Herança de Contextos: ao usuário são apresentadas, a cada instante, apenas as ligações às quais ele possui direito de acesso.

2. Controle do Percurso Realizado: o SBx mantém controle sobre o percurso realizado pelo usuário e utiliza essa informação para oferecer as opções de navegação discutidas no item 7.4.4.

3. Controle da Janela Atual: o SBx permite que todas as janelas presentes na tela - estando vísiveis ou não - possam ser visualizadas pelo usuário a qualquer instante. Isso permite que ele tenha acesso às informaçôes contidas em quaisquer dos nós já visitados. $\mathrm{O}$ usuário só pode continuar a navegar, entretanto, a partir do nó atual de seu percurso. Oferecemos, desta forma, facilidades de visualização dos nós, sem contudo confundir o usuário durante a navegação.

Ligação de Execução. Como já comentamos, esta ligação é importante pois permite caracterizar o SBx como um sistema hypermedia. Quando o usuário seleciona uma ligação desse tipo, o sistema providencia a execução do comando relacionado à ligação e, após o seu término, apresenta ao usuário um aviso desse fato.

\subsubsection{Pesquisa de Padrão}

O sistema Smalltalk, através do editor de texto, oferece um esquema de pesquisa de padrão sobre o conteúdo do texto. Utilizamos essa ferramenta para permitir ao usuário comum procurar alguma cadeia de caracteres específica dentro do nó. 


\subsubsection{Navegação em Gráfico de Nós e Ligações - Brow- ser}

Na seção 7.2.2 descrevemos um tipo especial de nó, que é utilizado para apresentação da vizinhança do nó atual. O conteúdo desse nó é, na realidade, uma lista dos nós que compõem uma hierarquia na qual o nó atual se enquadra. São apresentados, em relação ao nó atual: o pai, seus irmãos - ele próprio é colocado neste nível - e todos os seus filhos e sobrinhos. Para gerar a lista de nós válidos para a hierarquia, o SBx considera apenas as ligações do tipo hierárquica

Um aspecto importante a ser colocado é que um nó de browser é utilizado para auxílio à navegação, com o intuito de procurar ajudar o usuário a se localizar, mostrando-lhe sua vizinhança. Não é permitido, contudo, que o usuário navegue diretamente para um nó selecionando-o no browser - como permitem, por exemplo, os sistemas PlanText [Gullichsen 88] e NoteCards [Halasz 88]. Entretanto, é necessário avaliar se este tipo de permissão não pode confundir o usuário em sua navegação, uma vez que permitir a seleção de qualquer nó no browser pode ser interpretado como a seleção de uma ligação inexistente entre o nó atual e o destino. Se essa operação for oferecida, deve-se estudar, cuidadosamente, que tratamento dar a tal situação.

\subsubsection{Navegação em Caminhos Pré-Definidos}

Consideramos como pertinentes a este item três tipos de navegação implementados no SBx: a navegação direta ao nó imediatamente anterior no percurso realizado, a navegação direta para qualquer nó existente no percurso e a herança de contextos.

Navegação para o Nó Imediamente Anterior: esta navegação corresponde à seleção de uma ligação existente entre o nó atual e o anterior, back. Apesar desta ligação, na maioria das vezes, não existir explicitamente, consideramos que a navegação relacionada deve ser sempre implementada. Akscyn [Akscyn 88] comenta que, em estudos realizados por sua equipe, para cada seleção de ligação realizada, o usuário requisita uma navegação para o nó anterior. Vimos, então, a necessidade de permitir, no SBx, essa operação.

Navegação para algum Nó Anterior: esta operação pode ser vista como uma extensão da anterior e a implementamos com o objetivo de dar mais opções, e velocidade, quando o usuário decide retomar a navegação a partir de ponto já visitado. 
Herança de Contextos: colocamos novamente neste ponto a herança de contextos. Quando o criador define qual o escopo para uma determinada ligação, ele, na realidade, está definindo caminhos pelos quais os diversos tipos de usuário podem navegar. Para um mesmo conjunto de nós, podem existir inúmeros conjuntos de caminhos, definidos para tipos distintos de usuários.

Neste aspecto, uma expansão do sistema pode ser a implementação, para cada nó e escopo de usuário comum, de uma facilidade que permita a seleção automática de uma ligação.

Como consideração final, em relação a este assunto, gostaríamos de colocar um dado importante. Segundo Katz [Katz 89], em estudo realizado com alunos na navegação de hiperdocumentos dedicados ao ensino, quando se oferece aos alunos um caminho pré-definido para navegar, $95 \%$ deles navegam apenas pelo precurso pré-definido. Um dado desanimador.

\subsection{Criação de Hiperdocumentos}

Permitimos três vantagens básicas ao usuário criador:

1. visualização de todas as ligações existentes em cada nó;

2. operações de criação e remoção de ligações, criação de nós de texto e troca de ligações - tanto da âncora quanto do destino.

3. operações normais de edição no conteúdo dos nós de texto, desde que nâo envolvam as âncoras existentes.

Discutimos, a seguir, as responsabilidades envolvidas na criação de hiperdocumentos e também as vantagens oferecidas pelo sistema.

7.5.1 Visualização de todas as ligações

Uma vez que o sistema identifica o usuário corrente como um criador, ele deixa de verificar o escopo de acesso das ligações embutidas em cada nó. Com isso, o criador tem conhecimento de todas as ligações existentes em cada nó. Não 
implementamos um controle de diferenciação entre usuários criadores, o que pode ser necessário no caso de algumas aplicações. Tal controle pode ser realizado como uma extensão do SBx.

\subsubsection{Operações sobre as Ligaçōes}

Além das operações de navegação, permitimos ainda que o criador realize três tipos de operações sobre ligações:

- criação: o criador pode selecionar um item de texto dentro de um nó e requisitar que àquele item seja relacionada uma ligação. 0 sistema então obtém os dados de arquivo destino, escopo, tipo e posição de apresentação do nó na tela (caso não seja uma ligação de execução). No caso do arquivo destino não existir, o sistema providencia a criação de um arquivo vazio.

- remoção: o usuário pode requisitar, a qualquer momento, que a ligação relacionada a uma âncora seja eliminada. O sistema remove a âncora, mas o arquivo destino não é afetado.

- troca: duas opções possíveis são fornecidas ao usuário, a troca do item de definição de âncora e a troca do arquivo destino da ligação.

\subsubsection{Operaçōes de Edição}

Permitimos ao usuário realizar as operações de edição normais fornecidas pelo sistema Smalltalk, como por exemplo cópia, eliminação e seleção de texto. Porém, essas operações são permitidas apenas quando não se referem a ítens de âncora, uma vez que estes podem ser acessados, apenas, ratravés das operações especiais definidas anteriormente.

\subsection{Adaptação de Documentos}

Uma das vantagens de utilizarmos, na implementação do SBx, o padrão ASCII para gerenciamento do conteúdo dos arquivos, é que qualquer trabalho existente nesse padrão pode ser aproveitado para geração de hiperdocumentos. 
Não implementamos, porém, nenhum tipo de ferramenta especial que auxilie o criador a realizar automaticamente a geração de ligações, definição de escopos de nós ou deteç̧ão de referências implícitas nos documentos, aspectos importantes quando se fala da adaptação de documentos já existentes. Esta, como colocamos na seção 4.5 , é uma área de pesquisa que ainda está dando seus primeiros passos.

\subsection{Controle de Versões}

O SBx não possui facilidades para controle de versões. Porém, julgamos que este assunto pode ser objeto de estudo no futuro, dependendo das aplicações para as quais o sistema seja utilizado.

\subsection{Trabalho Cooperativo}

Uma vez que o sistema foi implementado para execução em microcomputadores PC-compatíveis, em modo mono-usuário, não implementamos controles sobre trabalho cooperativo. Caso este sistema seja transportado para um ambiente multiusuário, será necessário estudar esse aspecto.

\subsection{Expansões Sugeridas}

Apresentamos a seguir uma lista das expansões, sobre o sistema implementado, que foram sugeridas no decorrer deste capítulo.

- alteração do editor de textos para aceitar todos os caracteres da língua portuguesa;

- implementação esquema ponto-a-ponto para relacionamento entre nós;

- implementação do tipo de nó com informações gráficas;

- permissão da inibição momentânea dos caracteres de indicação de ligação;

- discussão das implicaçôes da navegação através do browser e a sua imple mentação; 
- reconhecimento de criadores de prioridades distintas;

- implementação de percursos pré-definidos;

- implementação de controle de versões;

- levantamento de requisitos necessários às aplicações específicas. 


\section{Capítulo 8}

\section{Conclusão}

Apresentamos neste trabalho vários dos aspectos relacionados à definição, à utilização e ao projeto de sistemas hipertexto. Além disso, formulamos uma proposta para a solução dos principais aspectos envolvidos no projeto deste tipo de sistemas e mostramos a viabilidade de nossa proposta realizando a sua implementação. Acreditamos ter sido este um trabalho pioneiro a nivel nacional.

Mostramos, também, muitas das vantagens trazidas com a utilização dos sistemas hipertexto em diversas aplicaçöes. Julgamos conveniente relembrar as vantagens mais importantes, tanto do ponto de vista do usuário comum como do ponto de vista do autor de hiperdocumentos. Em relação ao autor, podemos dizer que as vantagens dos sistemas hipertexto incluem:

- facilidades para realizar a estruturação do documento da forma que julgar mais conveniente;

- facilidade para modularizar suas idéias, além de poder fazer referência a um mesmo conteúdo quantas vezes julgar necessário;

- a facilidade de estabelecimento de ligacões permite o armazenamento e a estruturação de grande quantidade de informacões.

Em relação ao usuário de um sistema hipertexto, podemos citar as seguintes vantagens:

- a facilidade de navegação estimula o usuário a pesquisar na base de conhecimento; 
- a flexibilidade da ferramenta permite que os mais diversos tipos de informação sejam relacionados;

- opçães como o browser fornecem uma visão geral da posição do usuário em relação ao documento;

- o acesso à informação torna-se mais confiável, pois o fato de eliminarmos a repetição de informação, ao realizarmos referências a um mesmo nó, diminui o risco de inconsistencias;

- o trabalho cooperativo, quando suportado, auxilia todas as tarefas desenvolvidas em grupo;

- o controle automático de versões auxilia o gerenciamento das atividades envolvidas com quaisquer aplicações;

- os sistemas básicos permitem grande flexibilidade para atender às aplicações específicas;

- o número de tipos de aplicações que, podem explorar as vantagens dos sistemas hipertexto é praticamente ilimitado.

Entretanto, mostramos que existem alguns problemas na utilização de sistemas hipertexto, entre eles:

- a grande quantidade de informação pode fazer com que o usuário torne-se confuso e preocupado em assimilar uma quantidade de conhecimento em um ritmo insalubre;

- a flexibilidade de navegação pode, às vezes, fazer com que o usuário se desvie, ou mesmo se perca, do caminho necessário para a obtenção da informação desejada;

- a falta de obrigatoriedade, por parte do usuário, em seguir determinado percurso, torna, às vezes, mais complexo o trabalho do aütor.

Ressaltamos que um dos aspectos mais importantes sobre os sistemas hipertexto é o fato de serem uma ferrament $a$ muito especial. A flexibilidade e liberdade fornecida aos usuários do sistèma é que o tornam extremamente atraente para as mais diversas aplicações. Mas essa flexibilidade e liberdade têm criado novos problemas, que precisam ser solucionados. 
Os principais problemas em aberto sobre o tema, e as pesquisas em andamento mais divulgadas, fornecem-nos uma visão das difuculdades que os pesquisadores têm procurado superar:

- estudos sobre a interface com o usuário, que sem dúvida deve ser a mais amigável possivel;

- como auxiliar o usuário a encontrar o que procura (pesquisas automáticas na base de dados, algoritmos eficientes, definição de sinônimos, ferramentas gráficas para navegação e informação do contexto, definição de estruturas obrigatórias para armazenamento das informações, ferramentas para acesso cada vez mais rápido às informações armazenadas tanto local como remotamente, geracão automática de índices para a localização das informações, etc.);

- como auxiliar o autor a gerar os hiperdocumentos (quando ferramentas desse tipo são realmente necessárias, ferramentas para auxílo à estruturação da informação, ferramentas para catalogação da informação armazenada, etc.);

- como e quando formalizar os aspectos envolvidos com os sistemas;

- como levantar os requisitos que os sistemas devem atender às aplicações específicas; etc.

Com base nos estudos realizados, chegamos à proposta do projeto de um sistema que possui todas as características básicas de hipertexto, ao qual denominamos SBx.

O SBx pode ser utilizado para quaisquer aplicações cujos requisitos sejam atendidos por um sistema básico de hipertexto. Além disso, pode servir de base para a definição de sistemas mais específicos, desde que realizadas as extensões definidas por um prévio levantamento de requisitos.

Realizamos, também uma implementação que considerou todos os pontos definidos no projeto do $\mathrm{SBx}$, através da qual pudemos comprovar a validade da nossa proposta.

A importância e a atualidade da pesquisa nesta área é tal que já conta com simpósios internacionais específicos como o Hypertext 87 e 89, além de diversos estudos especiais em publicaçōes como a CACM (julho 1988), Byte (outubro 1988) e Computer (janeiro 1988). A nível nacional, o tema está sendo objeto de 
atenção em congressos (Semicro 1989, Congresso da Sociedade Brasileira de Computação 1989, Congresso Nacional de Informática - SUCESU 1989) e conferências [Katz 89], [Chaia 89].

Mostramos, também, que o campo de aplicação dos sistemas hipertexto é muito vasto. Consideramos importante enfatizar, entretanto, que o uso da ferramenta hipertexto, para qualquer aplicação, deve ser precedido de um cuidadoso levantamento dos requisitos a serem atendidos pelo sistema, de modo que ele possa servir eficientemente à aplicação em questão. Esse levantamento possibilita a identificação de quaisquer extensões que se façam necessárias sobre um sistema base, para torná-lo compatível com as necessidades da aplicação.

Outro aspecto muito importante a salientar é o fato de que, como uma ferramenta para uso para aplicações específicas, o sistema deve ser utilizado por pessoas que tenham domínio sobre a área de, aplicação em questão. Caso isso não ocorra, de nada valerão o levantamento de requisitos e a ferramenta dele resultante. Por exemplo, de nada adianta a construção de um sistema hipertexto com extensões especiais para aplicação ao ensino, se os hiperdocumentos forem criados por uma pessoa sem a capacitação científica e pedagógica necessária. Os sistemas hipertexto criam um ambiente propício à realização de inovações e o desenvolvimento de novas idéias, a sua importância tem sido comparada à invenção da imprensa mas, como Schulley [Schulley 89] afirma, é bom lembrar que a imprensa não escreveu nenhum livro em todos esses anos: são os autores que escrevem os livros. $\mathrm{O}$ mesmo ocorre com a tecnologia de sistemas hipertexto.

Qual o futuro dos sistemas hipertexto? Concordamos com alguns autores que os sistemas hipertexto vão estar presente em todas as situações em que a organização, recuperação e apresentação da informação armazenada nos mais diversos tipos de equipamentos, se façam necessários. A maioria dos autores acredita que os sistemas hipertexto estarão indubitavelmente entre as principais ferramentas das próximas décadas.

Vale colocarmos agora uma dúvida: até onde os sistemas hipertexto serão utilizados para o armazenamento e recuperação das informações apresentadas, hoje em dia, de forma seqüencial? Todos os meios de comunicação escrita serão substituídos?

Acreditamos que os sistemas hipertexto vão invadir as fronteiras nas quais hoje reinam apenas a literatura impressa. Porém, acreditamos também que, para algumas aplicaçôes, os dois sistemas coexistirão. Julgamos que ocorrerá uma divisão das aplicações, e que parte delas continuará a fazer uso conjunto tanto da representação convencional como da representação em hiperdocumentos. Uma 
aplicação na qual acreditamos, e esperamos, isso irá ocorrer é na literatura não técnica.

$\mathrm{O}$ assunto é amplo, atual e extremamente interessante. Existe, sem dúvida, muito trabalho para ser realizado nesta área. Acreditamos, com este trabalho, ter contribuído com a pesquisa sobre o tema. 


\section{Apêndice A}

\section{Figuras}

Reunimos neste apêndice algumas ilustrações referenciadas durante o trabalho e que correspondem a imagens de sistemas hipertexto.

Junto a cada figura colocamos:

- a referência ao artigo no qual a imagem foi obtida acompanhada do número da página;

- as seções nas quais a imagem é referenciada. 


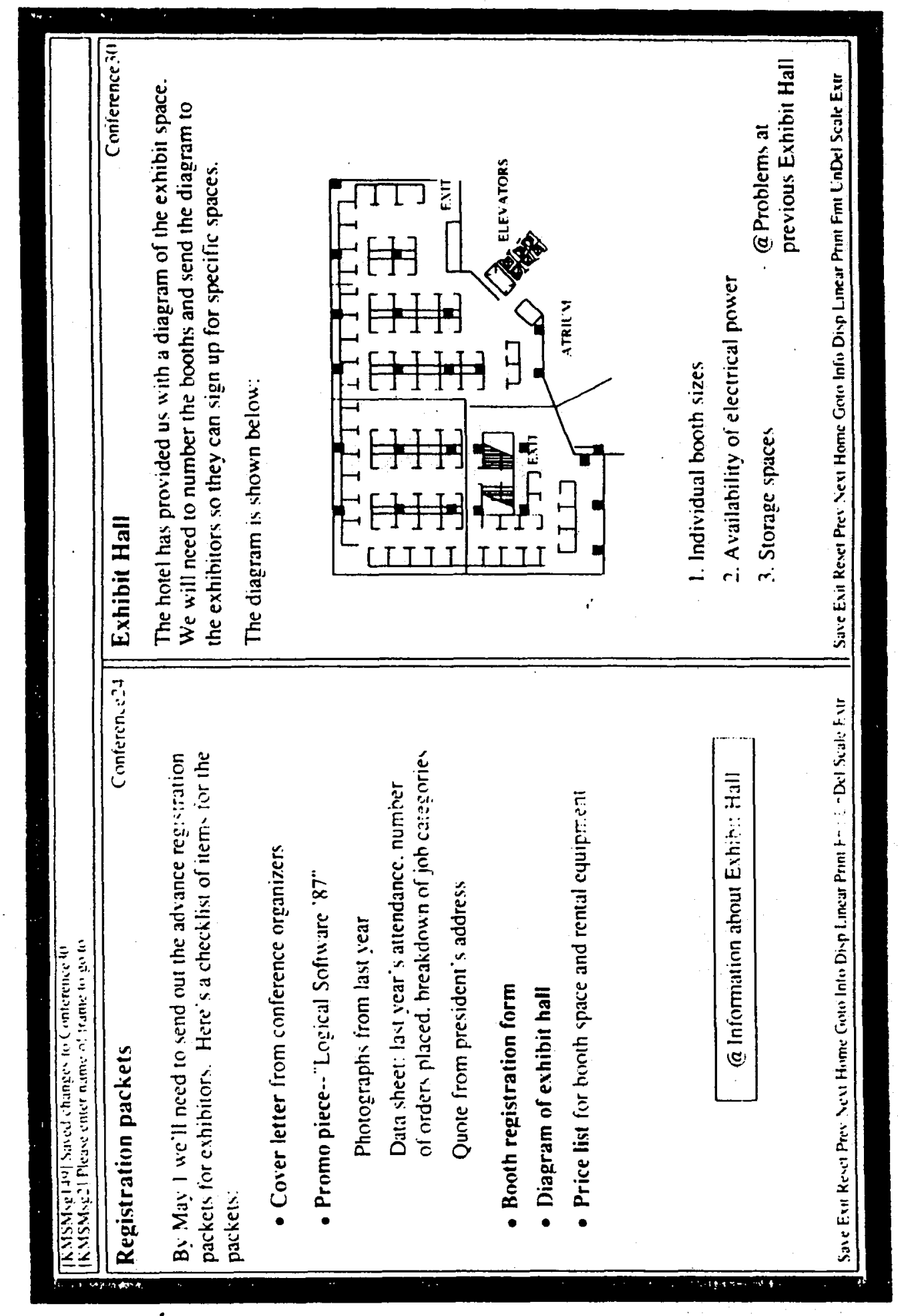

Figura A.1: Sistema KMS [Akscyn 88][pp 825]

- evolução histórica, seção 3

- divisão de um documento, seção 4.1.1

- alguns sistemas existentes, seção 5.4 
Plan for brochure cover

Here is the current mockup of the cover design for our brochure.

Please feel free to make comments.

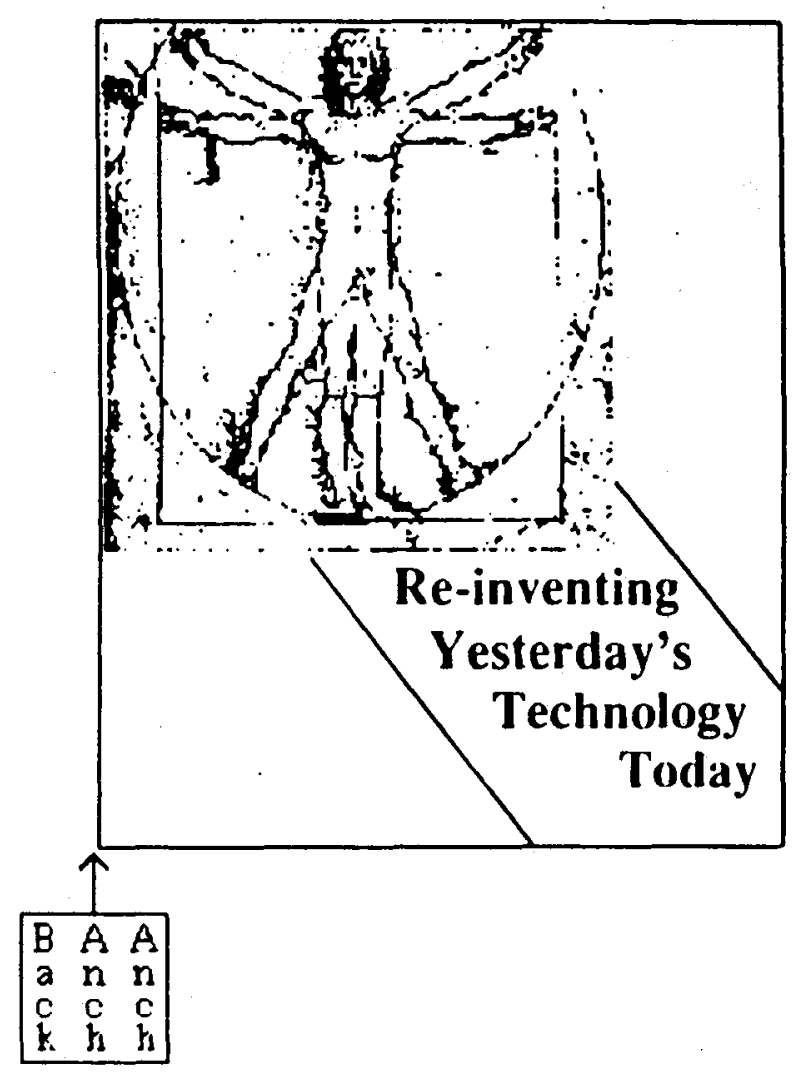

- @Make backup,tape

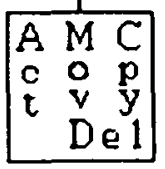

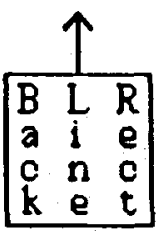

-@Comments

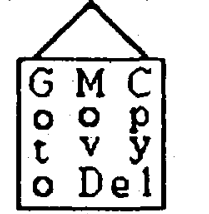

-@Alternative images

-@Old versions

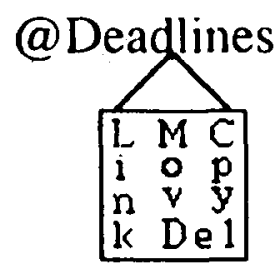

Save lixil Resel Prev Nexı Home Goto Info Disp Linear Print Fimı UnDel Scale Extr Grav

Figura A.2: Sistema KMS [Akscyn 88][pp 826]

- evolução histórica, seção 3

- tipos de nó, seção 4.1.2

- visualização da ligação, seção 4.2 .4

- alguns sistemas existentes, seção 5.4 


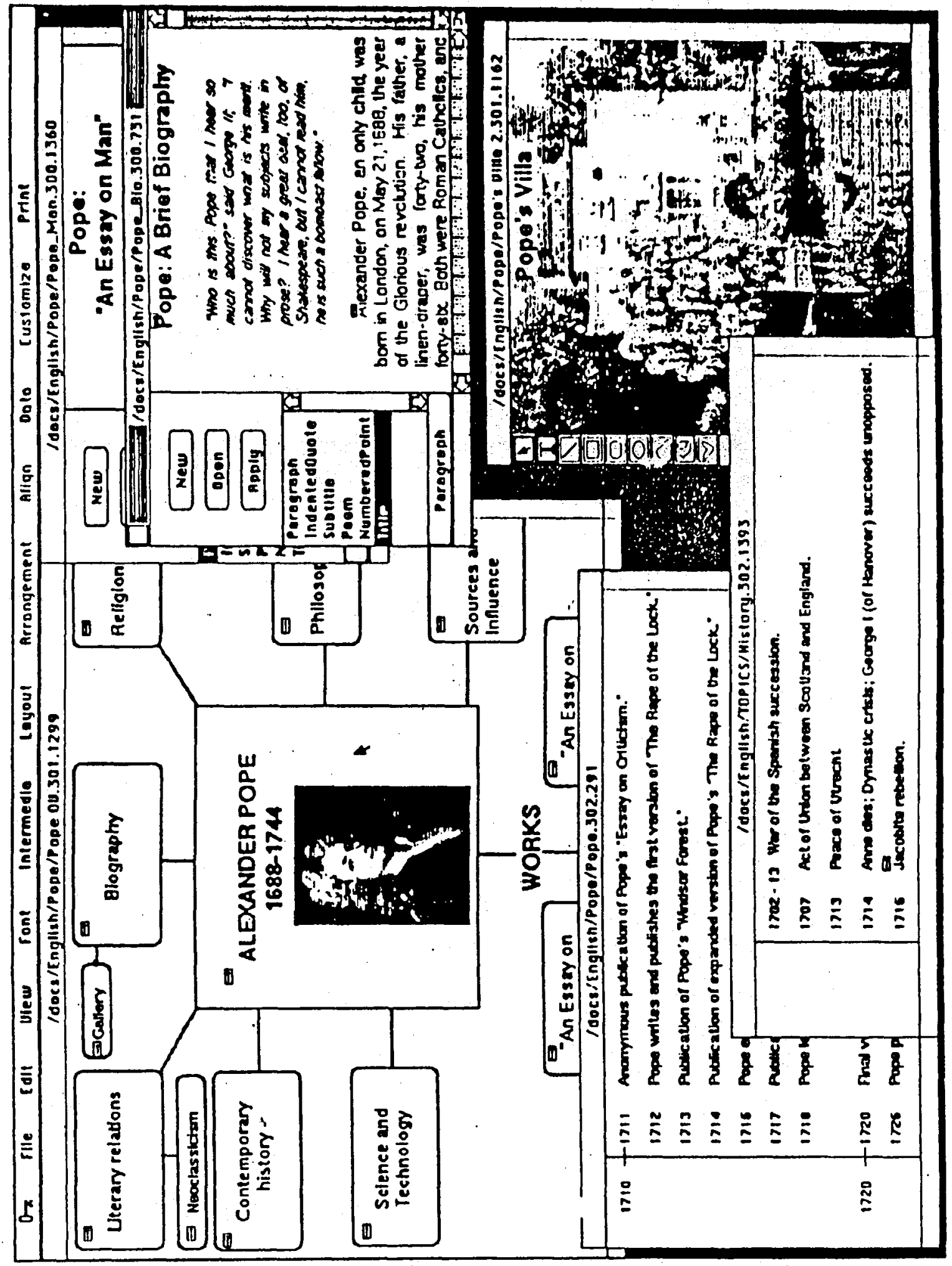

Figura A.3: Sistema Intermedia [Yankelovich 88][pp 83]

- evolução histórica, seção 3

- tipos de nó, seção 4.1.2

- alguns sistemas existentes, seção 5.2 

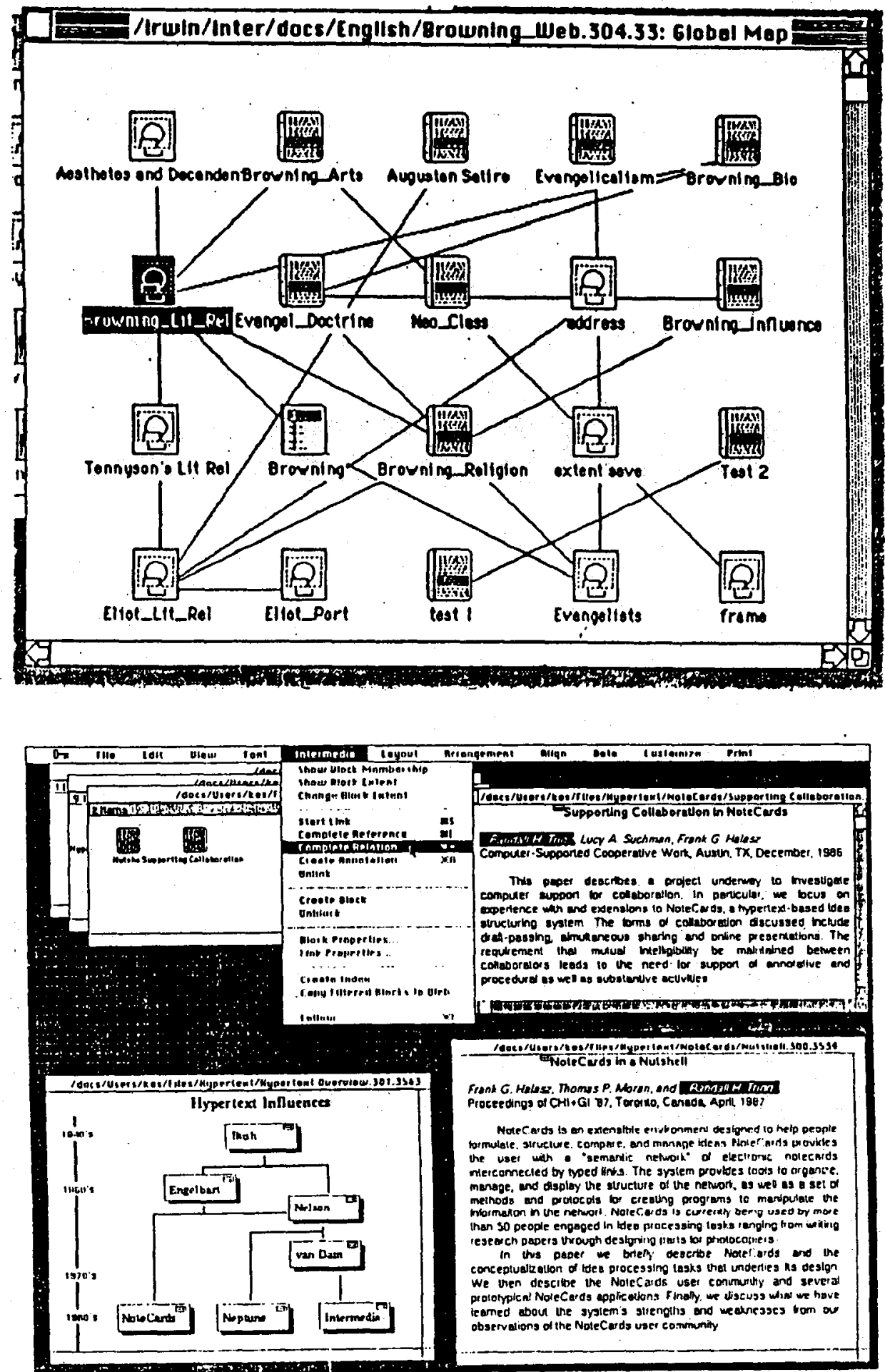

Figura A.4: Sistema Intermedia [Smith 88][pp 38-39]

- evolução histórica, seção 3

- visualização da ligação, seção 4.2.4

- navegação em um grafo de nós e ligações, seção 4.3.4

- alguns sistemas existentes, seção 5.2 


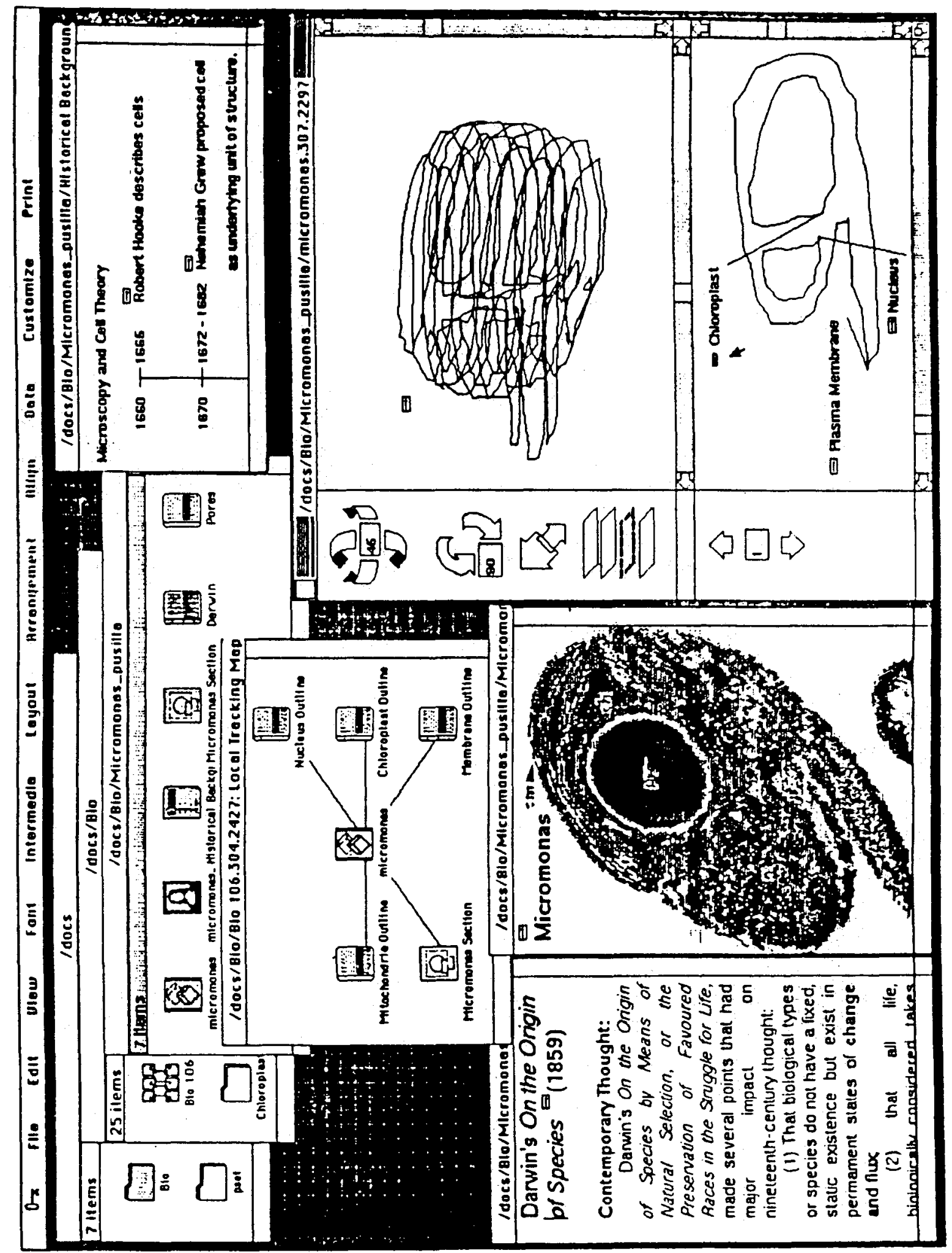

Figura A.5: Sistema Intermedia [Conklin 87][pp 28]

- evolução histórica, seção 3

- alguns sistemas existentes, seção 5.2 


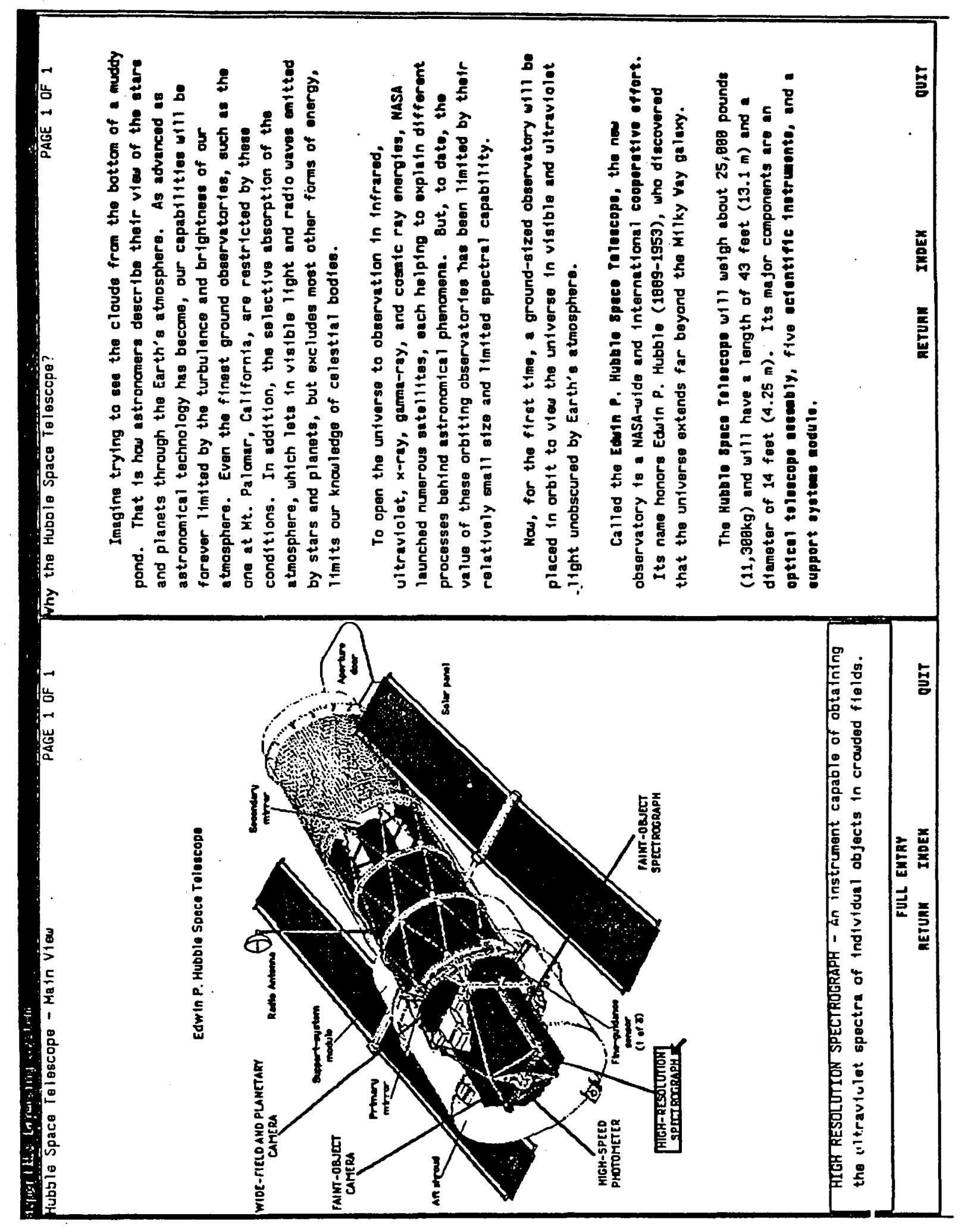

Figura A.6: Sistema Hyperties [Marchionini 88][pp 75]

- evolução histórica, seção 3 - divisão de um documento, seção 4.1.1

- visualização da ligação, seção 4.2.4 


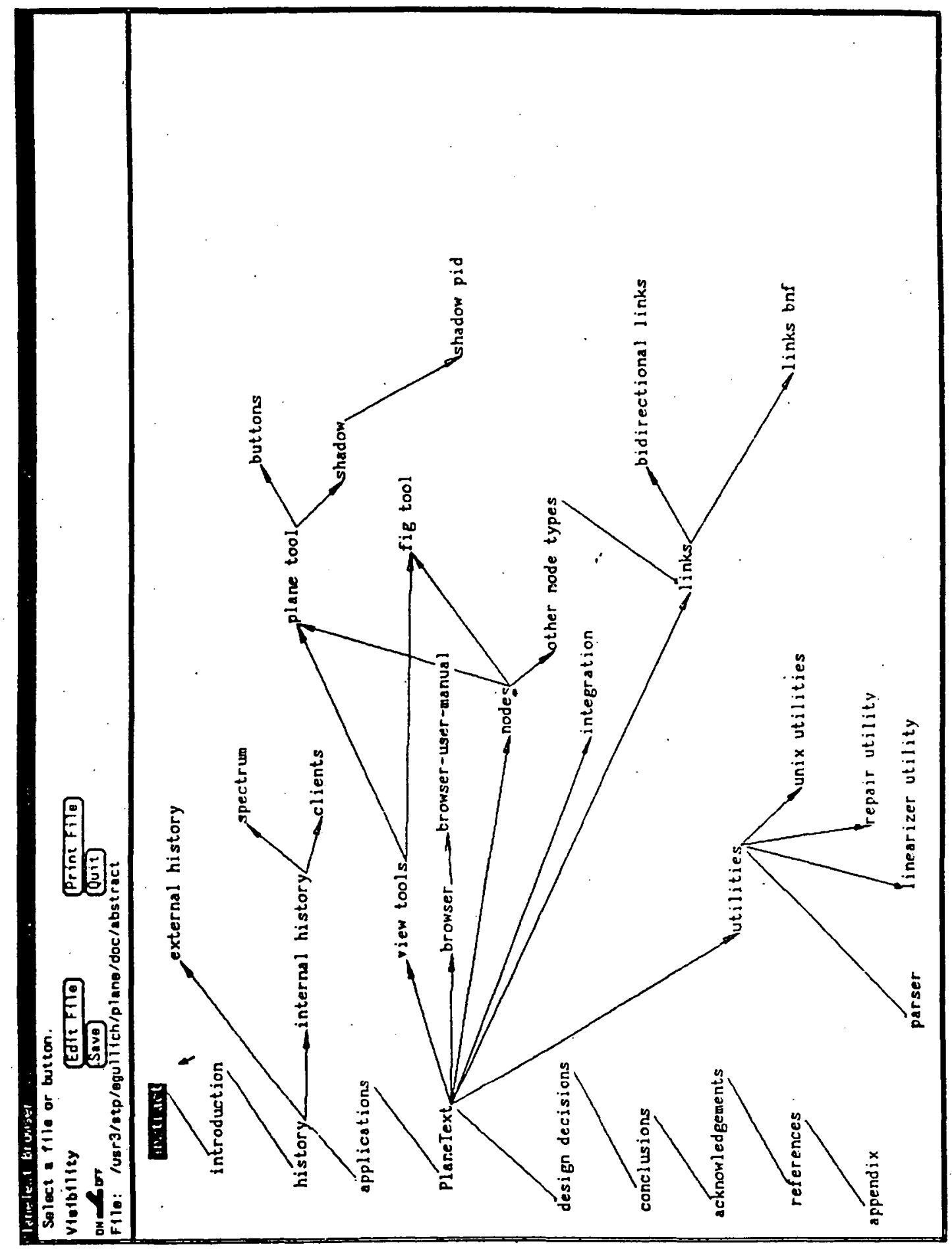

Figura A.7: Sistema PlanText [Gullichsen 88][pp ii]

- evolução histórica, seção 3 - navegação em um grafo de nós e ligações, seção 4.3.4 


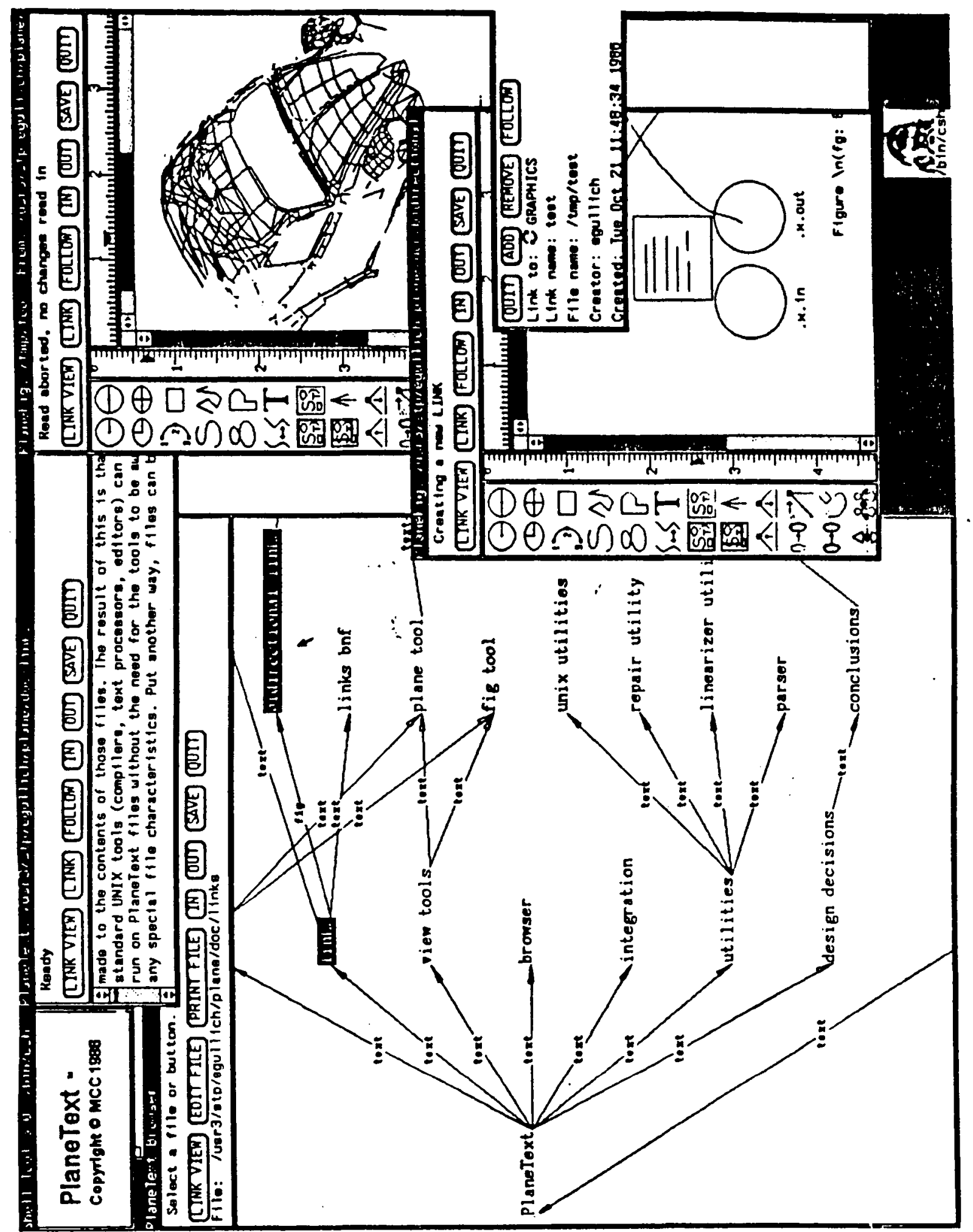

Figura A.8: Sistema PlanText [Conklin 87][pp 34]

- evolução histórica, seção 3 


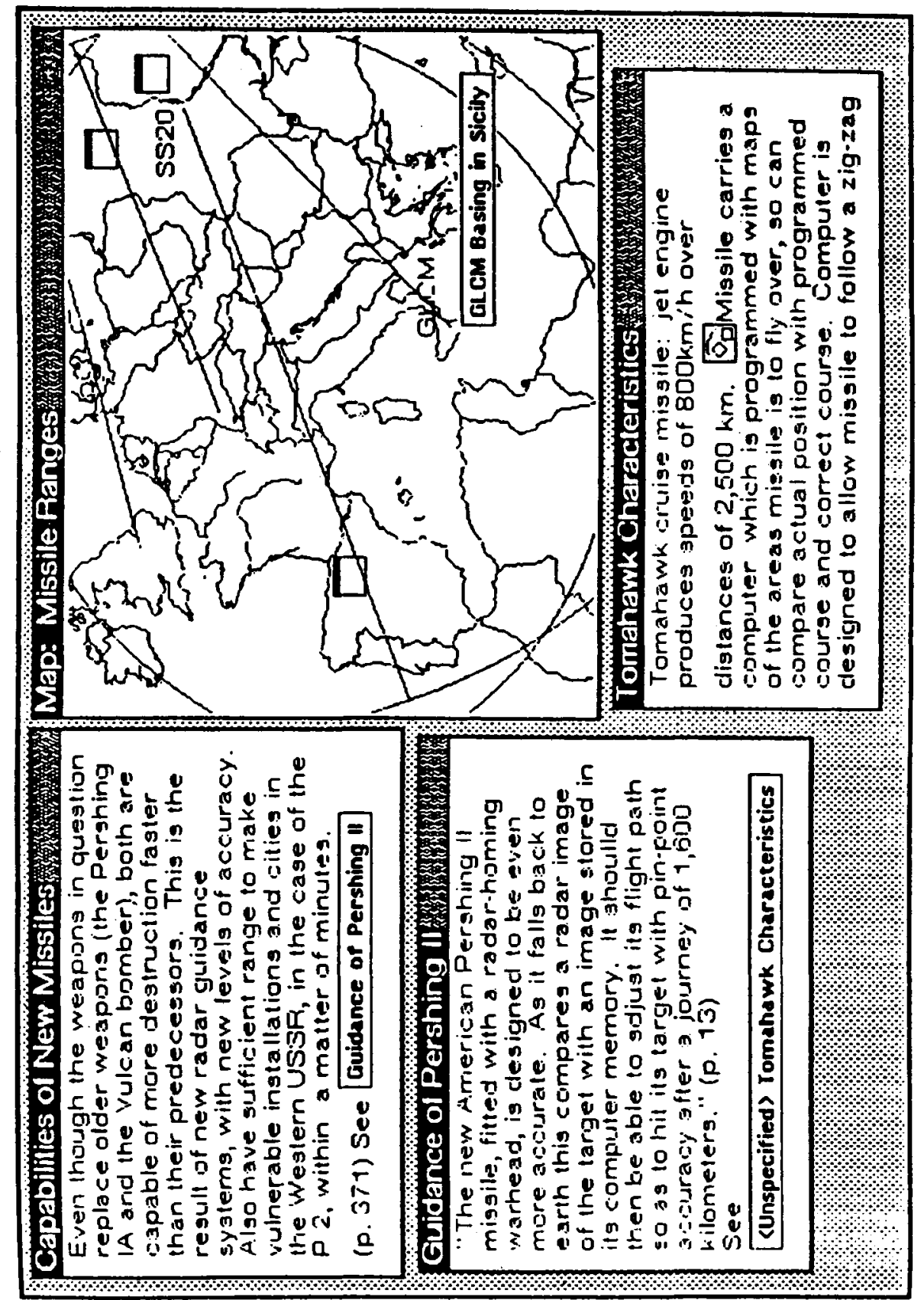

Figura A.9: Sistema NoteCards [Halasz 88][pp 837]

- evolução histórica, seção 3

- divisão de um documento, seção 4.1.1

- visualização da ligação, seção 4.2 .4

- alguns sistemas existentes, seção 5.3 


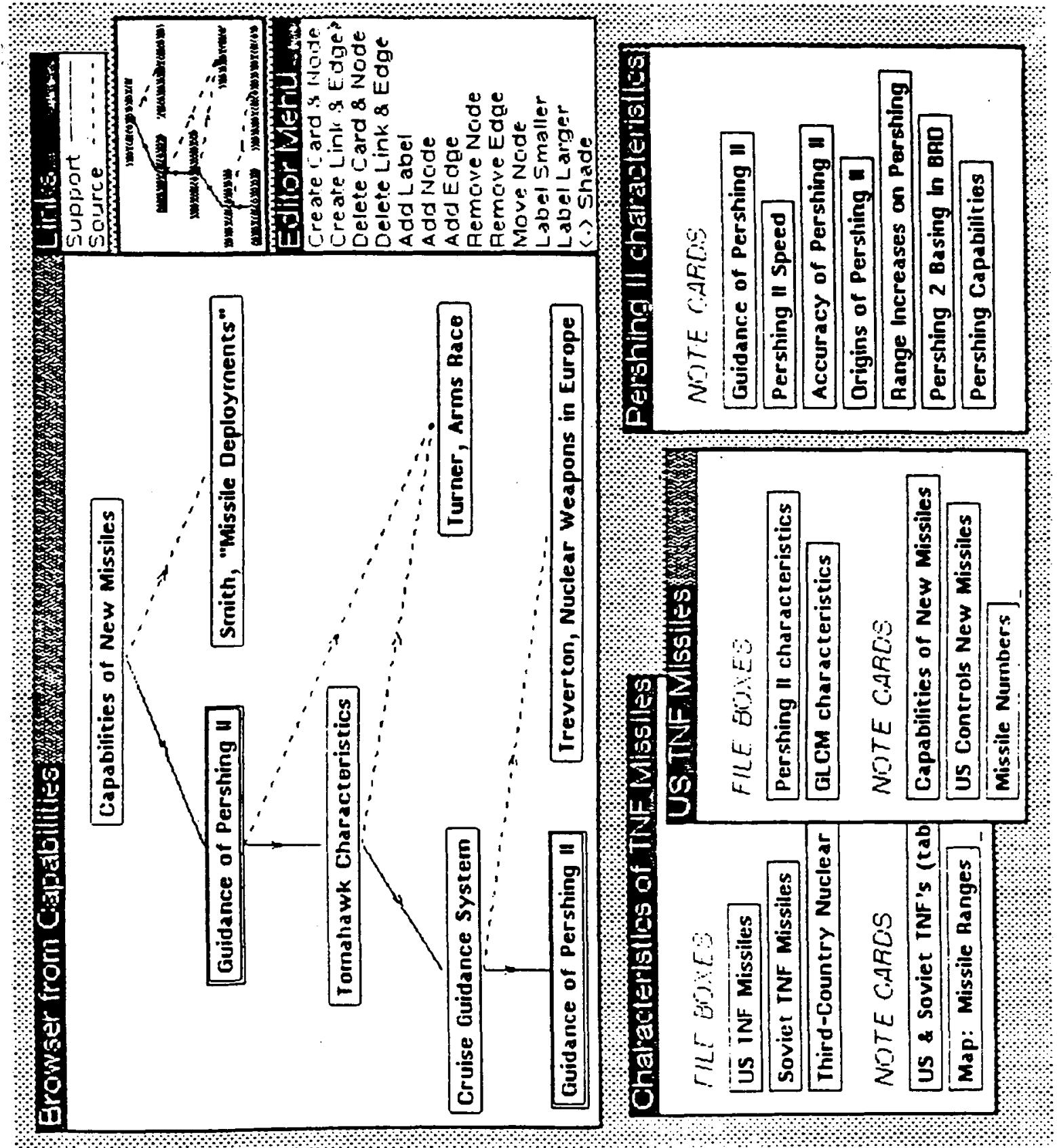

Figura A.10: Sistema NoteCards [Halasz 88][pp 838]

- evolução histórica, seção 3

- uso da estruturação existente, seção 4.3.5

- tipos de nó, seção 4.1.2

- alguns sistemas existentes, seção 5.3 


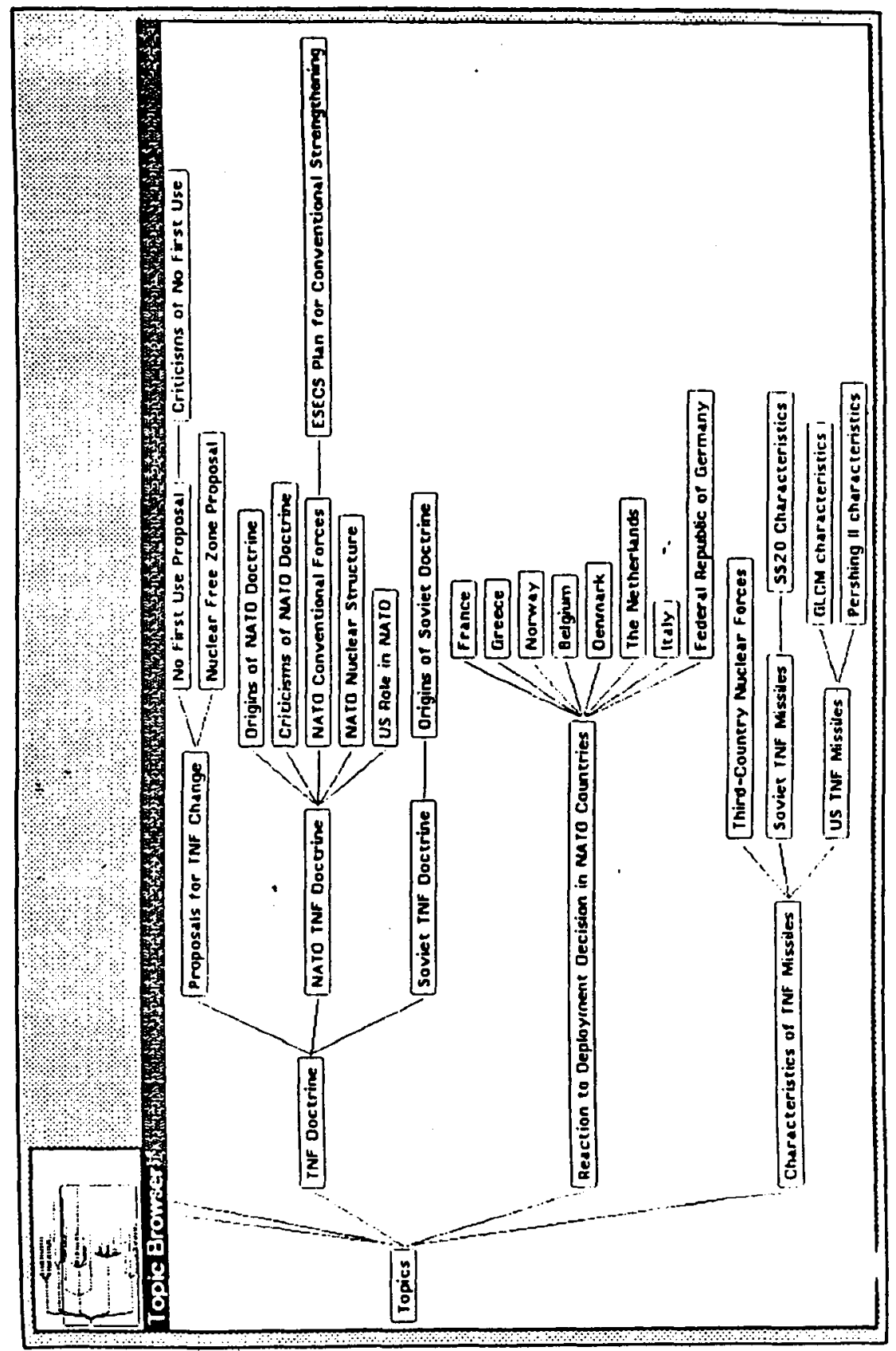

Figura A.11: Sistema NoteCards [Halasz 88][pp 839]

- evolução histórica, seção 3 - navegação em um grafo de nós e ligações, seção 4.3.4 


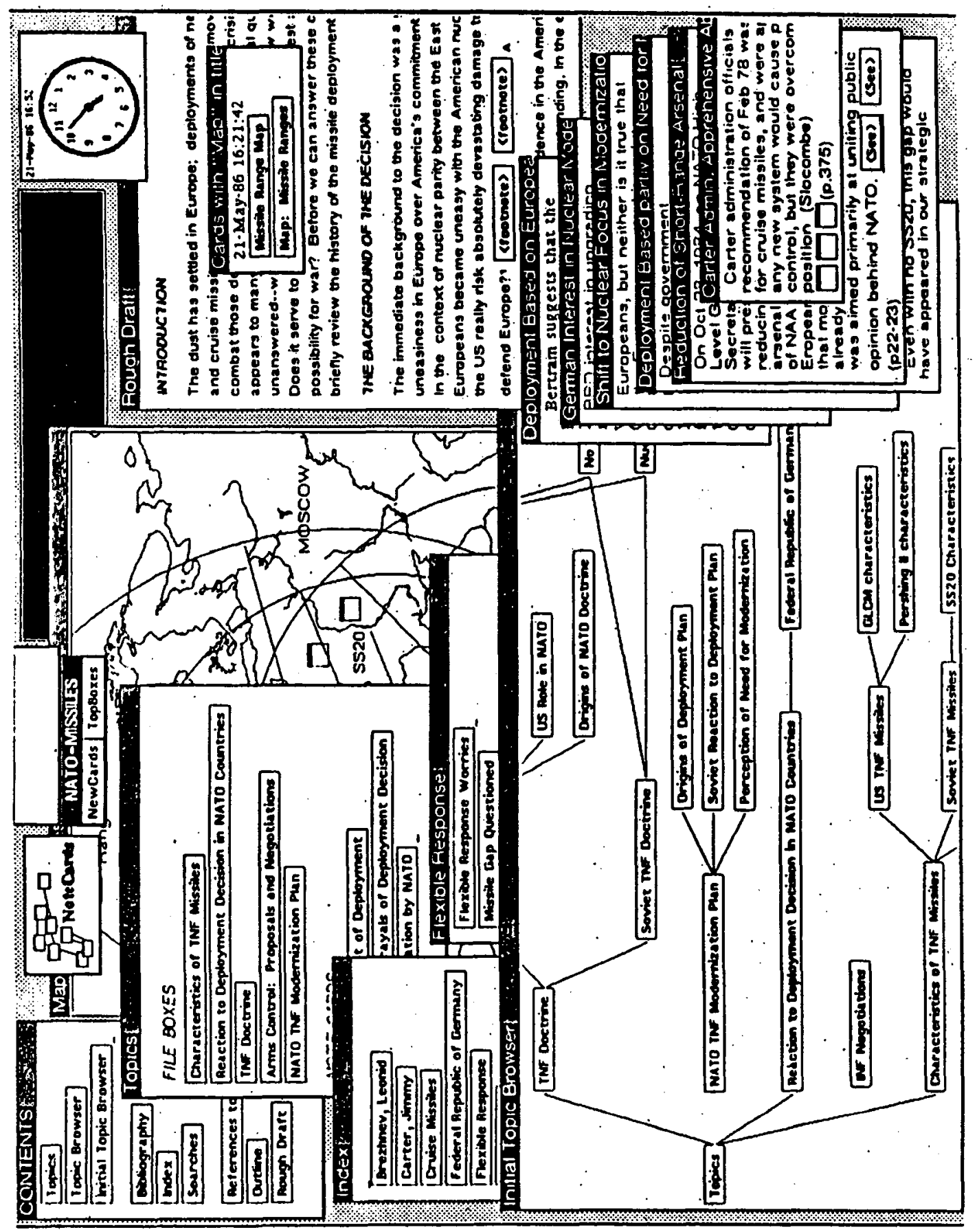

Figura A.13: Sistema NoteCards [Conklin 87][pp 56]

- evolução histórica, seção 3

- navegação em um grafo de nós e ligações, seção 4.3.4

- alguns sistemas existentes, seção 5.3 


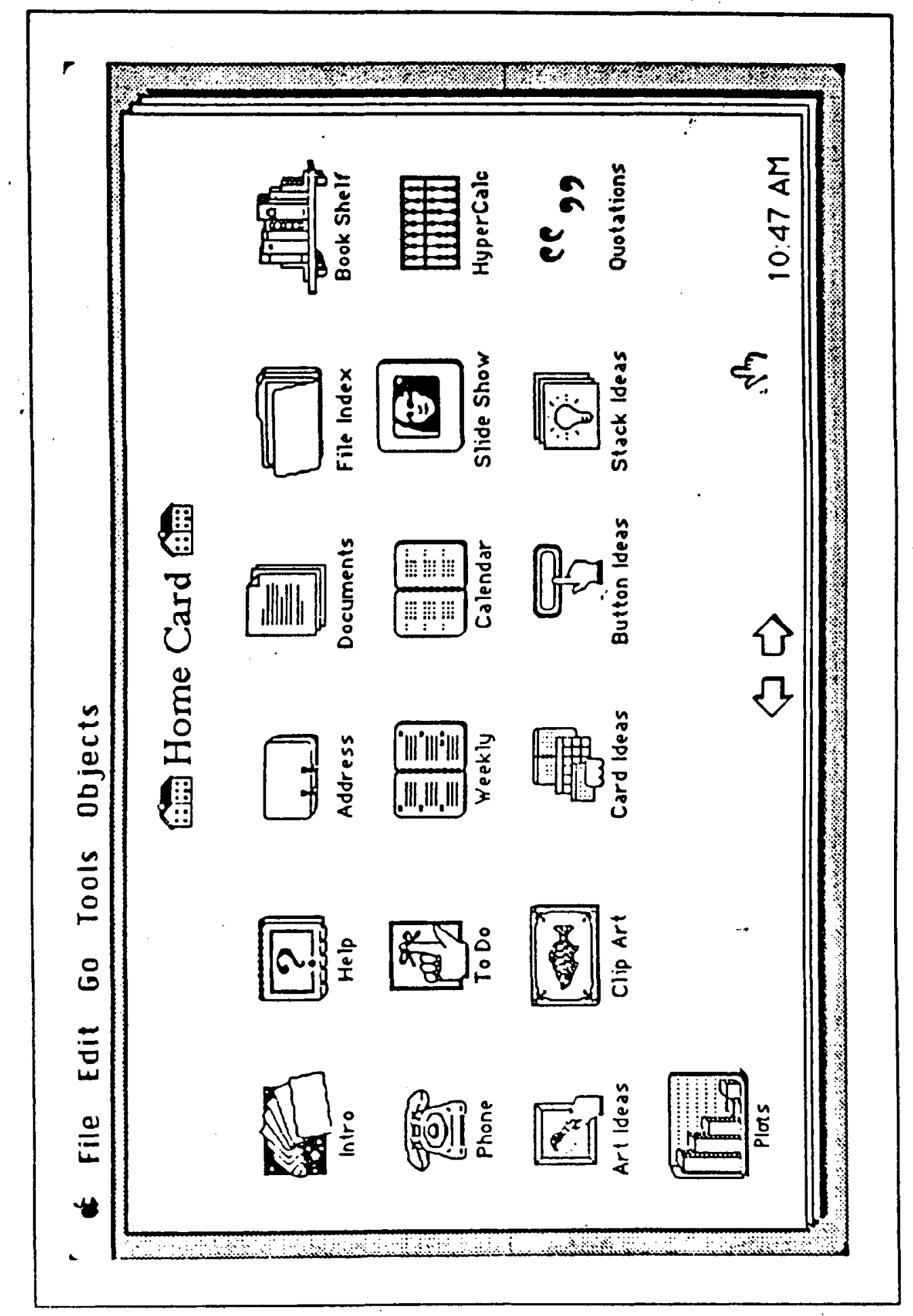

Figura A.14: Sistema HyperCard [Williams 87][pp 110]

- evolução histórica, seção 3 


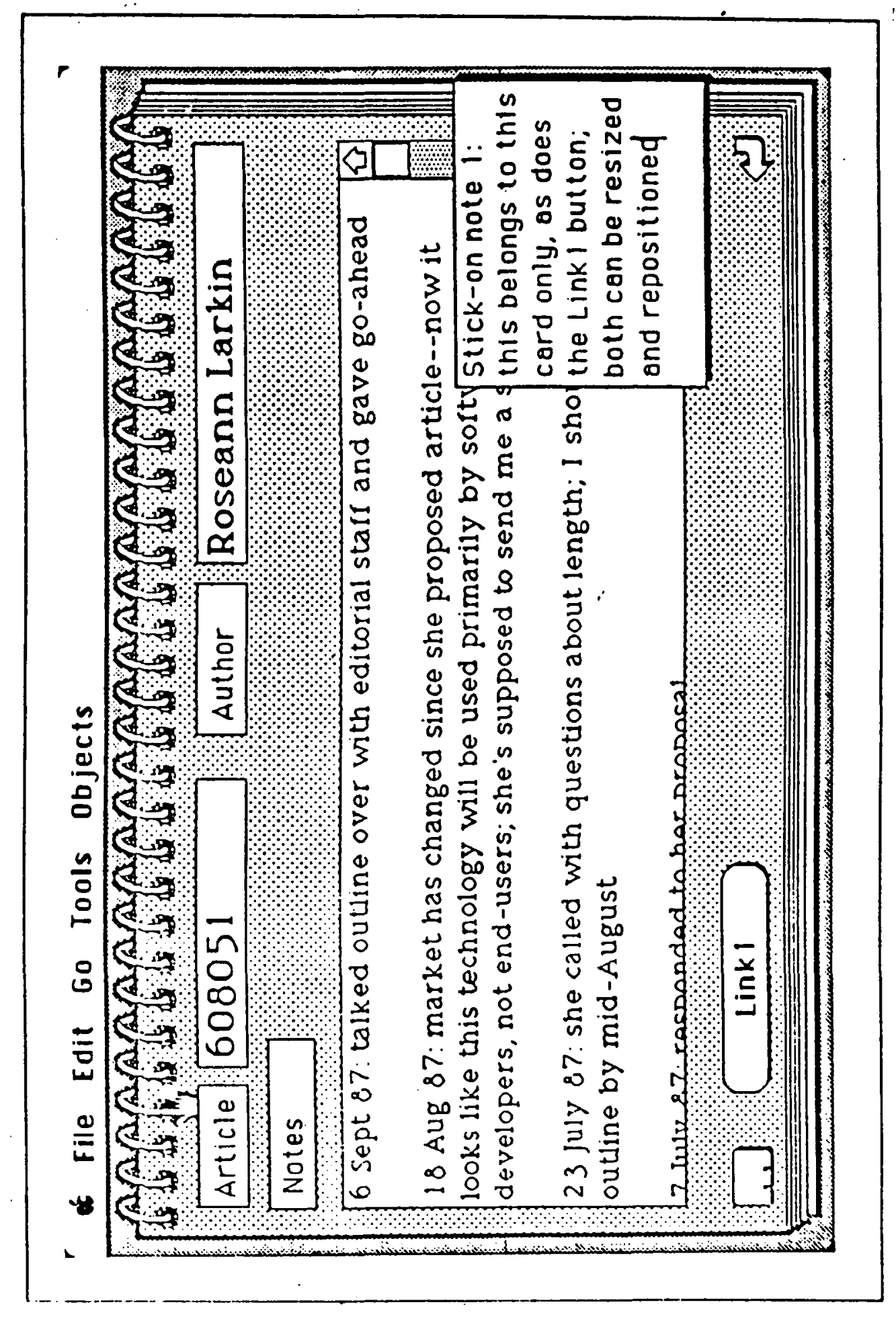

Figura A.15: Sistema HyperCard [Williams 87][pp 110]

- evolução histórica, seção 3 


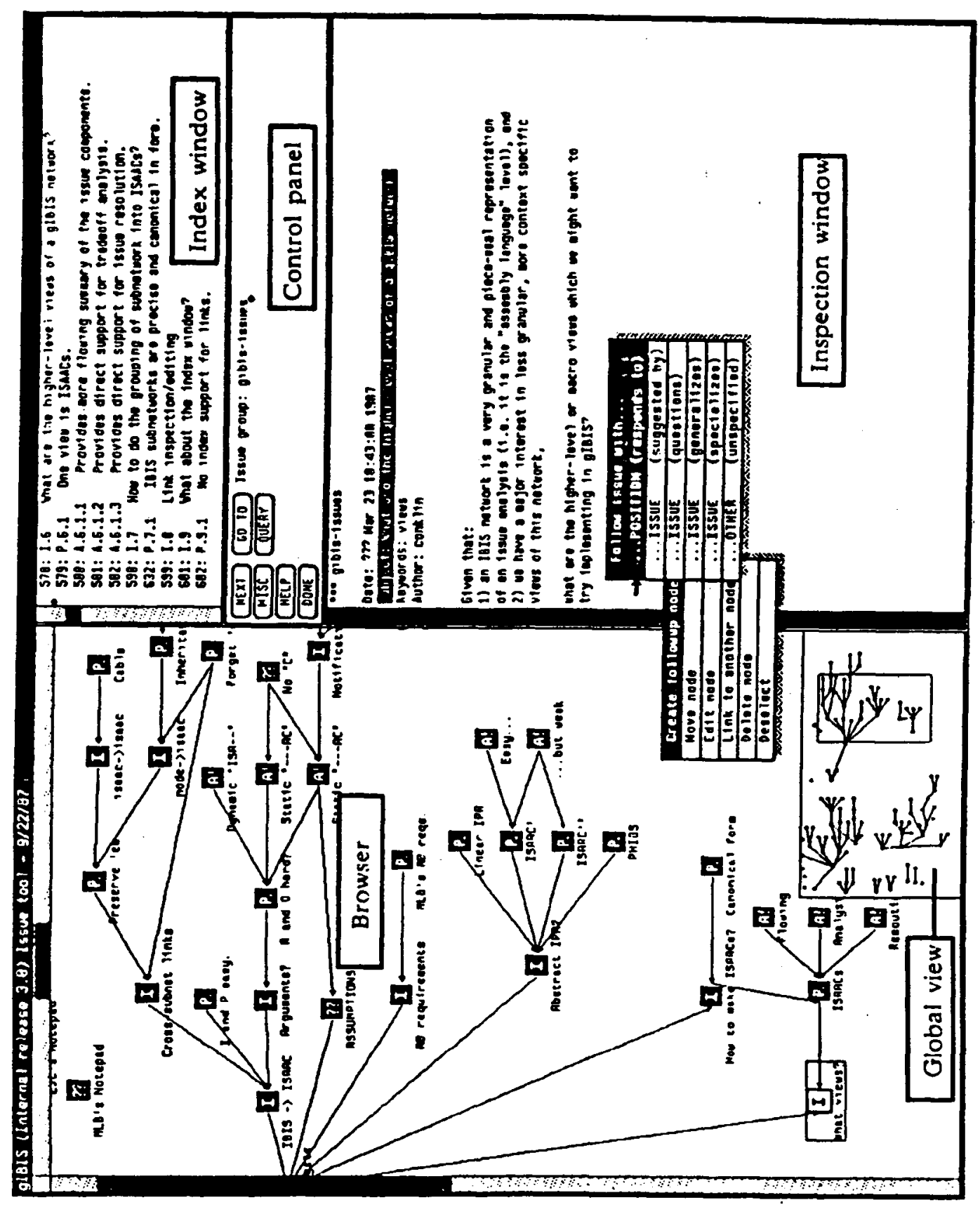

Figura A.16: Sistema gIBIS [Conklin 87][pp 18]

- evolução histórica, seção 3 


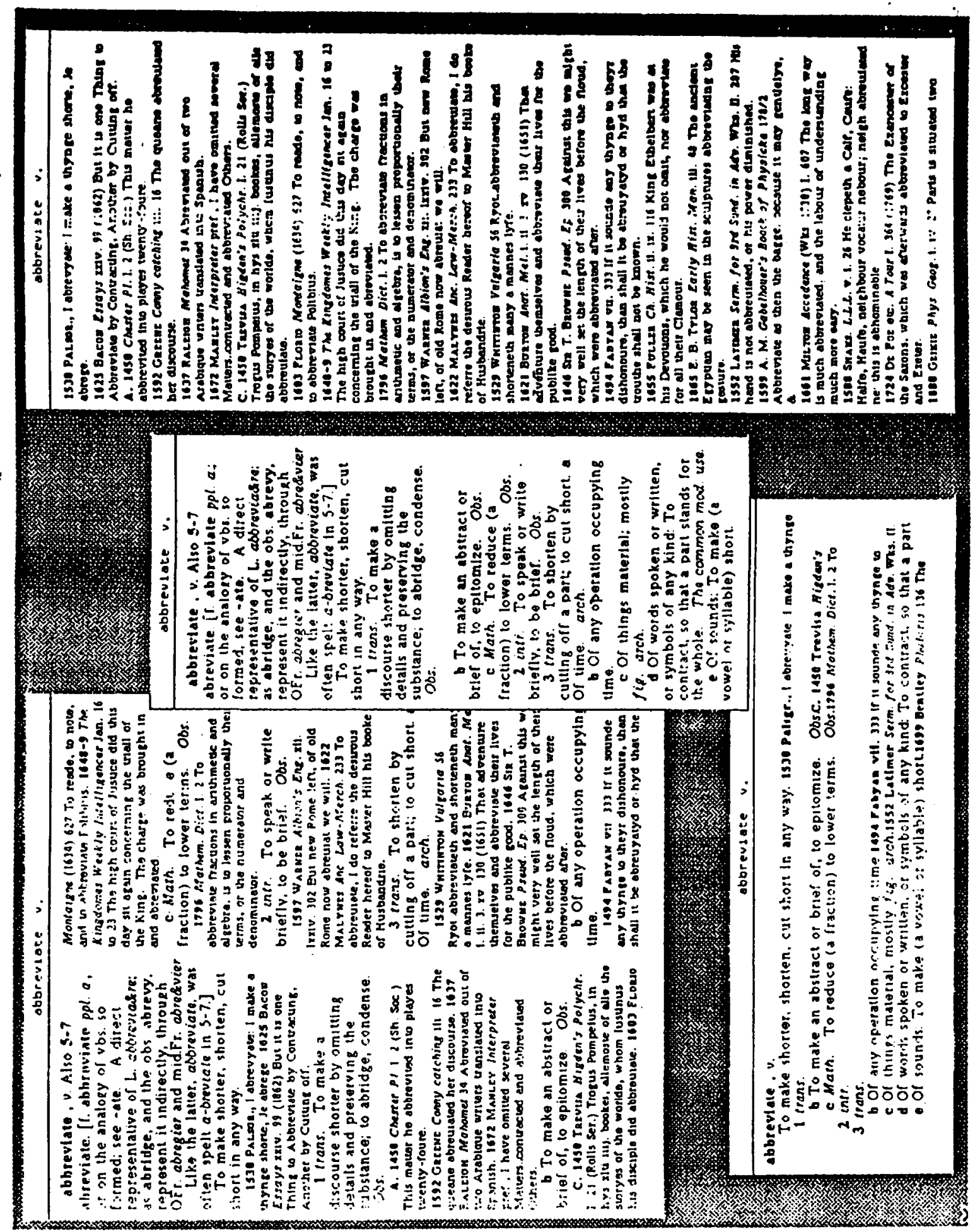

Figura A.17: Oxford English Dictionary [Raymond 88][pp 876]

- tipos de nó, seção 4.1.2 


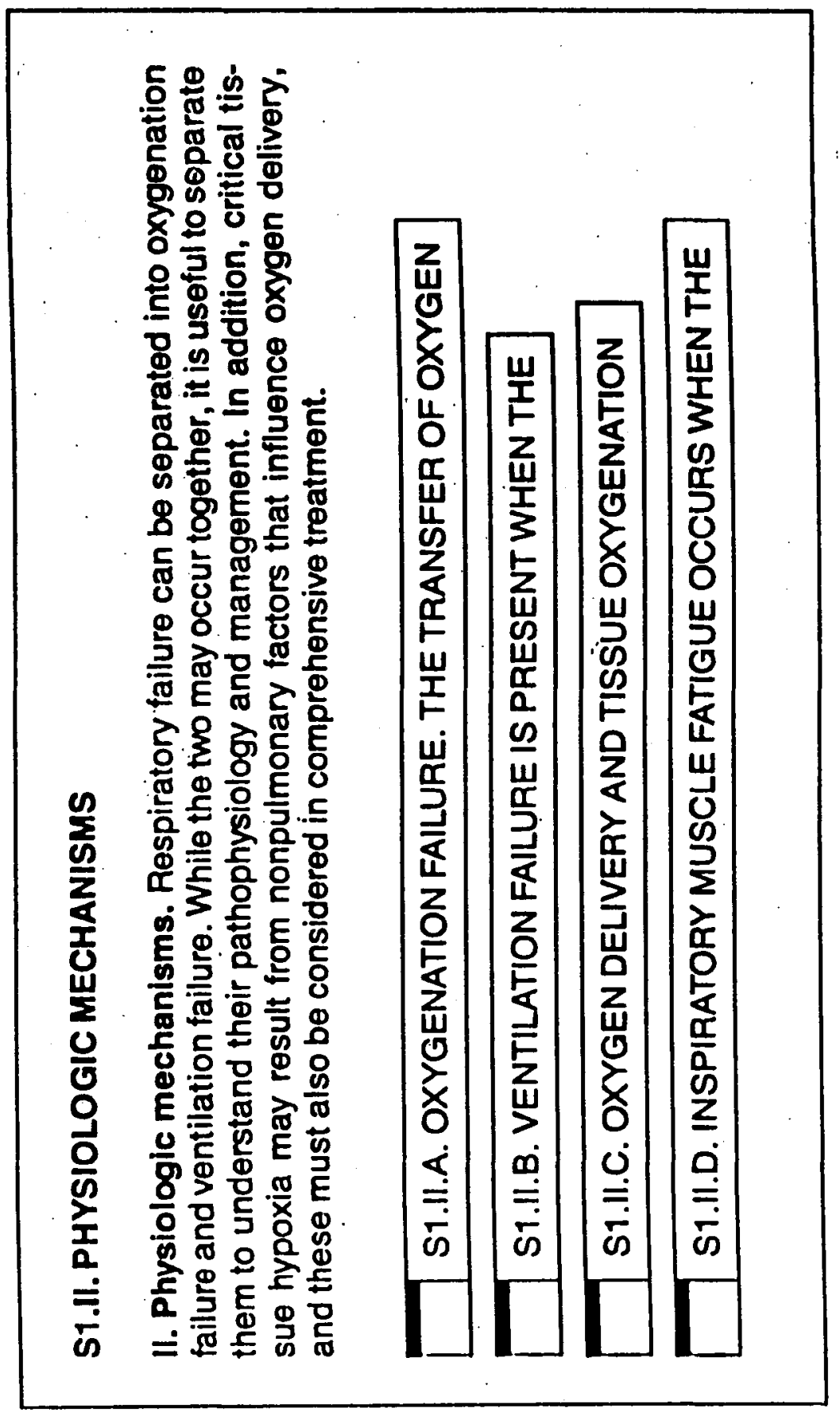

Figura A.18: A Hypertext Medical Handbook [Frisse 88][pp 248] - seleção através de índice na seção 4.3.2 


\section{Bibliografia}

[Akscyn 84] Akscyn, R.M.; McCraken, D.L. ZOG and the USS CARL VINSON: Lessons in System Development. Carnegie-Mellon TRCMU-CS-84-127, Março,1984.

[Akscyn 88] Akscyn, R.M.; McCraken, D.L.; Yoder, E.A. KMS: A Distributed Hypermedia System for Managing Knowledge in Organizations. CACM, Julho, 1988, pp 820-835.

[Beeman 87] Beeman, W.O.; Anderson, G.B; Larkin, J.; McClard, A.P.; McQuillan, P.; Shields, M. Hypertext and Pluralism: From Lineal to Nonlineal Thinking. Hypertext'87 Papers, pp 1-20.

[Begeman 88] Begeman, M.L.; Conklin, J. The Right Tool for the Job. Byte, Outubro, 1988, pp 255-266.

[Bigelow 88] Bigelow, J. Hypertext and CASE. IEEE Software, Março, 1988, pp 23-27.

[Bush 45] Bush, V. As We May Think. Atlantic Monthly, Julho, 1945, pp 101-108.

[Byte 88] No More Golden Vaporware: Xanadu Products Next Year, Nelson Says. Byte, Julho, 1988, pp 16.

[Campbell 88] Campbell, B.; Goodman, J.M. HAM: A General Purpose Hypertext Abstract Machine. CACM, Julho, 1988, pp 856-861.

[Chaia 89] Chaia, J. Um Sistema Hipertexto com Aplicações ao Ensino. Conferência apresentada em 25/08/89 na Escola de Comunicações e Artes - USP, São Paulo, 1989.

[Conklin 86] Conklin, J. A Theory and Tool for Coordination of Design Conversations. MCC TR-STP-236-86. 
[Conklin 87] Conklin, J. A Survey of Hypertext. MCC TR-STP-356-86, Rev. 2.

[Delisle 86a] Delisle, N.; Schwartz, M. Neptune: a Hypertext System for CAD Applications. Proceedings of ACM SIGMOD'86, Maio, 1986, pp 132-143.

[Delisle 86b] Delisle, N.; Schwartz, M. Contexts - A partitioning concept for hypertext. Proceedings of Conference on Computer - Supported Cooperative Work, 1986, pp 147-152.

[Engelbart 63] Engelbart, D.C. A Conceptual Framework for the Augmentation of Man's Intellect. Information Handling, vol 1, P.W. Howerton and D.C. Weeks, Eds, Spartan Books, London, 1963.

[Engelbart 68] Engelbart, D.C.; English, W.K. A Research Center for Augmenting Human Intellect. AFIPS Conference Proceedings, vol 33, parte 1, The Thompson Book Company, Washington, D.C, 1968.

[Farrer 85] Farrer, H.; Becker, C.G.; Faria, E.C.; Matos, H.F.; Santos, M.A.; Maia, M.L. Algoritmos Estruturados. Ed. Guanabara Dois, 1985.

[Fiderio 88] Fiderio, J. A Grand Vision. Byte, Outubro, 1988, pp 237-244.

[Frisse 88a] Frisse, M. Searching for Information in a Hypertext Medical Handbook. CACM , Julho, 1988, pp 880-886.

[Frisse 88b] Frisse, M. From Text to Hypertext. Byte, Outubro, 1988, pp 247-253.

[Garg 88] Garg, P.K. Abstraction Mechanisms in Hypertext. CACM, Julho, 1988, pp 862-870.

[Garret 86] Garret, L.N.; Smith, K.E.; Meyrowitz, N.K. Intermedia: Issues, Strategies, and Tactics in the Design of a Hypermedia Document System. Proceedings of Conference on ComputerSupported Cooperative Work, 1986, pp 163-174.

[Goldberg 83] Goldberg, A.; Robson, D. Smalltalk-80 The Language and its Implementation. Addison-Wesley, 1985.

[Goldstein 80] Goldstein, I.P.; Bobrow, D.G. Description for a Programming Enviroment. Proceedings of 1st Conf,AAAI, Agosto, 1980. 
[Goldstein 84] Goldstein, I.P.; Bobrow, D.G. A Layered Approach to Software Design. Interactive Programming Enviroments, D.Barstrow, H.Shrobe e E.Sandewall (Eds) MacGraw-Hill, 1984, pp 387-413.

[Gullichsen 88] Gullichsen, E; D'Souza, D.; The K.S.; Lincoln, P. The PlaneTextBook. MCC TR STP-206-88, Julho, 1988.

[Halasz 87] Halasz, F.G. NoteCards in a Nutshell. Proceedings of the 1987 ACM Conference of Human Factors in Computer Systems. Abril, 1987, pp 45-52.

[Halasz 88] Halasz, F.G. Reflections on NoteCards: Seven Issues for the Next Generation of Hypermedia Systems. CACM, Julho, 1988, pp 836-852.

[Hansen 88] Hansen, J.H; Haas, C. Reading and Writing with Computers: a Framework for Explaining Differences in Performance. CACM, Setembro, 1988, pp 1080-1089.

[Hershey 87]' Hershey, W. Guide. Byte, Outubro, 1987, pp 244-246.

[Katz 89] Katz, L. Aplicações de Vídeo-Disco à Medicina. Conferência apresentada em 21/08/89 na Escola Paulista de Medicina, São Paulo.

[Lowe 85] Lowe, D.G. Cooperative structuring of information: the representation of reasoning and debate. Int.J.Man-Machine Studies, 23, 1985, pp 97-111.

[Marchionini 88] Marchionini, G.; Shneiderman, B. Finding Facts vs. Browsing Knowledge in Hypertext Systems. Computer, Janeiro, 1988, pp 70-80.

[Minsky 75] Minsky, M. A Framework for Representing Knowledge. The Psichology of Computer Vision. MacGraw-Hill, 1985.

[Nelson 80] Nelson, T.H. Replacing the Printed Word: A Complete Lyterary System. Proceedings of IFIP Congress 80, Outubro, 1980, pp 1013-1023.

[Nelson 81] Nelson, T.H. Literary Machines. 1981. Disponível com o autor.

[Nelson 88] Nelson, T.H. Managing Immense Storage. Byte, Janeiro, 1988, pp 225-238. 
[Pimentel 89a] Pimentel, M.G.C. Sistemas Hipertexto: Discussões e uma Proposta. Anais do XXII Congresso Nacional de Informática, Setembro, 1989.

[Pimentel 89b] Pimentel, M.G.C. Detalhes da Implementação de um Sistema Hipertexto. Relatório técnico em preparação, a ser submetido para publicação em Notas do ICMSC-USP, 1989.

[Pitman 85] Pitman, K.M. CREF: An Editing Facility for Managing Structured Text. A.I. Memo 829, MIT AI Laboratory, Fevereiro, 1985.

[Raymond 88] Raymond, D.R.; Tompa, F.W. Hypertext and the Oxford English Dictionary. CACM, Julho, 1988, pp 871-879.

[Rittel 73] Rittel, H.; Webber, M. Dilemmas in a General Theory of Planning. Policy Sciences, vol 4, 1973.

[Rocha 87] Rocha, A.R.C.Análise e Projeto Estruturado de Sistemas. Ed. Campus, 1987.

[Smalltalk 86] Smalltalk/V. Digitalk Inc.

[Schulley 89] Schulley. J. The Relationship Between Business and Higher Education: A Perspective on the 21th Century. CACM, Setembro, 1989.

[Smith 86] Smith, J.B.; Weiss, S.F; Ferguson, G.J.; Bolter, J.D.; Lansman, M.; Beard D.V. WE: A Writing Enviroment for Professionals. TR-86-025, Departament of Computer Science, University of North Carolina at Chapel Hill, Agosto, 1986.

[Smith 88] Smith, K.E. Hypertext - Linking to the Future. ONLINE, Março, 1988, pp 32-40.

[Trigg 83] Trigg, R.H. A Network-based Approach to Text Handling for the Online Scientific Community. PhD Thesis, University of Maryland, 1983.

[Vasconcelos 88] Vasconcelos, A.M.; Melo, A.C.V.; Meira, S.L. Links em um Sistema Hipertexto. Anais do II SBES, 1988, pp 75-85.

[Walker 85] Walker, J.H. The Document Examiner. SIGGRAPH Video Review, Issue 19, Edicao compilada do CHI'85: Human Factors in Computing System, 1985.

[Williams 87] Williams, G. Hypercard. Byte, Dezembro, 1987, pp 109-117. 
[Yankelovich 85] Yankelovich, N.; Meyrowitz, N.K.; van Dam, A. Reading and Writing the Eletronic Book. Computer, Outubro, 1985, pp 1530 .

[Yankelovich 87] Yankelovich, N.; Landow, G.; Heywood, P. Designing Hypermedia "Ideabases" - The Intermedia Experience. IRIS TR 87-4.

[Yankelovich 88] Yankelovich, N.; Haan, B.J.; Meyrowitz, N.K.; Drucker, S.M. Intermedia: The Construction of a Seamless Information Environment. Computer, Janeiro, 1988, pp 81-96.

[Yoder 89] ～Yoder, E.; Akscyn, R.; McCraken, D. Collabotarion in KMS, A Shared Hypermedia System. Proceedings of CHI'89, Austin, Texas, Maio 1989.

[Yourdon 78] Yourdon, E.; Constantine, L.L.

Structured Design. Ed. Yourdon Press, segunda edição, 1978. 